European Journal of Medicinal Chemistry, 2018, 159, 104-125.

doi : 10.1016/j.ejmech.2018.08.092

\title{
A Phenotypic Approach to the Discovery of Compounds that Promote Non- Amyloidogenic Processing of the Amyloid Precursor Protein: Toward a New Profile of Indirect $\beta$-Secretase Inhibitors
}

\author{
Marion Gay, ${ }^{\mathrm{a} \$}$ Caroline Evrard, ${ }^{\mathrm{a} \$}$ Florian Descamps, ${ }^{\mathrm{a} \$}$ Pascal Carato, ${ }^{\mathrm{a} \#}$ Nicolas Renault, ${ }^{\mathrm{b}}$ \\ Mathilde Coevoet, ${ }^{\mathrm{a}}$ Sabiha Eddarkaoui, ${ }^{\mathrm{a}}$ Catherine Baud, ${ }^{\mathrm{a}}$ Paul-Emmanuel Larchanché, ${ }^{\mathrm{a}}$ Luc \\ Buée, ${ }^{\mathrm{a}}$ Jamal El Bakali, ${ }^{\mathrm{a}}$ Valérie Vingtdeux, ${ }^{\mathrm{a}^{*}}$ Nicolas Sergeant, ${ }^{\mathrm{a}}$ Patricia Melnyk ${ }^{\mathrm{a}}$
}

${ }^{a}$ Université de Lille, Inserm, CHU Lille, UMR-S 1172 - JPArc - Centre de Recherche JeanPierre AUBERT Neurosciences et Cancer, F-59000 Lille, France

${ }^{b}$ Université de Lille, Inserm, CHU Lille, U995 - LIRIC - Lille Inflammation Research International Center, F-59000 Lille, France

\$These authors contributed equally to this work
\# Present address: Univ. Poitiers, CIC INSERM 1402, F-86073 Poitiers, France. 


\begin{abstract}
Dysregulation of the Amyloid Precursor Protein (APP) processing leading to toxic species of amyloid $\beta$ peptides $(A \beta)$ is central to Alzheimer's disease (AD) etiology. A $\beta$ peptides are produced by sequential cleavage of APP by $\beta$-secretase (BACE-1) and $\gamma$-secretase. Lysosomotropic agent, chloroquine (CQ), has been reported to inhibit A $\beta$ peptide production. However, this effect is accompanied by an inhibition of lysosome-mediated degradation pathways. Following on from the promising activity of two series of APP metabolism modulators derived from CQ, we sought to develop new series of compounds that would retain the inhibitory effects on $A \beta$ production without altering lysosome functions. Herein, we applied a ligand-based pharmacophore modeling approach coupled with de novo design that led to the discovery of a series of biaryl compounds. Structure-activity relationship studies revealed that minor modifications like replacing a piperidine moiety of compound $\mathbf{3 0}$ by a cyclohexyl (compound 31) allowed for the identification of compounds with the desired profile. Further studies have demonstrated that compounds $\mathbf{3 0}$ and $\mathbf{3 1}$ act through an indirect mechanism to inhibit $\beta$-secretase activity. This work shows that it is possible to dissociate the inhibitory effect on $A \beta$ peptide secretion of CQ-derived compounds from the lysosome-mediated degradation effect, providing a new profile of indirect $\beta$-secretase inhibitors.
\end{abstract}

\title{
Keywords:
}

Alzheimer's disease, Amyloid Precursor Protein, chloroquine, lysosome, autophagy, $\beta$ secretase, BACE-1, indirect inhibitor, phenotypic 


\section{Introduction}

Alzheimer's disease (AD), the most frequent form of dementia, is characterized by a slow decline of cognitive and behavioral abilities. Two neuropathological lesions provide the definite diagnosis of AD: neurofibrillary tangles and amyloid deposits [1]. Neurofibrillary tangles are characterized by intraneuronal accumulation and aggregation of abnormally modified isoforms of the microtubule-associated tau proteins. Parenchymal amyloid deposits are composed of amyloid- $\beta$ (A $\beta$ ) peptides, which derive from its precursor, the so-called amyloid precursor protein (APP) (for a comprehensive review see ref. [2]). Current treatments for AD remain symptomatic and provide only limited benefits to the patients. Therefore, alternative therapeutic options are urgently needed and over the past few years, much effort has been dedicated to the development of disease-modifying therapeutics [3]. One such strategy consists of reducing the levels of toxic species of A $\beta$ peptides by targeting APP processing and more specifically secretases that cleave APP to produce A $\beta$ peptides. Indeed, the metabolism of APP involves the action of several secretases and is sub-cellularly compartmentalized. APP is known to undergo proteolytic processing through two main pathways: the non-amyloidogenic pathway, initiated by $\alpha$-secretase cleavage and the amyloidogenic pathway initiated by $\beta$-secretase cleavage (Figure 1) [4,5]. Both secretase-mediated steps release soluble ectodomains of APP (sAPP $\alpha$ and sAPP $\beta$ ) and membrane-bound carboxyl-terminal fragments (APP-CTFs), known as $\alpha \mathrm{CTF}$ and $\beta \mathrm{CTF}$. The latter are further cleaved by $\gamma$-secretase to give $\mathrm{p} 3$ and $\mathrm{A} \beta$ peptides, respectively, along with the APP intracellular domain (AICD).

Redirection of APP processing can be achieved either by blocking the amyloidogenic pathway or by promoting the non-amyloidogenic pathway. Because amyloidogenic processing is initiated by the cleavage of APP by $\beta$-secretase ( $\beta$-site amyloid-precursor-protein-cleaving enzyme 1, BACE-1), this protease has been suggested as an attractive target to lower A $\beta$ levels and the resulting amyloid plaques [6,7]. Recently, a mutation in APP (APP-A673T) that protects against the development of $\mathrm{AD}$ and age-related cognitive decline has been identified, providing further evidence that reducing $\beta$-secretase cleavage of APP may protect against AD $[8,9]$. Most efforts regarding $\beta$-secretase inhibitors have been focused on active site binders [10], and although $\beta$-secretase inhibitor drug development has proven challenging, several inhibitors are currently under clinical development [3,11]. Given that $\beta$-secretase has multiple substrates involved in important cellular and tissue functions, its inhibition may produce mechanism-based side effects [7]. As an alternative, a recent study showed that the anticancer drug Gleevec lowers $A \beta$ levels through indirect inhibition of $\beta$-secretase processing of APP [12]. Another recent study taking advantage of the compartmentalization of APP processing, 
showed that $\beta$-secretase inhibitors can be designed to specifically inhibit APP processing in the endosomal compartment with no effect on non-amyloid substrates [13]. Indeed, the endosomal/lysosomal compartments are known to be of importance for APP metabolism, APP degradation as well as for the production of $A \beta$ peptides [14-16]. In this context, the lysosomotropic agent, chloroquine (CQ) has been reported to inhibit A $\beta$ peptide production $[17,18]$. However, the alkalizing property of CQ also leads to the inhibition of lysosomemediated degradation pathways, resulting in the accumulation of APP-CTFs and AICD $[14,19,20]$, and in the disruption of the autophagic flux [21]. Autophagy-lysosomal pathway dysfunction has been suggested to play a detrimental role in the pathophysiology of AD [2224]. Therefore, CQ-derived compounds that would maintain the effect on $A \beta$ peptides without disrupting lysosomal functions would be of interest.

We have recently developed two series of compounds derived from either CQ (series A) or amodiaquine (AQ, series $B$ ) that demonstrated a strong inhibitory effect on both $A \beta_{1-40}$ and $A \beta_{1}$ 42 secretions [17,25-28]. The lead compound of series A is currently ending phase I clinical trials. However, as observed for CQ, these effects were accompanied by a strong increase in the levels of $\alpha \mathrm{CTF}$ s and AICD suggesting an alteration of lysosomal functions. Therefore, based on these earlier works, we sought to develop new series of compounds that would retain the effects on $A \beta$ production without affecting $\alpha$ CTFs and AICD stabilities. To that purpose, in the absence of a defined molecular target of the previously developed compounds, a ligand-based pharmacophore modeling approach [29], coupled with de novo design was implemented. Herein, we describe a new series of compounds based on a biaryl scaffold decorated with amino side chains. Among these compounds, several were shown to inhibit A $\beta$ peptides secretion and to promote $\alpha \mathrm{CTF}$ s and AICD stabilities, as the parent compounds (series A and B). However, the structure activity relationship (SAR) study allowed for the discovery of compounds that kept the effect on $\mathrm{A} \beta$ peptides but had no impact on $\alpha \mathrm{CTF}$ s and AICD stabilities. Further studies on two structurally very close compounds (30 and $\mathbf{3 1}$ ) with different profile regarding $\alpha \mathrm{CTFs}$ and AICD stabilities suggest that an indirect $\beta$-secretase inhibitory effect can be achieved without the alkalizing property which is associated with the disruption of lysosomal functions.

\section{Results and discussion}

\subsection{Ligand-based pharmacophore modeling}

A ligand-based approach was applied to determine a common pharmacophoric model between the two series of compounds developed previously (Figure 2A). Because no model was able to predict compounds with the desired profile (decrease of $A \beta$ peptides secretion with no impact 
on $\alpha$ CTFs and AICD stabilities), the pharmacophore study took into account the sole inhibitory effect on $A \beta$ production. Hence, a set of 51 compounds of series $A[17,28]$ and 35 of series $B$ $[25,30]$ (Data and structures shown in Tables S1 and S2) was chosen regarding the ability of the compounds to inhibit $A \beta_{1-42}$ secretion (subsequently named anti-A $\beta$ ). Compounds were classified into 4 classes: 2 (highly active), 1 (moderately active), 0 (inactive) and ND (not determined). The dominant and common property to all of the molecules is their high positive formal charge, which is comprised between +2 and +4 . This ionization state could be ambiguous

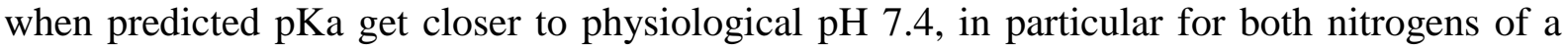
piperazine group or for nitrogens of benzimidazole and quinoline heterocyclic moieties. In order to increase the possibility of pharmacophore detection on the basis of positively ionized features, the ionization state with the highest formal charge was selected for each molecule. 3D pharmacophore models were scored based on their ability to discriminate between active and inactive compounds (Table S3). The best model, describing four spatial points Positive/Positive/Positive/Aromatic (PPPA), was computed from the 18 molecules with the highest inhibitory activity of $A \beta_{1-42}$ expression. This 3D pharmacophore model seemed more efficient in comparison with the 3-points PPA pharmacophores. Using the PPPA pharmacophoric model, several substructure were considered. This paper focuses on a biarylbased series of compounds (Figure 2B). This biphenyl scaffold was substituted on the first phenyl ring by $N$-piperidinylethoxy and 3 -( $N$-piperidinyl)propanamino side chains and a benzylic tertiary amine in ortho position of the second phenyl ring. Structural modifications around this scaffold included, i) the modulation of the nature (piperidine, morpholine, dimethylamine and $N$-methylpiperazine) and the position (ortho, meta and para) of the benzylic tertiary amine, ii) the length of the linker separating the piperidine moieties from the first phenyl ring ( $n, m=2$ to 4 ), iii) replacement of the second phenyl group by a pyrrole, and iv) stepwise removal of the three tertiary amines.

\subsection{Synthetic chemistry}

Compounds 24-37 were obtained as described in Scheme 1. Commercially available benzoxazol-2-one was regioselectively brominated in position $6\left(\mathrm{Br}_{2} / \mathrm{AcOH}\right)$, followed by $N$ alkylation, ring opening under alkaline conditions [31]. In this case, dioxane was used instead of $\mathrm{MeOH}$ to avoid side products. $O$-alkylation using $\mathrm{NaH}$ as a base gave intermediates 8-14 in moderate to good yields. Subsequent Suzuki-coupling reaction with appropriate boronic acids afforded compounds $\mathbf{1 5 - 2 3}$ and $\mathbf{3 7}$. The last step consisted in a reductive amination, which was performed using two different procedures. Indeed, compounds 24-31 were obtained performing 
the reaction in $\mathrm{DCE}$ and using $\mathrm{NaBH}(\mathrm{OAc})_{3}$ as the reductive agent (procedure $\mathrm{A}$ ), while compounds 32-36 required the addition of titanium isopropoxide in $\mathrm{EtOH}$ and the use of $\mathrm{NaBH}_{4}$ as the reductive agent (procedure B [32]).

Compounds 39, 41 and $\mathbf{4 4}$ were obtained as described in Scheme 2. The first step consisted in a nucleophilic substitution (either $O$-alkylation or $N$-alkylation) followed by a Suzuki-coupling reaction to give compounds $\mathbf{3 9}, \mathbf{4 0}$ and $\mathbf{4 3}$. Subsequent reductive amination under procedure A afforded final compounds $\mathbf{4 1}$ and $\mathbf{4 4 .}$

Compound 51 was obtained as outlined in Scheme 3. Benzoxazol-2-one was first nitrated regioselectively in position 6 with nitric acid, followed by $N$-alkylation and ring opening under alkaline conditions to give intermediate 47. Subsequent $O$-alkylation using $\mathrm{K}_{2} \mathrm{CO}_{3}$ as a base, and nitro reduction with ammonium formate gave 49. The latter was subjected to a ClausonKaas reaction with 2,5-dimethoxy-3-tetrahydrofurancarboxaldehyde in acetic acid to form pyrrole intermediate $\mathbf{5 0}$ [33]. The last step consisted in a reductive amination in DCE and using $\mathrm{NaBH}(\mathrm{OAc})_{3}$ as the reductive agent to give compound $\mathbf{5 1}$.

\subsection{Structure-Activity Relationship studies}

Final compounds were evaluated for their ability to modulate APP processing on SY5Y human neuroblastoma cell line stably expressing the neuronal isoform of human wild-type $\mathrm{APP}^{695}$ (SY5Y-APPwt). $A \beta$ levels $\left(A \beta_{1-40}\right.$ and $\left.A \beta_{1-42}\right)$ after treatment with reference and tested compounds were measured by ELISA (Table 1). Results are expressed as $\mathrm{IC}_{50}$ values which correspond to the concentration of a given compound that inhibits $A \beta$ expression by $50 \%$ (either $\mathrm{A} \beta_{1-40}$ or $\mathrm{A} \beta_{1-42}$ ). APP carboxy-terminal fragments ( $\alpha \mathrm{CTF}$ s and AICD) levels were assessed by Western-blotting (WB). The effect of reference and tested compounds on $\alpha$ CTFs and AICD are expressed as the intensity of corresponding WB bands. Compounds effect was measured at various concentrations $(1,3,10 \mu \mathrm{M}$, Figure 3 ) and compared to the effect of CQ at $3 \mu \mathrm{M}$ (Table 1). First, when considering the effect on $A \beta$ levels, regardless of the modulations, all synthesized compounds decreased $\mathrm{A} \beta$ levels with $\mathrm{IC}_{50}$ values ranging from 1.2 to $13.7 \mu \mathrm{M}$. While compound $39\left(\mathrm{~A} \beta_{1-40}: \mathrm{IC}_{50}=9.1 \mu \mathrm{M}\right.$ and $\left.\mathrm{A} \beta_{1-42}: \mathrm{IC}_{50}=13.7 \mu \mathrm{M}\right)$ displayed similar activity to $\mathrm{CQ}\left(\mathrm{A} \beta_{1-40}: \mathrm{IC}_{50}=7.0 \mu \mathrm{M}\right.$ and $\left.\mathrm{A} \beta_{1-42}: \mathrm{IC}_{50}=12.7 \mu \mathrm{M}\right)$, all other evaluated compounds were found to be more active ( $\mathrm{IC}_{50}$ ranging from 1.2 to $5.2 \mu \mathrm{M}$ ). The different modulations applied, including the modification of the position of the piperidine borne by the second phenyl group (compare 24, 26 and 27), the replacement of the piperidine by other tertiary amines (compare 24 vs 25 and 26-29) and the modification of the length of both piperidine alkyl chains on the other side of the molecule (30 vs 32-36) had little impact on A $\beta$ 
levels. Finally, replacing one of the phenyl rings of $\mathbf{3 0}\left(\mathrm{A} \beta_{1-40}\right.$ : $\mathrm{IC}_{50}=2.8 \mu \mathrm{M}$ and $\mathrm{A} \beta_{1-42}$ : $\mathrm{IC}_{50}$ $=3.4 \mu \mathrm{M})$ with a pyrrole (compound 51) led to a two-fold decrease in activity $\left(\mathrm{A} \beta_{1-40}\right.$ : $\mathrm{IC}_{50}=$ $5.0 \mu \mathrm{M}$ and $\left.\mathrm{A} \beta_{1-42}: \mathrm{IC}_{50}=6.5 \mu \mathrm{M}\right)$. The main factor that appears to influence this activity is the number of tertiary amines. Indeed, 41 (two tertiary amines, $\mathrm{A} \beta_{1-40}$ : $\mathrm{IC}_{50}=1.5 \mu \mathrm{M}$ and $\mathrm{A} \beta_{1-42}$ : $\mathrm{IC}_{50}=1.2 \mu \mathrm{M}$ ) was 10 -fold more active than 39 (one tertiary amine, $\mathrm{A} \beta_{1-40}$ : $\mathrm{IC}_{50}=9.1 \mu \mathrm{M}$ and $\mathrm{A} \beta_{1-42}: \mathrm{IC}_{50}=13.7 \mu \mathrm{M}$ ), while adding an extra tertiary amine did not improve activity (e.g. compare 41, $\mathrm{A} \beta_{1-40}: \mathrm{IC}_{50}=1.5 \mu \mathrm{M}$ and $\mathrm{A} \beta_{1-42}: \mathrm{IC}_{50}=1.2 \mu \mathrm{M}$ and 33, $\mathrm{A} \beta_{1-40}: \mathrm{IC}_{50}=1.4 \mu \mathrm{M}$ and $\left.\mathrm{A} \beta_{1-42}: \mathrm{IC}_{50}=1.2 \mu \mathrm{M}\right)$. Hence, with regard to $\mathrm{A} \beta$ levels, two basic centers are required in this series to get an efficient inhibitory activity. Interestingly, compounds displaying one or two tertiary amines had little (41 and 44) or no impact (31 and 39) on AICD and $\alpha$ CTFs stabilities while compounds with three tertiary amines significantly promote AICD and $\alpha \mathrm{CTFs}$ stabilities. Indeed, as can be seen from Table 1 and Figures 2A and 2B, compounds displaying three tertiary amines (24-30, 32-36 and 51) were all more potent than CQ $(3 \mu \mathrm{M})$ in increasing AICD and $\alpha \mathrm{CTFs}$ levels (up to 6 fold, Table 1). For example, compared to control conditions, compound 30 and $32(3 \mu \mathrm{M})$ increased $\alpha \mathrm{CTF}$ levels by almost 30 and 50-fold, respectively and AICD levels by more than 40 and 30-fold, respectively. On the other hand, replacing one piperidine of compound $\mathbf{3 0}$ by a cyclohexyl group (31) completely abolished AICD and $\alpha \mathrm{CTF}$ activities as compound $\mathbf{3 1}$ had a similar profile as the untreated conditions. This result shows that it is possible to retain the effects on $A \beta$ secretion without affecting $\alpha C T F$ s and AICD stabilities and encouraged us to further refine APP processing profile of compounds $\mathbf{3 0}$ and $\mathbf{3 1}$.

\subsection{Effects of compounds 30 and 31 on APP metabolism}

Following this primary screening and structure activity relationship analysis, a detailed and comparative analysis of compounds $\mathbf{3 0}$ and $\mathbf{3 1}$ was performed. First, toxicity assays were performed with both compounds on SY5Y-APPwt cells and in primary neurons. Compounds were tested up to $5 \mu \mathrm{M}$ and no toxicity was observed (Figure S1). Effects of both compound was then assessed simultaneously on APP metabolism. Full-length APP proteins were resolved and detected with the APP-C17 antiserum as two bands at $110 \mathrm{kDa}$ and $115 \mathrm{kDa}$. The lowest APP band corresponds to the neosynthesized or immature form of APP whereas the highest band corresponds to the glycosylated, namely the mature form of APP. Both were quantified, and no modification of immature APP levels was observed with either compounds (Figure 4A, $\mathrm{D}$ and F). While compound $\mathbf{3 1}$ did not modify the expression of mature APP, compound 30 significantly increased mature APP expression at $5 \mu \mathrm{M}$ by $221 \%$ (Figure $4 \mathrm{~A}, \mathrm{C}$ and E). These results were confirmed using primary neuronal cultures in which treatment with compound 30 
at 3 and $5 \mu \mathrm{M}$ induced a significant increase in mature APP of $130 \%$ when compared to the control condition (Figure S2A, C). In primary neurons, compound $\mathbf{3 1}$ had also no effect on total APP expression (Figure S2A, E).

Full-length APP is further processed by $\alpha$-, $\beta$ - and $\gamma$-secretases to generate APP-CTFs and AICD. A significant accumulation of APP-CTFs and AICD was observed following treatment with compound 30 (Figure 4B, G, H). This accumulation of APP-CTFs was also observed in primary neurons (Figure S2A and D). Surprisingly, compound $\mathbf{3 1}$ did not demonstrate any effect on APP-CTFs or AICD expression in both SY5Y-APPwt cells and primary neuronal cultures (Figure 4B, I, J and Figure S3A, F).

As shown previously (Table 1 ), compounds $\mathbf{3 0}$ and $\mathbf{3 1}$ significantly reduced $A \beta_{1-40}$ and $A \beta_{1-42}$ production (Figure $4 \mathrm{~K}-\mathrm{N}$ ). This reduction of $\mathrm{A} \beta$ production may be caused by either an increase of the $\alpha$-secretase cleavage or a decrease of either the $\beta$ - or $\gamma$-secretase cleavage of APP. Thus, we assessed the secretion of $\operatorname{sAPP} \alpha$ and $\operatorname{sAPP} \beta$, which are the shedded byproducts of $\alpha$ - and $\beta$ secretase, respectively. Both compounds $\mathbf{3 0}$ and $\mathbf{3 1}$ were found to significantly reduce sAPP $\beta$ concentration (Figure 4P and R). On the opposite, sAPP $\alpha$ concentration was significantly increased by compound $\mathbf{3 0}$ and to a lesser extend by compound $\mathbf{3 1}$ (Figure $4 \mathrm{O}$ and Q). Together these results strongly suggest that compounds $\mathbf{3 0}$ and $\mathbf{3 1}$ reduce $A \beta_{1-40}$ and $A \beta_{1-42}$ secretion by repressing $\beta$-secretase cleavage of APP while increasing the secretion of SAPP $\alpha$.

To determine whether compounds 30 and 31 were direct BACE-1 inhibitors, an enzymatic assay monitoring the cleavage of a fluorogenic peptide substrate (Mca-S-E-V-N-L-D-AE-F-R$\mathrm{K}(\mathrm{Dnp})-\mathrm{R}-\mathrm{R}-\mathrm{NH}_{2}$ ) was performed [34]. In contrast to reference OM 99-2 ( $\left.\mathrm{IC}_{50}=59 \mathrm{nM}\right)$, under the assay conditions (cf. experimental section), neither compound $\mathbf{3 0}$ nor $\mathbf{3 1}$ inhibited the cleavage of the fluorogenic peptide even at a concentration of $10 \mu \mathrm{M}$ (\% inhibition < $10 \%)$. All together, these data show that compounds $\mathbf{3 0}$ and $\mathbf{3 1}$ are acting through an indirect mechanism to inhibit $\beta$-secretase activity.

Although compounds $\mathbf{3 0}$ and $\mathbf{3 1}$ derived from the same pharmacophore, only compound $\mathbf{3 0}$ increased the expression of mature APP, APP-CTFs and AICD, suggesting that compounds 30 and 31 operated through different mechanisms. CQ is a well-known inhibitor of the autophagic flux and lysosomal degradation pathway, and compounds of series A derive from a CQ library of molecules. Therefore, we assessed whether the activity of compound $\mathbf{3 0}$ involved a repression of lysosomal activities that could explain the observed accumulation of mature APP, APP-CTFs and AICD. To address this question, we studied the effect of both compounds 30 and $\mathbf{3 1}$ on the autophagic flux. To that purpose, we assessed two markers associated with autophagy: p62 and LC3-I lipidation into LC3-II, which is characterized by the appearance of 
a second band at $14 \mathrm{kDa}$ under the LC3-I band of $18 \mathrm{kDa}$. Treatment with compound 30 at 5 $\mu \mathrm{M}$ induced an increase of p62 expression by $476 \%$ as compared to the control condition (Figure 5A and B). LC3-I lipidation into LC3-II was also increased by 591\% (Figure 5A and D). Similar results were obtained in primary neurons starting at a concentration of $3 \mu \mathrm{M}$ of compound 30 (Figure S2B, G and H). In sharp contrast, compound 31 showed no effect on these two autophagy markers in either cell systems (Figure 5A, C, E and Figure S3B, I and J). As the increase of p62 and LC3 lipidation suggest an inhibition of the autophagic flux, we cotreated the cells with compound $\mathbf{3 0}$ and Bafilomycine A1 (BafA1), a well-known inhibitor of the autophagic flux [35]. In co-treatment with BafA1, compound $\mathbf{3 0}$ demonstrated similar accumulations of p62 and LC3-II as with BafA1 alone (Figure 5F, G and H). Indeed, no additive effect of co-treatments was observed for p62 expression or LC3 lipidation, showing that compound 30 display an inhibitory effect on the autophagic flux. Inhibition of the autophagic flux and accumulation of p62 and LC3 were further confirmed by immunofluorescence in SY5Y-APPwt cells (Figure 5I and J) and in primary neurons (Figure S2K and L). Treatment with compound 30 at $5 \mu \mathrm{M}$ displayed a significant accumulation of p62 and LC3 positive vesicles inside these two different cell models. Together, these results demonstrate that compound $\mathbf{3 0}$ acts as an inhibitor of the autophagic flux, and thus of lysosomal degradation properties. Importantly, compound 31, which displays a similar activity than compound 30 toward $\mathrm{A} \beta$ reduction, does not bear this later property.

\section{Conclusion}

This work reports the design, synthesis and in vitro biological evaluation of a biaryl-based series of modulators of APP processing. SAR studies revealed that all compounds were able to decrease $A \beta$ secretion but minor modifications like replacing a piperidine moiety of $\mathbf{3 0}$ by a cyclohexyl (compound 31) totally abolished AICD and $\alpha$ CTFs stabilities. The effect of compound $\mathbf{3 0}$ and related analogues on AICD and $\alpha \mathrm{CTF}$ s stabilities was shown to be linked to an alteration of lysosomal functions. Compound 31, on the other hand, behave as an indirect $\beta$ secretase inhibitor with no effect on lysosomes. Importantly, this work shows that it is possible to dissociate the lysosomotropic effect of CQ-derived compounds from their action on $A \beta$ secretion, providing a new profile of indirect $\beta$-secretase inhibitors. Although the exact mechanism of action remains to be elucidated, this novel series provides an opportunity for the development of novel $\beta$-secretase inhibitors potentially useful for the treatment of AD. 


\section{Experimental sections}

\subsection{Chemistry}

The reaction monitoring was performed by thin layer chromatography (TLC) on MachereyNagel Alugram® Sil 60/UV254 (thickness $0.2 \mathrm{~mm})$. TLC were revealed by UV $(\lambda=254 \mathrm{~nm})$ and/or the appropriate stain (iodine, nynhydrine). Purification of the compounds was carried out by column chromatography (either flash or manual). Manual chromatography was performed using Macherey-Nagel silica gel (0.04-0.063 $\mathrm{mm}$ of particule size). Flash chromatography was performed on a Reveleris ${ }^{\circledR}$ Flash Chromatography System using Macherey-Nagel Chromabond flash RS columns. NMR spectra were recorded on a Bruker DRX 300 spectrometer (operating at $300 \mathrm{MHz}$ for ${ }^{1} \mathrm{H}$ and $75 \mathrm{MHz}$ for ${ }^{13} \mathrm{C}$ ). Chemical shifts are reported in parts per million ( $\mathrm{ppm}$ ) relative to an internal reference (either tetramethylsilane or residual deuterated solvents ${ }^{1} \mathrm{H}$ signals). Each signal is reported with its chemical shift $(\delta)$, multiplicity $(\mathrm{s}=$ singulet, $\mathrm{d}=$ doublet, $\mathrm{t}=$ triplet, $\mathrm{q}=$ quartet, $\mathrm{m}=$ multiplet, $\mathrm{br}=$ broad $)$, coupling constant ( $\mathrm{in} \mathrm{Hz}$, when applicable) and relative integral. The attributions of protons and carbons were achieved by analysis of $1 \mathrm{D}$ and $2 \mathrm{D}$ experiments $\left({ }^{1} \mathrm{H},{ }^{13} \mathrm{C}, \mathrm{COSY}, \mathrm{HQC}\right.$ and HMBC). LCMS were performed on a Varian triple quadrupole $1200 \mathrm{~W}$ mass spectrometer equipped with a non-polar C18 TSK-gel Super ODS $(4.6$ x $50 \mathrm{~mm})$ column, using electrospray ionisation and a UV detector (diode array). Elution was performed at a flow rate of $2 \mathrm{~mL} / \mathrm{min}$ with water-formic acid $(\mathrm{pH}=3.8)$ as eluent $\mathrm{A}$ and $\mathrm{ACN}$-formic acid $(\mathrm{pH}=3.8)$ as eluent $\mathrm{B}$, employing a $0.25 \mathrm{~min}$ plateau with $0 \% \mathrm{~B}$ and a linear gradient from $0 \% \mathrm{~B}$ to $98 \% \mathrm{~B}$ in $3.25 \mathrm{~min}$, followed by a 0.5 min plateau with $98 \% \mathrm{~B}$. Then, column re-equilibration was performed for $1 \mathrm{~min}$. HRMS were recorded on a Hight Resolution Mass Spectrometer (HRMS) Thermo Scientific ${ }^{\mathrm{TM}}$ Exactive $^{\mathrm{TM}}$. Analysed compounds were dissolved in methanol and directly injected in the ionisation source ESI, in positive or negative mode according to the analyzed compound, and recorded for one minute. The Xcalibur software was used to determine the elementar composition of main pics of the spectrum. The purity of final compounds was determined by high pressure liquid chromatography (HPLC) using two columns: C18 Interchrom UPTISPHERE and C4 Interchrom UPTISPHERE. The HPLC analysis was carried out on a Shimadzu LC-2010AHT system equipped with a UV detector set at 254 and $215 \mathrm{~nm}$. The compounds were dissolved in $100 \mu \mathrm{L}$ of buffer B and $900 \mu \mathrm{L}$ of buffer $\mathrm{A}$. The eluent system used was: buffer $\mathrm{A}\left(\mathrm{H}_{2} \mathrm{O} / \mathrm{TFA}\right.$, 100:0.1) and buffer B (ACN/ $\left.\mathrm{H}_{2} \mathrm{O} / \mathrm{TFA}, 80: 20: 0.1\right)$. Retention times (tr) were obtained at a flow rate of $0.2 \mathrm{~mL} / \mathrm{min}$ for $37 \mathrm{~min}$ using a gradient form $100 \%$ of buffer A over $1 \mathrm{~min}$, to $100 \%$ buffer B over the next $30 \mathrm{~min}$, to $100 \%$ of buffer A over 1 min and $100 \%$ of buffer A over 1 
min. All tested compounds showed a purity of $\geq 95 \%$. The melting point analyses were performed on Barnstead Electrothermel Melting Point Series IA9200 and were not corrected. All final compounds were transformed into their hydrochloride salt forms (before testing) using the following procedure: the compound was dissolved in $\mathrm{MeOH}$ and $2 \mathrm{~N} \mathrm{HCl}_{\text {aq }}$ was added dropwise until pH1. The solvent was evaporated and the compound was freeze-dried.

\section{6-Bromo-3H-1,3-benzoxazol-2-one (1)}

$3 H$-1,3-Benzoxazol-2-one (5.00 g, $37.00 \mathrm{mmol})$ was dissolved in acetic acid $(50 \mathrm{~mL})$ and bromine $(1.9 \mathrm{~mL}, 37.0 \mathrm{mmol})$ was added dropwise. The reaction mixture was stirred at $20{ }^{\circ} \mathrm{C}$ for $4 \mathrm{~h}$. The reaction mixture was poured onto ice and the precipitate was collected by filtration, washed with water and air-dried to give a pink powder (7.48 g, $34.8 \mathrm{mmol}, 94 \%)$. Mp $191.6-$ $192.3{ }^{\circ} \mathrm{C} .{ }^{1} \mathrm{H}$ NMR $\left(300 \mathrm{MHz}, \mathrm{DMSO}-d_{6}\right): \delta 11.81(\mathrm{~s}, 1 \mathrm{H}), 7.57$ (dd, $J=1.9 \mathrm{~Hz}, J=0.3 \mathrm{~Hz}$, $1 \mathrm{H}), 7.30(\mathrm{dd}, J=8.3 \mathrm{~Hz}, J=1.9 \mathrm{~Hz}, 1 \mathrm{H}), 7.04(\mathrm{dd}, J=8.3 \mathrm{~Hz}, J=0.3 \mathrm{~Hz}, 1 \mathrm{H}) .{ }^{13} \mathrm{C} \mathrm{NMR}(75$ MHz, DMSO- $\left.d_{6}\right): \delta 154.5,144.5,130.3,126.9,113.5,113.2,111.7$. LCMS $m / z$ calc for $[\mathrm{M}-$ $\mathrm{H}]^{+}:$211.9, 213.9, found: $211.8,213.8$.

General procedure for the synthesis of compounds 2 and 3. 6-bromo-3H-1,3-benzoxazol-2one 1 (5.00 g, $23.36 \mathrm{mmol})$ was suspended in $\mathrm{ACN}(150 \mathrm{~mL})$ and $\mathrm{K}_{2} \mathrm{CO}_{3}(9.69 \mathrm{~g}, 70.09 \mathrm{mmol})$ was added. The reaction mixture was stirred at $80{ }^{\circ} \mathrm{C}$ for $30 \mathrm{~min}$. 1-(2-Chloroethyl)piperidine hydrochloride (4.30 g, $23.36 \mathrm{mmol}$ ) or 3-chloropropylpiperidine hydrochloride (5.5 g, 28 mmol) was added and the reaction mixture was stirred at $80^{\circ} \mathrm{C}$ for another $12 \mathrm{~h}$. The inorganics were removed by filtration and the solvent was evaporated. The residue was purified by flash chromatography (DCM/MeOH$\left(\mathrm{NH}_{3}\right)$, 9.8:0.2 (v/v)) to afford compounds 2 and $\mathbf{3}$.

6-Bromo-3-[2-(piperidin-1-yl)ethyl]-1,3-benzoxazol-2-one (2)

Beige solid (7.58 g, $23.1 \mathrm{mmol}, 99 \%)$. Mp 85.1- 85.8 ${ }^{\circ} \mathrm{C} .{ }^{1} \mathrm{H}$ NMR (300 MHz, $\left.\mathrm{CDCl}_{3}\right): \delta 7.36$ $(\mathrm{d}, J=1.8 \mathrm{~Hz}, 1 \mathrm{H}), 7.31(\mathrm{dd}, J=8.3,1.8 \mathrm{~Hz}, 1 \mathrm{H}), 6.92(\mathrm{~d}, J=8.3 \mathrm{~Hz}, 1 \mathrm{H}), 3.90(\mathrm{t}, J=6.6 \mathrm{~Hz}$, 2H), $2.64(\mathrm{t}, J=6.6 \mathrm{~Hz}, 2 \mathrm{H}), 2.51-2.38(\mathrm{~m}, 4 \mathrm{H}), 1.60-1.35(\mathrm{~m}, 6 \mathrm{H}) .{ }^{13} \mathrm{C}$ NMR $(75 \mathrm{MHz}$, $\left.\mathrm{CDCl}_{3}\right): \delta 154.1,143.1,130.7,126.6,114.4,113.5,109.9,56.0,54.7,40.3,26.0,24.2$. LCMS $m / z$ calc for $[\mathrm{M}+\mathrm{H}]^{+}:$325.1, 327.1 found: $325.1,327.1$.

6-Bromo-3-[3-(piperidin-1-yl)propyl]-1,3-benzoxazol-2-one (3)

Colorless oil (7.76 g, $22.9 \mathrm{mmol}, 98 \%) .{ }^{1} \mathrm{H}$ NMR (300 MHz, $\left.\mathrm{CDCl}_{3}\right): \delta 7.36$ (d, $J=1.8 \mathrm{~Hz}$, $1 \mathrm{H}), 7.30(\mathrm{dd}, J=8.3 \mathrm{~Hz}, J=1.8 \mathrm{~Hz}, 1 \mathrm{H}), 6.98(\mathrm{~d}, J=8.3 \mathrm{~Hz}, 1 \mathrm{H}), 3.88(\mathrm{t}, J=6.7 \mathrm{~Hz}, 2 \mathrm{H})$; 
$2.35-2.28(\mathrm{~m}, 6 \mathrm{H}), 1.98-1.89(\mathrm{~m}, 2 \mathrm{H}), 1.60-1.51(\mathrm{~m}, 4 \mathrm{H}), 1.46-1.38(\mathrm{~m}, 2 \mathrm{H}) .{ }^{13} \mathrm{C} \mathrm{NMR}$ (75 MHz, $\left.\mathrm{CDCl}_{3}\right): \delta 154.1,143.1,130.8,126.6,114.4,113.5,109.7,55.5,54.5,40.6,25.9$, 24.8, 24.4. LCMS $m / z$ calc for $[\mathrm{M}+\mathrm{H}]^{+}: 338.1,340.1$, found: $338.9,340.8$.

6-bromo-3-[4-(piperidin-1-yl)butyl]-1,3-benzoxazol-2-one (4)

To a solution of 1-bromo-4-chlorobutane (2.17 mL, $18.7 \mathrm{mmol}), \mathrm{K}_{2} \mathrm{CO}_{3}(3.87 \mathrm{~g}, 28.04 \mathrm{mmol})$ in $\mathrm{ACN}(1 \mathrm{~mL})$ was added dropwise at a solution of 6-bromo-3H-1,3-benzoxazol-2-one (1) in $\operatorname{ACN}(3 \mathrm{~mL})$. The mixture was heated at $80{ }^{\circ} \mathrm{C}$ for $12 \mathrm{~h}$. The inorganics were removed by filtration and the solvent was evaporated. The residue was purified by column chromatography (cyclohexane/ethyl acetate), 9:1 (v:v)) to afford 6-bromo-3-(4-chlorobutyl)-1,3-benzoxazol-2one as a white solid (1.2 g, $3.94 \mathrm{mmol}) . \mathrm{Mp} 61.9-62.4{ }^{\circ} \mathrm{C} .{ }^{1} \mathrm{H} \mathrm{NMR}\left(300 \mathrm{MHz}, \mathrm{CDCl}_{3}\right): \delta$ $7.39(\mathrm{~d}, J=1.8 \mathrm{~Hz}, 1 \mathrm{H}), 7.34(\mathrm{dd}, J=8.3,1.8 \mathrm{~Hz}, 1 \mathrm{H}), 6.88(\mathrm{~d}, J=8.3 \mathrm{~Hz}, 1 \mathrm{H}), 3.87$ (t, $J=6.8$ $\mathrm{Hz}, 2 \mathrm{H}), 3.60(\mathrm{t}, J=6.1 \mathrm{~Hz}, 2 \mathrm{H}), 2.27-1.74(\mathrm{~m}, 4 \mathrm{H}) .{ }^{13} \mathrm{C} \mathrm{NMR}\left(75 \mathrm{MHz}, \mathrm{CDCl}_{3}\right): \delta 154.1$, $143.1,130.2$, 126.9, 114.8, 113.8, 109.2, 77.5, 77.0, 76.6, 44.0, 41.6, 29.2, 25.0. LCMS m/z calc for $[\mathrm{M}+\mathrm{ACN}+\mathrm{H}]^{+}: 345.6,347.6$, found: $345.1,347.1$.

6-Bromo-3-(4-chlorobutyl)-1,3-benzoxazol-2-one (1.2 g, $3.94 \mathrm{mmol})$ was dissolved in piperidine $(19 \mathrm{~mL})$ and refluxed for $12 \mathrm{~h}$. The mixture was concentrated in vacuo and the residue was dissolved in $1 \mathrm{~N} \mathrm{NaOH}(20 \mathrm{~mL})$ and extracted with $\mathrm{DCM}(3 \times 60 \mathrm{~mL})$. The combined organic layers were dried over $\mathrm{MgSO}_{4}$, filtrated and concentrated in vacuo. The residue was purified by column chromatography (DCM/MeOH$\left.\left(\mathrm{NH}_{3}\right), 9.5: 0.5(\mathrm{v}: \mathrm{v})\right)$ to afford a beige powder $\left(1.07 \mathrm{~g}, 3.0 \mathrm{mmol}, 16 \%\right.$ over two steps). Mp 100.2-101.0 ${ }^{\circ} \mathrm{C} .{ }^{1} \mathrm{H}$ NMR (300 $\left.\mathrm{MHz}, \mathrm{CDCl}_{3}\right): \delta 7.37(\mathrm{~d}, J=1.8 \mathrm{~Hz}, 1 \mathrm{H}), 7.32(\mathrm{dd}, J=8.3,1.8 \mathrm{~Hz}, 1 \mathrm{H}), 6.88(\mathrm{~d}, J=8.3 \mathrm{~Hz}$, $1 \mathrm{H}), 3.83(\mathrm{t}, J=7.2 \mathrm{~Hz}, 2 \mathrm{H}), 2.38-2.27(\mathrm{~m}, 6 \mathrm{H}), 1.86-1.70(\mathrm{~m}, 2 \mathrm{H}), 1.66-1.42(\mathrm{~m}, 8 \mathrm{H}) .{ }^{13} \mathrm{C}$ NMR (75 MHz, $\mathrm{CDCl}_{3}$ ): $\delta$ 154.0, 143.1, 130.4, 126.7, 114.6, 113.6, 109.4, 58.5, 58.4, 54.6, 42.3, 42.2, 30.0, 25.8, 24.4, 23.9. LCMS $\mathrm{m} / z$ calc for $[\mathrm{M}+\mathrm{H}]^{+}: 353.1,355.1$, found: 353.1, 355.1 .

\section{General procedure for the synthesis of compounds 5-7 is exemplified by the protocol used} for the synthesis of 5 . To a solution of 6-bromo-3-[2-(piperidin-1-yl)ethyl]-1,3-benzoxazol-2one (2) $(4.0 \mathrm{~g}, 12.3 \mathrm{mmol})$ in dioxane $(19 \mathrm{~mL})$, aqueous $2.5 \mathrm{~N} \mathrm{NaOH}(98.4 \mathrm{~mL}, 246 \mathrm{mmol})$ was added. The mixture was stirred at $20{ }^{\circ} \mathrm{C}$ for $12 \mathrm{~h}$. After cooling to $0{ }^{\circ} \mathrm{C}$, a $1 \mathrm{~N} \mathrm{HCl}$ solution was added to reach $\mathrm{pH} 8$. After $30 \mathrm{~min}$ of stirring, the mixture was extracted with DCM $(3 \times 100$ $\mathrm{mL}$ ). The combined organic layers were dried over $\mathrm{MgSO}_{4}$ and evaporated to afford 5-bromo2-((2-(piperidin-1-yl)ethyl)amino)phenol 5 as a beige solid (3.1 g, $10.4 \mathrm{mmol}, 84 \%)$ that was 
used without further purification. $\mathrm{Mp} 126.8-127.5{ }^{\circ} \mathrm{C} .{ }^{1} \mathrm{H} \mathrm{NMR}\left(300 \mathrm{MHz}, \mathrm{CDCl}_{3}\right): \delta 6.95$ $(\mathrm{d}, J=2.1 \mathrm{~Hz}, 1 \mathrm{H}), 6.87(\mathrm{dd}, J=8.3,2.1 \mathrm{~Hz}, 1 \mathrm{H}), 6.66(\mathrm{~d}, J=8.3 \mathrm{~Hz}, 1 \mathrm{H}), 3.25-3.15(\mathrm{t}, J=$ $5.7 \mathrm{~Hz}, 2 \mathrm{H}), 2.60-2.31(\mathrm{~m}, 6 \mathrm{H}), 1.75-1.64(\mathrm{~m}, 4 \mathrm{H}), 1.56-1.45(\mathrm{~m}, 2 \mathrm{H}) .{ }^{13} \mathrm{C} \mathrm{NMR}(75 \mathrm{MHz}$, $\left.\mathrm{CDCl}_{3}\right): \delta 151.1,135.8,122.7,120.9,119.8,113.8,57.3,54.3,44.7,25.0,23.9$. LCMS $m / z$ calc for $[\mathrm{M}+\mathrm{H}]^{+}:$299.1, 301.1, found: 299.1, 301.1.

5-Bromo-2-([3-(piperidin-1-yl)propyl]amino)phenol (6)

Brown oil (2.16 g, $6.9 \mathrm{mmol}, 95 \%) .{ }^{1} \mathrm{H}$ NMR (300 MHz, MeOD): $\delta 6.82-6.78$ (m, 2H), 6.49 $(\mathrm{d}, J=8.1 \mathrm{~Hz}, 1 \mathrm{H}), 3.15(\mathrm{t}, J=6.7 \mathrm{~Hz}, 2 \mathrm{H}), 2.57-2.52(\mathrm{~m}, 6 \mathrm{H}), 1.89-1.80(\mathrm{~m}, 2 \mathrm{H}), 1.69-$ $1.62(\mathrm{~m}, 4 \mathrm{H}), 1.54-1.50$ (m, 2H). ${ }^{13} \mathrm{C}$ NMR (75 MHz, MeOD): $\delta$ 145.8, 136.7, 122.1, 115.9, $111.5,107.6,56.7,53.9,41.8,25.0,24.7,23.4$. LCMS $m / z$ calc for $[\mathrm{M}+\mathrm{H}]^{+}: 313.1,315.1$, found: $312.9,314.9$.

5-bromo-2-[(4-(piperidin-1-yl)butyl)amino]phenol (7)

Beige solid (246 mg, $0.75 \mathrm{mmol}, 50 \%)$. Mp 130.3 - 130.9 ${ }^{\circ} \mathrm{C} .{ }^{1} \mathrm{H}$ NMR (300 MHz, DMSO-d 6 ): $\delta 6.79-6.73(\mathrm{~m}, 2 \mathrm{H}), 6.40(\mathrm{~d}, J=9.0 \mathrm{~Hz}, 1 \mathrm{H}), 3.02(\mathrm{t}, J=6.5 \mathrm{~Hz}, 2 \mathrm{H}), 2.39-2.22(\mathrm{~m}, 6 \mathrm{H})$, $1.59-1.27(\mathrm{~m}, 12 \mathrm{H}) .{ }^{13} \mathrm{C}$ NMR (75 MHz, DMSO- $\left.d_{6}\right): \delta 145.2,137.1,121.9,115.7,110.6$, 105.4, 58.0, 53.9, 42.5, 40.3, 40.1, 39.8, 39.5, 39.2, 39, 38.7, 26.3, 25.4, 24.0, 23.8. LCMS m/z calc for $[\mathrm{M}+\mathrm{H}]^{+}: 327.1,329.1$ found: $327.2,329.2$.

General procedure for the synthesis of compounds 8, 9, 11-14 is exemplified by the protocol used for the synthesis of 8 . To a solution of 5-bromo-2-([2-(piperidin-1yl)ethyl]amino)phenol (5) (550 mg, $1.84 \mathrm{mmol})$ in DMF (23 mL), at $0{ }^{\circ} \mathrm{C}$, NaH (147 mg, 3.68 mmol) was added. After stirring the mixture for $30 \mathrm{~min}$, 1-(2-chloroethyl)piperidine hydrochloride $\left(338 \mathrm{mg}, 1.84 \mathrm{mmol}\right.$ ) was added at $0{ }^{\circ} \mathrm{C}$. The reaction mixture was stirred for another $12 \mathrm{~h}$ at rt. The mixture was diluted with $20 \mathrm{~mL}$ of water and extracted with DCM (3 x $60 \mathrm{~mL}$ ). The combined organic layers were dried over $\mathrm{MgSO}_{4}$ and evaporated. The residue was purified by column chromatography $\left(\mathrm{DCM} / \mathrm{MeOH}\left(\mathrm{NH}_{3}\right)\right.$, 9.5:0.5 (v:v)) to afford 4-bromo-2(2-(piperidin-1-yl)ethoxy)- $N$-(2-(piperidin-1-yl)ethyl)aniline (8) as a brown oil (587 mg, 1.43 mmol, $78 \%$ \%). ${ }^{1} \mathrm{H}$ NMR (300 MHz, $\left.\mathrm{CDCl}_{3}\right): \delta 6.96(\mathrm{dd}, J=8.4,1.9 \mathrm{~Hz}, 1 \mathrm{H}), 6.86(\mathrm{~d}, J=1.9$ $\mathrm{Hz}, 1 \mathrm{H}), 6.43(\mathrm{~d}, J=8.4 \mathrm{~Hz}, 1 \mathrm{H}), 4.91(\mathrm{~s}, 1 \mathrm{H}), 4.10(\mathrm{t}, J=5.8 \mathrm{~Hz}, 2 \mathrm{H}), 3.22-3.05(\mathrm{~m}, 2 \mathrm{H})$, $2.82(\mathrm{t}, J=5.8 \mathrm{~Hz}, 2 \mathrm{H}), 2.68-2.34(\mathrm{~m}, 10 \mathrm{H}), 1.71-1.52(\mathrm{~m}, 8 \mathrm{H}), 1.51-1.39(\mathrm{~m}, 4 \mathrm{H}) .{ }^{13} \mathrm{C}$ NMR (75 MHz, $\left.\mathrm{CDCl}_{3}\right): \delta 146.9,138.0,124.0,114.1,110.8,107.3,66.7,58.0,57.3,54.9,54.4$, 40.3, 26.1, 26.0, 24.5, 24.2. LCMS $m / z$ calc for $[\mathrm{M}+\mathrm{H}]^{+}:$410.4, 412.4 found: 410.2, 412.2. 
4-Bromo- $N$-[2-(piperidin-1-yl)ethyl]-2-[3-(piperidin-1-yl)propoxy]aniline (9)

Brown oil (450 mg, 1.06 mmol, $32 \%)$. ${ }^{1} \mathrm{H}$ NMR (300 MHz, $\mathrm{CDCl}_{3}$ ): $\delta 6.95$ (dd, $J=8.4,2.1 \mathrm{~Hz}$, $1 \mathrm{H}), 6.85(\mathrm{~d}, J=2.1 \mathrm{~Hz}, 1 \mathrm{H}), 6.43(\mathrm{~d}, J=8.4 \mathrm{~Hz}, 1 \mathrm{H}), 4.81(\mathrm{t}, J=5.0 \mathrm{~Hz}, 1 \mathrm{H}), 4.01(\mathrm{t}, J=6.2$ $\mathrm{Hz}, 2 \mathrm{H}), 3.14(\mathrm{~m}, 2 \mathrm{H}), 2.69-2.25(\mathrm{~m}, 12 \mathrm{H}), 2.11-1.91(\mathrm{~m}, 2 \mathrm{H}), 1.73-1.31(\mathrm{~m}, 12 \mathrm{H}) .{ }^{13} \mathrm{C}$ NMR (75 MHz, $\left.\mathrm{CDCl}_{3}\right): \delta 147.0,137.8,123.7,113.7,110.8,107.5,67.1,57.5,57.2,56.1,54.7$, $40.3,26.8,26.1,25.9,24.4$. LCMS $m / z$ calc for $[\mathrm{M}+\mathrm{H}]^{+}:$: 424.2, 426.2 found: 424.3, 426.2.

4-Bromo-2-[2-(piperidin-1-yl)ethoxy]- $N$-[3-(piperidin-1-yl)propyl]aniline (11)

Brown oil (2.30 g, $5.42 \mathrm{mmol}, 79 \%)$. ${ }^{1} \mathrm{H}$ NMR (300 MHz, $\left.\mathrm{CDCl}_{3}\right): \delta 6.95$ (dd, $J=8.4 \mathrm{~Hz}, J=$ $2.2 \mathrm{~Hz}, 1 \mathrm{H}), 6.86(\mathrm{~d}, J=2.2 \mathrm{~Hz}, 1 \mathrm{H}), 6.45(\mathrm{~d}, J=8.4 \mathrm{~Hz}, 1 \mathrm{H}), 4.73$ (br s, 1H), 4.09 (t, $J=6.2$ $\mathrm{Hz}, 2 \mathrm{H}), 3.13(\mathrm{t}, J=6.7 \mathrm{~Hz}, 2 \mathrm{H}), 2.76(\mathrm{t}, J=6.1 \mathrm{~Hz}, 2 \mathrm{H}), 2.51-2.36(\mathrm{~m}, 10 \mathrm{H}), 1.88-1.79$ $(\mathrm{m}, 2 \mathrm{H}), 1.64-1.57(\mathrm{~m}, 8 \mathrm{H}), 1.49-1.41(\mathrm{~m}, 4 \mathrm{H}) .{ }^{13} \mathrm{C} \mathrm{NMR}\left(75 \mathrm{MHz}, \mathrm{CDCl}_{3}\right): \delta 146.2,138.1$, 124.1, 114.4, 110.7, 107.2, 66.6, 57.9, 57.4, 54.8, 42.5, 26.3, 26.0, 24.3. LCMS m/z calc for $[\mathrm{M}+\mathrm{H}]^{+}:$424.2, 426.2, found: 424.3, 426.2

4-Bromo-2-(3-(piperidin-1-yl)propoxy)- $N$-(3-(piperidin-1-yl)propyl)aniline (12)

Brown oil (940 mg, $2.1 \mathrm{mmol}, 56 \%) .{ }^{1} \mathrm{H}$ NMR (300 MHz, $\left.\mathrm{CDCl}_{3}\right): \delta 6.94$ (dd, $J=8.4,2.1 \mathrm{~Hz}$, $1 \mathrm{H}), 6.85(\mathrm{~d}, J=2.1 \mathrm{~Hz}, 1 \mathrm{H}), 6.44(\mathrm{~d}, J=8.4 \mathrm{~Hz}, 1 \mathrm{H}), 4.55(\mathrm{~s}, 1 \mathrm{H}), 4.01(\mathrm{t}, J=6.4 \mathrm{~Hz}, 2 \mathrm{H})$, $3.22-3.03(\mathrm{~m}, 2 \mathrm{H}), 2.55-2.20(\mathrm{~m}, 12 \mathrm{H}), 2.07-1.95(\mathrm{~m}, 2 \mathrm{H}), 1.90-1.76(\mathrm{~m}, 2 \mathrm{H}), 1.70-$ $1.55(\mathrm{~m}, 8 \mathrm{H}), 1.50-1.40(\mathrm{~m}, 4 \mathrm{H}) .{ }^{13} \mathrm{C}$ NMR $\left(75 \mathrm{MHz}, \mathrm{CDCl}_{3}\right): \delta 146.7,137.7,123.7,113.7$, 110.6, 107.3, 67.1, 57.4, 55.9, 54.7, 54.6, 42.4, 29.7, 26.8, 26.3, 25.9, 24.4. LCMS $\mathrm{m} / z$ calc for $[\mathrm{M}+\mathrm{H}]^{+}:$438.2, 440.2, found:438.3, 440.2.

4-Bromo- $N$-[4-(piperidin-1-yl)butyl]-2-[2-(piperidin-1-yl)ethoxy]aniline (13)

Brown oil (513 mg, $1.17 \mathrm{mmol}, 55 \%) .{ }^{1} \mathrm{H}$ NMR (300 MHz, $\left.\mathrm{CDCl}_{3}\right): \delta 6.96(\mathrm{dd}, J=8.4,2.1$ $\mathrm{Hz}, 1 \mathrm{H}), 6.87(\mathrm{~d}, J=2.1 \mathrm{~Hz}, 1 \mathrm{H}), 6.44(\mathrm{~d}, J=8.4 \mathrm{~Hz}, 1 \mathrm{H}), 4.37$ (s, 1H), 4.08 (t, $J=5.9 \mathrm{~Hz}$, 2H), $3.12(\mathrm{~s}, 2 \mathrm{H}), 2.76(\mathrm{t}, J=5.9 \mathrm{~Hz}, 2 \mathrm{H}), 2.58-2.27(\mathrm{~m}, 10 \mathrm{H}), 1.78-1.36(\mathrm{~m}, 16 \mathrm{H}) .{ }^{13} \mathrm{C}$ NMR (75 MHz, $\left.\mathrm{CDCl}_{3}\right): \delta 146.5,138,124.2,114.6,110.7,107.1,66.8,59.1,57.9,55,54.6$, 43.5, 27.4, 26.0, 24.5, 24.2. LCMS $m / z$ calc for $[\mathrm{M}+\mathrm{H}]^{+}:$438.2, 440.2, found 438.3, 440.3.

4-Bromo-2-(2-cyclohexylethoxy)- $N$-(3-(piperidin-1-yl)propyl)aniline (14)

Brown oil (80 mg, $0.19 \mathrm{mmol}, 59 \%$ ). ${ }^{1} \mathrm{H} \mathrm{NMR}\left(300 \mathrm{MHz}, \mathrm{CDCl}_{3}\right): \delta 6.96$ (dd, $J=8.4 \mathrm{~Hz}, J=$ $2.1 \mathrm{~Hz}, 1 \mathrm{H}), 6.83(\mathrm{~d}, J=2.1 \mathrm{~Hz}, 1 \mathrm{H}), 6.45(\mathrm{~d}, J=8.4 \mathrm{~Hz}, 1 \mathrm{H}), 3.99(\mathrm{t}, J=6.75 \mathrm{~Hz}, 2 \mathrm{H}), 3.13$ 
(t, $J=6.6 \mathrm{~Hz}, 2 \mathrm{H}), 2.47-2.43(\mathrm{~m}, 6 \mathrm{H}), 1.90-1.60(\mathrm{~m}, 13 \mathrm{H}), 1.50-1.44(\mathrm{~m}, 3 \mathrm{H}), 1.25-1.22$ $(\mathrm{m}, 3 \mathrm{H}), 1.04-0.97$ (m, 2H). ${ }^{13} \mathrm{C}$ NMR (75 MHz, $\left.\mathrm{CDCl}_{3}\right): \delta 146.9,137.9,123.5,113.5,110.5$, $107.4,66.6,57.3,54.7,42.5,36.5,34.8,33.3,26.5,26.2,26.1,25.7,24.3$. LCMS m/z calc for $[\mathrm{M}+\mathrm{H}]^{+}:$423.2, 425.2, found: 423.2, 425.0.

4-Bromo-2-(4-chlorobutoxy)- $N$-(2-(piperidin-1-yl)ethyl)aniline (10)

To a solution of 5-bromo-2-([2-(piperidin-1-yl)ethyl]amino)phenol (5) (1 g, $3.34 \mathrm{mmol})$ in DMF (42 mL), at $0{ }^{\circ} \mathrm{C}, \mathrm{NaH}(334 \mathrm{mg}, 8.36 \mathrm{mmol})$ was added. After stirring the mixture for 30 min, 1-bromo-4-chlorobutane $(0.43 \mathrm{ml}, 3.34 \mathrm{mmol})$ in DMF $(5 \mathrm{ml})$ was added dropwise at $0{ }^{\circ} \mathrm{C}$. The reaction mixture was stirred for another $12 \mathrm{~h}$ at rt. The mixture was diluted with $40 \mathrm{~mL}$ of water and extracted with DCM $(3 \times 60 \mathrm{~mL})$. The combined organic layers were dried over $\mathrm{MgSO}_{4}$ and evaporated. The residue was purified by column chromatography (DCM/MeOH(NH$), 9.8: 0.2$ (v:v)) to afford 4-bromo-2-(4-chlorobutoxy)- $N$-(2-(piperidin-1yl)ethyl)aniline as a colorless oil $(450 \mathrm{mg}, 1.15 \mathrm{mmol}) .{ }^{1} \mathrm{H}$ NMR $\left(300 \mathrm{MHz}, \mathrm{CDCl}_{3}\right): \delta 6.97$ $(\mathrm{dd}, J=8.3,2.1 \mathrm{~Hz}, 1 \mathrm{H}), 6.84(\mathrm{~s}, 1 \mathrm{H}), 6.44(\mathrm{dd}, J=8.3,1.5 \mathrm{~Hz}, 1 \mathrm{H}), 4.88(\mathrm{~s}, 1 \mathrm{H}), 4.06-3.97$ $(\mathrm{m}, 2 \mathrm{H}), 3.70-3.58(\mathrm{~m}, 2 \mathrm{H}), 3.21-3.07(\mathrm{~m}, 2 \mathrm{H}), 2.61(\mathrm{t}, J=5.2 \mathrm{~Hz}, 2 \mathrm{H}), 2.48-2.35(\mathrm{~m}, 4 \mathrm{H})$, 2.12 - $1.94(\mathrm{~m}, 4 \mathrm{H}), 1.68-1.44(\mathrm{~m}, 6 \mathrm{H}) .{ }^{13} \mathrm{C} \mathrm{NMR}\left(75 \mathrm{MHz}, \mathrm{CDCl}_{3}\right): \delta 146.8,137.9,123.9$, 113.6, 110.9, 107.4, 67.4, 57.1, 54.3, 44.7, 40.2, 29.4, 26.7, 26.2, 24.5. LCMS $\mathrm{m} / \mathrm{z}$ calc for $[\mathrm{M}+\mathrm{H}]^{+}:$389.1, 391.1, 393.1, found: 389.1, 391.1, 393.2.

4-Bromo-2-(4-chlorobutoxy)- $N$-(2-(piperidin-1-yl)ethyl)aniline (438 mg, $1.12 \mathrm{mmol}$ ) was dissolved in piperidine $(11 \mathrm{~mL})$ and was refluxed for $12 \mathrm{~h}$. The mixture was concentrated in vacuo and the residue was dissolved in $1 \mathrm{~N} \mathrm{NaOH}(20 \mathrm{~mL})$ and extracted with DCM $(3 \times 60$ $\mathrm{mL}$ ). The combined organic layers were dried over $\mathrm{MgSO}_{4}$, filtrated and concentrated in vacuo. The residue was purified by column chromatography (DCM/MeOH(NH$), 9.8: 0.2(\mathrm{v}: \mathrm{v}))$ to afford 10 as a brown oil (246 mg, $0.56 \mathrm{mmol}, 18 \%$ over two steps). ${ }^{1} \mathrm{H}$ NMR (300 MHz, $\left.\mathrm{CDCl}_{3}\right): \delta 6.95(\mathrm{dd}, J=8.4,2.1 \mathrm{~Hz}, 1 \mathrm{H}), 6.83(\mathrm{~d}, J=2.1 \mathrm{~Hz}, 1 \mathrm{H}), 6.43(\mathrm{~d}, J=8.4 \mathrm{~Hz}, 1 \mathrm{H}), 4.81$ (s, 1H), $3.98(\mathrm{t}, J=6.3 \mathrm{~Hz}, 2 \mathrm{H}), 3.27-2.98(\mathrm{~m}, 2 \mathrm{H}), 2.60$ (t, $J=6.3 \mathrm{~Hz}, 2 \mathrm{H}), 2.49-2.27$ (m, $10 \mathrm{H}), 2.00-1.78(\mathrm{~m}, 2 \mathrm{H}), 1.76-1.52(\mathrm{~m}, 10 \mathrm{H}), 1.50-1.39(\mathrm{~m}, 4 \mathrm{H}) .{ }^{13} \mathrm{C} \mathrm{NMR}(75 \mathrm{MHz}$, $\left.\mathrm{CDCl}_{3}\right): \delta 147.0,137.9,123.6,113.6,110.7,107.5,68.3,59.0,57.2,54.6,54.4,40.8,27.5,26.2$, 25, 24.5, 23.5. LCMS $m / z$ calc for $[\mathrm{M}+\mathrm{H}]^{+}:$438.2, 439.2, found: 438.3, 440.3.

General procedure for the synthesis of compounds 15-23 is exemplified by the protocol used for the synthesis of 15. 2-Formylbenzeneboronic acid ( $63 \mathrm{mg}, 0.42 \mathrm{mmol}$ ) was dissolved in a mixture of toluene $(8 \mathrm{~mL})$ and $\mathrm{EtOH}(3.2 \mathrm{~mL}) . \mathrm{K}_{2} \mathrm{CO}_{3}(62 \mathrm{mg}, 0.45 \mathrm{mmol})$ and 4-bromo- 
2-[2-(piperidin-1-yl)ethoxy]- $N$-[3-(piperidin-1-yl)propyl]aniline (11) (150 mg, $0.35 \mathrm{mmol})$ were added and the reaction was stirred for $30 \mathrm{~min}$ and deoxygenated by passing a stream of $\mathrm{N}_{2}$ through it. $\mathrm{Pd}_{2} \mathrm{dba}_{3}(7 \mathrm{mg}, 0.01 \mathrm{mmol})$ and $\mathrm{P}(o \text {-tol })_{3}(22 \mathrm{mg}, 0.07 \mathrm{mmol})$ were added and the mixture was refluxed for $18 \mathrm{~h}$. After cooling to $\mathrm{rt}$, the mixture was poured into water, extracted with ethyl acetate. The combined organic layers were dried over $\mathrm{MgSO}_{4}$ and evaporated. The residue was purified by flash chromatography (PE/EtOAc/MeOH$\left(\mathrm{NH}_{3}\right)$, 10:0:0 to 5.2:4.4:0.4 (v/v)) to afford 3'-(2-(piperidin-1-yl)ethoxy)-4'-((3-(piperidin-1yl)propyl)amino)-[1,1'-biphenyl]-2-carbaldehyde (15) as a brown oil (146 mg, $0.32 \mathrm{mmol}$, 92\%). ${ }^{1} \mathrm{H}$ NMR (300 MHz, $\left.\mathrm{CDCl}_{3}\right): \delta 10.03(\mathrm{~s}, 1 \mathrm{H}), 7.99-7.96(\mathrm{~m}, 1 \mathrm{H}) ; 7.62-7.58(\mathrm{~m}, 1 \mathrm{H})$; $7.47-7.38$ (m, 2H), 6.87 (dd, $J=7.9 \mathrm{~Hz}, J=1.9 \mathrm{~Hz}, 1 \mathrm{H}$ ), 6.82 (d, $J=1.9 \mathrm{~Hz}, 1 \mathrm{H}), 6.67$ (d, $J$ $=7.9 \mathrm{~Hz}, 1 \mathrm{H}), 4.98(\mathrm{br} \mathrm{s}, 1 \mathrm{H}), 4.16(\mathrm{t}, J=6.1 \mathrm{~Hz}, 2 \mathrm{H}), 3.25(\mathrm{t}, J=6.7 \mathrm{~Hz}, 2 \mathrm{H}), 2.81(\mathrm{t}, J=6.1$ $\mathrm{Hz}, 2 \mathrm{H}), 2.53-2.41(\mathrm{~m}, 10 \mathrm{H}), 1.94-1.85(\mathrm{~m}, 2 \mathrm{H}), 1.68-1.58(\mathrm{~m}, 8 \mathrm{H}), 1.49-1.43(\mathrm{~m}, 4 \mathrm{H})$. ${ }^{13} \mathrm{C}$ NMR (75 MHz, $\left.\mathrm{CDCl}_{3}\right): \delta 193.2,146.6,145.8,139.0,133.8,133.3,130.6,127.5,126.7$, 125.0, 124.2, 113.0, 109.3, 66.6, 58.0, 57.4, 54.9, 42.4, 26.4, 25.9, 24.3. LCMS $\mathrm{m} / z$ calc for $[\mathrm{M}+\mathrm{H}]^{+}:$450.3, found: 450.1 .

3'-(2-(piperidin-1-yl)ethoxy)-4'-((3-(piperidin-1-yl)propyl)amino)-[1,1'-biphenyl]-3carbaldehyde (16)

Brown oil (600 mg, $1.33 \mathrm{mmol}, 96 \%) .{ }^{1} \mathrm{H}$ NMR (300 MHz, $\left.\mathrm{CDCl}_{3}\right): \delta 10.07$ (s, 1H), 8.05 (t, $J$ $=1.6 \mathrm{~Hz}, 1 \mathrm{H}), 7.81(\mathrm{~m}, 1 \mathrm{H}), 7.75(\mathrm{dt}, J=7.7 \mathrm{~Hz}, J=1.6 \mathrm{~Hz}, 1 \mathrm{H}), 7.55(\mathrm{t}, J=7.7 \mathrm{~Hz}, 1 \mathrm{H}), 7.18$ $(\mathrm{dd}, J=8.2 \mathrm{~Hz}, J=2.0 \mathrm{~Hz}, 1 \mathrm{H}), 7.07$ (d, $J=2.0 \mathrm{~Hz}, 1 \mathrm{H}), 6.68(\mathrm{~d}, J=8.2 \mathrm{~Hz}, 1 \mathrm{H}), 4.95$ (br s, 1H), $4.22(\mathrm{t}, J=6.2 \mathrm{~Hz}, 2 \mathrm{H}), 3.24(\mathrm{t}, J=6.7 \mathrm{~Hz}, 2 \mathrm{H}), 2.83(\mathrm{t}, J=6.2 \mathrm{~Hz}, 2 \mathrm{H}), 2.56-2.41(\mathrm{~m}$, 10H), $1.91-1.87(\mathrm{~m}, 2 \mathrm{H}) ; 1.67-1.59(\mathrm{~m}, 8 \mathrm{H}), 1.49-1.45(\mathrm{~m}, 4 \mathrm{H}) .{ }^{13} \mathrm{C} \mathrm{NMR}(75 \mathrm{MHz}$, $\left.\mathrm{CDCl}_{3}\right): \delta 192.7,146.4,142.5,139.1,136.8,132.2,129.3,127.3,120.4,110.0,66.6,58.1,57.4$, 55.1, 54.7, 42.4, 26.4, 26.0, 24.3. LCMS $m / z$ calc for $[\mathrm{M}+\mathrm{H}]^{+}: 450.3$, found: 450.3 .

3'-(2-(piperidin-1-yl)ethoxy)-4'-((3-(piperidin-1-yl)propyl)amino)-[1,1'-biphenyl]-4carbaldehyde (17)

Brown oil (285 mg, $0.63 \mathrm{mmol}, 88 \%) .{ }^{1} \mathrm{H} \mathrm{NMR}\left(300 \mathrm{MHz}, \mathrm{CDCl}_{3}\right): \delta 10.01$ (s, 1H), 7.89 (d, $J$ $=8.4 \mathrm{~Hz}, 2 \mathrm{H}), 7.69(\mathrm{~d}, J=8.4 \mathrm{~Hz}, 2 \mathrm{H}), 7.23(\mathrm{dd}, J=8.4 \mathrm{~Hz}, J=2.1,1 \mathrm{H}), 7.10(\mathrm{~d}, J=2.1 \mathrm{~Hz}$, $1 \mathrm{H}), 6.67(\mathrm{~d}, J=8.4 \mathrm{~Hz}, 1 \mathrm{H}), 5.05(\mathrm{br} \mathrm{s}, 1 \mathrm{H}), 4.23(\mathrm{t}, J=6.3 \mathrm{~Hz}, 2 \mathrm{H}), 3.27(\mathrm{t}, J=6.6 \mathrm{~Hz}, 2 \mathrm{H})$, $2.86(\mathrm{t}, J=6.0 \mathrm{~Hz}, 2 \mathrm{H}), 2.61-2.39(\mathrm{~m}, 10 \mathrm{H}), 1.93(\mathrm{~m}, 2 \mathrm{H}), 1.75-1.58(\mathrm{~m}, 8 \mathrm{H}), 1.53-1.43$ (m, 4H). ${ }^{13} \mathrm{C}$ NMR (75 MHz, $\left.\mathrm{CDCl}_{3}\right): \delta 191.9,147.6,146.2$, 139.6, 134.0, 133.3, 127.0, 126.4, 
121.1, 110.0, 66.5, 57.9, 57.2, 54.8, 42.1, 25.8, 25.5, 24.1. LCMS $m / z$ calc for $[\mathrm{M}+\mathrm{H}]^{+}: 450.3$, found: 450.2 .

3'-(2-(piperidin-1-yl)ethoxy)-4'-((2-(piperidin-1-yl)ethyl)amino)-[1,1'-biphenyl]-2carbaldehyde (18)

Brown oil (459 mg, 1.05 mmol, 92\%). ${ }^{1} \mathrm{H}$ NMR (300 MHz, $\mathrm{CDCl}_{3}$ ): $\delta 10.03$ (s, 1H), 7.98 (dd, $J=7.8,1.4 \mathrm{~Hz}, 1 \mathrm{H}), 7.59(\mathrm{tt}, J=13.1,6.5 \mathrm{~Hz}, 1 \mathrm{H}), 7.45-7.41(\mathrm{~m}, 2 \mathrm{H}), 6.87(\mathrm{dd}, J=8.0,1.9$ $\mathrm{Hz}, 1 \mathrm{H}), 6.81(\mathrm{~d}, J=1.9 \mathrm{~Hz}, 1 \mathrm{H}), 6.66(\mathrm{~d}, J=8.0 \mathrm{~Hz}, 1 \mathrm{H}), 5.13(\mathrm{~s}, 1 \mathrm{H}), 4.16$ (t, $J=5.8 \mathrm{~Hz}$, 2H), $3.25(\mathrm{~m}, 2 \mathrm{H}), 2.85(\mathrm{t}, J=5.8 \mathrm{~Hz}, 2 \mathrm{H}), 2.66(\mathrm{t}, J=6.3 \mathrm{~Hz}, 2 \mathrm{H}), 2.59-2.50(\mathrm{~m}, 4 \mathrm{H}), 2.49$ -2.40 (m, 4H), $1.67-1.39$ (m, 12H). $\left.{ }^{13} \mathrm{C} \mathrm{NMR} \mathrm{(75} \mathrm{MHz,} \mathrm{CDCl}_{3}\right): \delta 193.2,146.7,146.1,139$, 133.8, 133.3, 130.6, 127.5, 126.7, 125.2, 124.1, 109.4, 66.6, 58.1, 57.4, 55, 54.4, 40.2, 26.1, 26, 24.5, 24.2. LCMS $m / z$ calc for $[\mathrm{M}+\mathrm{H}]^{+}: 436.3$, found 436.3 .

4'-((2-(piperidin-1-yl)ethyl)amino)-3'-(3-(piperidin-1-yl)propoxy)-[1,1'-biphenyl]-2carbaldehyde (19)

Brown oil (378 mg, $0.84 \mathrm{mmol}, 92 \%)$. Brown oil (378 mg, 92\%). ${ }^{1} \mathrm{H} \mathrm{NMR}\left(300 \mathrm{MHz}, \mathrm{CDCl}_{3}\right.$ ): $\delta 10.04(\mathrm{~s}, 1 \mathrm{H}), 7.98(\mathrm{dd}, J=7.8,1.3 \mathrm{~Hz}, 1 \mathrm{H}), 7.65-7.54(\mathrm{~m}, 1 \mathrm{H}), 7.50-7.37$ (m, 2H), 6.86 $(\mathrm{dd}, J=8.0,1.8 \mathrm{~Hz}, 1 \mathrm{H}), 6.80(\mathrm{~d}, J=1.8 \mathrm{~Hz}, 1 \mathrm{H}), 6.66(\mathrm{~d}, J=8.0 \mathrm{~Hz}, 1 \mathrm{H}), 5.02(\mathrm{t}, J=4.9 \mathrm{~Hz}$, $1 \mathrm{H}), 4.07(\mathrm{t}, J=6.2 \mathrm{~Hz}, 2 \mathrm{H}), 3.25(\mathrm{dd}, J=11.5,6.0 \mathrm{~Hz}, 2 \mathrm{H}), 2.66(\mathrm{t}, J=6.2 \mathrm{~Hz}, 2 \mathrm{H}), 2.57-$ $2.32(\mathrm{~m}, 10 \mathrm{H}), 1.67-1.54(\mathrm{~m}, 8 \mathrm{H}), 1.52-1.41(\mathrm{~m}, 4 \mathrm{H}) .{ }^{13} \mathrm{C} \mathrm{NMR}\left(75 \mathrm{MHz}, \mathrm{CDCl}_{3}\right): \delta 193.3$, 146.7, 146.2, 138.8, 133.8, 133.3, 130.7, 127.5, 126.7, 125.2, 123.8, 112.2, 109.3, 66, 57.3, $56.2,54.7,54.4,40.2,26,26.2,25.9,24.5,24.4$. LCMS $\mathrm{m} / z$ calc for $[\mathrm{M}+\mathrm{H}]^{+}:$450.6, found 450.38

3'-(4-(piperidin-1-yl)butoxy)-4'-((2-(piperidin-1-yl)ethyl)amino)-[1,1'-biphenyl]-2carbaldehyde (20)

Brown oil (150 mg, $0.32 \mathrm{mmol}, 71 \%) .{ }^{1} \mathrm{H}$ NMR (300 MHz, $\left.\mathrm{CDCl}_{3}\right): \delta 10.04$ (s, 1H), 7.98 (dd, $J=7.8,1.3 \mathrm{~Hz}, 1 \mathrm{H}), 7.65-7.56(\mathrm{~m}, 1 \mathrm{H}), 7.49-7.38(\mathrm{~m}, 2 \mathrm{H}), 6.86(\mathrm{dd}, J=8.0,1.8 \mathrm{~Hz}, 1 \mathrm{H})$, $6.78(\mathrm{~d}, J=1.8 \mathrm{~Hz}, 1 \mathrm{H}), 6.66(\mathrm{~d}, J=8.0 \mathrm{~Hz}, 1 \mathrm{H}), 5.01(\mathrm{~d}, J=4.8 \mathrm{~Hz}, 1 \mathrm{H}), 4.04$ (t, $J=6.2 \mathrm{~Hz}$, $2 \mathrm{H}), 3.31-3.18(\mathrm{~m}, J=11.6,4.6 \mathrm{~Hz}, 2 \mathrm{H}), 2.66(\mathrm{t}, J=6.2 \mathrm{~Hz}, 2 \mathrm{H}), 2.54-2.24(\mathrm{~m}, 10 \mathrm{H}), 1.94$ $-1.79(\mathrm{~m}, 4 \mathrm{H}), 1.79-1.53(\mathrm{~m}, 8 \mathrm{H}), 1.53-1.37(\mathrm{~m}, 4 \mathrm{H}) .{ }^{13} \mathrm{C} \mathrm{NMR}\left(75 \mathrm{MHz}, \mathrm{CDCl}_{3}\right): \delta 193.3$, 146.8, 146.2, 138.8, 133.8, 133.3, 130.7, 127.5, 126.7, 125.2, 123.7, 112.2, 109.4, 68.2, 59.1, 57.3, 54.6, 54.4, 40.3, 26.2, 25.9, 24.5, 23.5. LCMS $m / z$ calc for $[\mathrm{M}+\mathrm{H}]^{+}$: 464.3, found 464.4. 
3'-(3-(piperidin-1-yl)propoxy)-4'-((3-(piperidin-1-yl)propyl)amino)-[1,1'-biphenyl]-2carbaldehyde (21)

Brown oil (573 mg, $1.24 \mathrm{mmol}, 80 \%) .{ }^{1} \mathrm{H}$ NMR (300 MHz, $\left.\mathrm{CDCl}_{3}\right): \delta 10.02$ (s, 1H), 7.98 (d, $J$ $=7.6 \mathrm{~Hz}, 1 \mathrm{H}), 7.59(\mathrm{t}, J=7.6 \mathrm{~Hz}, 1 \mathrm{H}), 7.49-7.36(\mathrm{~m}, 2 \mathrm{H}), 6.85(\mathrm{dd}, J=8.0,1.7 \mathrm{~Hz}, 1 \mathrm{H}), 6.80$ $(\mathrm{s}, 1 \mathrm{H}), 6.67(\mathrm{~d}, J=8.0 \mathrm{~Hz}, 1 \mathrm{H}), 4.79(\mathrm{~s}, 1 \mathrm{H}), 4.07(\mathrm{t}, J=6.4 \mathrm{~Hz}, 2 \mathrm{H}), 3.25(\mathrm{~d}, J=6.2 \mathrm{~Hz}, 2 \mathrm{H})$, $2.58-2.33(\mathrm{~m}, 12 \mathrm{H}), 2.07-1.99(\mathrm{~m}, 2 \mathrm{H}), 1.96-1.79(\mathrm{~m}, 2 \mathrm{H}), 1.61(\mathrm{~m}, 8 \mathrm{H}), 1.51-1.41(\mathrm{~m}$, $4 \mathrm{H}) .{ }^{13} \mathrm{C} \mathrm{NMR}\left(75 \mathrm{MHz}, \mathrm{CDCl}_{3}\right): \delta 193.3,146.8,145.9,138.7,133.8,133.3,130.7,127.5$, 125.1, 123.8, 112.3, 109.2, 67.0, 57.4, 56.0, 54.8, 54.7, 42.4, 26.9, 26.5, 25.9, 24.5. LCMS m/z calc for $[\mathrm{M}+\mathrm{H}]^{+}: 464.3$, found 464.4 .

4'-((4-(piperidin-1-yl)butyl)amino)-3'-(2-(piperidin-1-yl)ethoxy)-[1,1'-biphenyl]-2-

carbaldehyde (22)

Brown oil (439 mg, 0.94 mmol, 97\%). ${ }^{1} \mathrm{H}$ NMR (300 MHz, $\mathrm{CDCl}_{3}$ ): $\delta 10.02$ (s, 1H), 7.98 (dd, $J=7.8,1.5 \mathrm{~Hz}, 1 \mathrm{H}), 7.59(\mathrm{td}, J=7.5,1.5 \mathrm{~Hz}, 1 \mathrm{H}), 7.45(\mathrm{dd}, J=8.0,1.2 \mathrm{~Hz}, 1 \mathrm{H}), 7.40(\mathrm{~d}, J=$ $7.5 \mathrm{~Hz}, 1 \mathrm{H}), 6.86(\mathrm{dd}, J=8.0,1.9 \mathrm{~Hz}, 1 \mathrm{H}), 6.82(\mathrm{~d}, J=1.9 \mathrm{~Hz}, 1 \mathrm{H}), 6.66(\mathrm{~d}, J=8.0 \mathrm{~Hz}, 1 \mathrm{H})$, $4.61(\mathrm{~s}, 1 \mathrm{H}), 4.14(\mathrm{t}, J=5.9 \mathrm{~Hz}, 2 \mathrm{H}), 3.21(\mathrm{~d}, J=6.1 \mathrm{~Hz}, 2 \mathrm{H}), 2.80(\mathrm{t}, J=6.0 \mathrm{~Hz}, 2 \mathrm{H}), 2.63-$ $2.26(\mathrm{~m}, 10 \mathrm{H}), 1.77-1.38(\mathrm{~m}, 16 \mathrm{H}) .{ }^{13} \mathrm{C} \mathrm{NMR}\left(75 \mathrm{MHz}, \mathrm{CDCl}_{3}\right): \delta 193.2,146.6,145.7,139.0$, 133.8, 133.3, 130.6, 127.5, 126.7, 125.0, 124.2, 113.1, 109.2, 66.6, 59.1, 58.0, 55.0, 54.6, 43.4, 27.5, 26.0, 24.6, 24.5, 24.2. LCMS $m / z$, calc for $[\mathrm{M}+\mathrm{H}]^{+}: 464.65$, found 464.45

3'-(2-cyclohexylethoxy)-4'-((3-(piperidin-1-yl)propyl)amino)-[1,1'-biphenyl]-3-carbaldehyde (23)

Brown oil (748 mg, $1.67 \mathrm{mmol}, 80 \%) .{ }^{1} \mathrm{H} \mathrm{NMR}\left(300 \mathrm{MHz}, \mathrm{CDCl}_{3}\right): \delta 10.03$ (s, 1H), 7.99 (d, $J$ $=7.4 \mathrm{~Hz}, 1 \mathrm{H}), 7.60-7.57(\mathrm{~m}, 1 \mathrm{H}), 7.48-7.41(\mathrm{~m}, 2 \mathrm{H}), 6.86-6.66(\mathrm{~m}, 3 \mathrm{H}), 4.77($ br s, $1 \mathrm{H})$, $4.06(\mathrm{t}, J=6.8 \mathrm{~Hz}, 2 \mathrm{H}), 3.26(\mathrm{~m}, 2 \mathrm{H}), 2.48(\mathrm{~m}, 6 \mathrm{H}), 2.46-0.97(\mathrm{~m}, 21 \mathrm{H}) .{ }^{13} \mathrm{C} \mathrm{NMR}(75 \mathrm{MHz}$, $\left.\mathrm{CDCl}_{3}\right): \delta 193.3,146.8,146.0,138.6,133.8,133.3,130.6,127.5,126.6,125.2,123.6,112.0$, $109.1,66.5,57.4,54.7,42.4,36.7,34.8,33.3,26.4,26.2,25.7,24.3$. LCMS $m / z$ calc for $[\mathrm{M}+\mathrm{H}]^{+}:$449.3, found 449.4.

General procedure for the synthesis of compounds 24-30 is exemplified by the protocol used for the synthesis of 24 . 3'-(2-(piperidin-1-yl)ethoxy)-4'-((3-(piperidin-1yl)propyl)amino)-[1,1'-biphenyl]-4-carbaldehyde 17 (290 $\mathrm{mg}, 0.65 \mathrm{mmol})$ was dissolved in DCE (12 mL). Piperidine ( $96 \mu \mathrm{L}, 0.97 \mathrm{mmol})$ was added. After $2 \mathrm{~h}$ at $\mathrm{rt}, \mathrm{NaBH}(\mathrm{OAc})_{3}(206$ $\mathrm{mg}, 0.97 \mathrm{mmol})$ and acetic acid $(56 \mu \mathrm{L}, 0.97 \mathrm{mmol})$ were added. After $16 \mathrm{~h}$ at $\mathrm{rt}$, saturated 
$\mathrm{NaHCO}_{3}$ solution was added. The reaction mixture was stirred for another hour. DCM was added and the layers were separated. The organic layer was washed three times with saturated $\mathrm{NaHCO}_{3}$ solution. The organic layer was dried over $\mathrm{MgSO}_{4}$ and evaporated. The residue was purified by flash chromatography $\left(\mathrm{DCM} / \mathrm{MeOH}\left(\mathrm{NH}_{3}\right), 10: 0\right.$ to $9: 1(v / v)$ ) to afford 2-[2(Piperidin-1-yl)ethoxy]- $N$-[3-(piperidin-1-yl)propyl]-4-[4-(piperidin-1-

ylmethyl)phenyl]aniline 24 as a colorless oil $(260 \mathrm{mg}, 0.50 \mathrm{mmol}, 77 \%) .{ }^{1} \mathrm{H}$ NMR (300 MHz, $\left.\mathrm{CDCl}_{3}\right): \delta 7.51(\mathrm{~d}, J=8.5 \mathrm{~Hz}, 2 \mathrm{H}), 7.32(\mathrm{~d}, J=8.5 \mathrm{~Hz}, 2 \mathrm{H}), 7.13(\mathrm{dd}, J=8.1 \mathrm{~Hz}, J=1.9 \mathrm{~Hz}$, $1 \mathrm{H}), 7.04(\mathrm{~d}, J=1.9 \mathrm{~Hz}, 1 \mathrm{H}), 6.66(\mathrm{~d}, J=8.2 \mathrm{~Hz}, 1 \mathrm{H}), 4.20(\mathrm{t}, J=6.0 \mathrm{~Hz}, 2 \mathrm{H}), 3.50(\mathrm{~s}, 2 \mathrm{H})$, $3.22(\mathrm{t}, J=6.7 \mathrm{~Hz}, 2 \mathrm{H}), 2.81(\mathrm{t}, J=6.0 \mathrm{~Hz}, 2 \mathrm{H}), 2.54-2.34(\mathrm{~m}, 14 \mathrm{H}), 1.93-1.84(\mathrm{~m}, 2 \mathrm{H})$, $1.66-1.38(\mathrm{~m}, 18 \mathrm{H}) .{ }^{13} \mathrm{C}$ NMR $\left(75 \mathrm{MHz}, \mathrm{CDCl}_{3}\right): \delta 146.2,140.2,138.3,136.1,129.6,129.1$, $126.0,120.2,110.1,66.6,63.6,58.1,57.5,55.1,54.5,42.5,26.6,26.0,24.4$. LCMS $m / z$ calc for $[\mathrm{M}+\mathrm{H}]^{+}:$: 519.4, found: 519.3. HR-MS: m/z Calculated: 519.4057 , found: $519.4060[\mathrm{M}+\mathrm{H}]^{+}$ $=\mathrm{C}_{33} \mathrm{H}_{51} \mathrm{~N}_{4} \mathrm{O}$.

4-(4-[(Dimethylamino)methyl]phenyl)-2-[2-(piperidin-1-yl)ethoxy]- $N$-[3-(piperidin-1yl)propyl] aniline (25)

In the present case dimethylamine $2 \mathrm{M}$ in THF was used and the product was obtained as a colorless oil (130 mg, $0.27 \mathrm{mmol}, 61 \%$ ). ${ }^{1} \mathrm{H} \mathrm{NMR}$ (300 MHz, $\left.\mathrm{CDCl}_{3}\right): \delta 7.49$ (d, $J=8.4 \mathrm{~Hz}$, 2H), $7.31(\mathrm{~d}, J=8.4 \mathrm{~Hz}, 2 \mathrm{H}), 7.12(\mathrm{dd}, J=8.2 \mathrm{~Hz}, J=2.1 \mathrm{~Hz}, 1 \mathrm{H}), 7.04(\mathrm{~d}, J=2.1 \mathrm{~Hz}, 1 \mathrm{H})$, $6.65(\mathrm{~d}, J=8.2 \mathrm{~Hz}, 1 \mathrm{H}), 4.20(\mathrm{t}, J=6.1 \mathrm{~Hz}, 2 \mathrm{H}), 3.45(\mathrm{~s}, 2 \mathrm{H}), 3.23(\mathrm{t}, J=6.8 \mathrm{~Hz}, 2 \mathrm{H}), 2.82(\mathrm{t}$, $J=6.1 \mathrm{~Hz}, 2 \mathrm{H}), 2.55-2.41(\mathrm{~m}, 10 \mathrm{H}), 2.25(\mathrm{~s}, 3 \mathrm{H}), 1.90-1.85(\mathrm{~m}, 2 \mathrm{H}), 1.66-1.58(\mathrm{~m}, 8 \mathrm{H})$, $1.51-1.44(\mathrm{~m}, 4 \mathrm{H}) .{ }^{13} \mathrm{C} \mathrm{NMR}\left(75 \mathrm{MHz}, \mathrm{CDCl}_{3}\right): \delta 146.2,140.4,138.3,136.4,129.5,129.0$, $126.4,120.2$, 110.0, 66.4, 64.1, 58.1, 57.4, 54.8, 45.3, 42.5, 26.4, 25.8, 24.3. LCMS $\mathrm{m} / z$ calc for $[\mathrm{M}+\mathrm{H}]^{+}: 479.3$, found: 479.4 . HR-MS: $\mathrm{m} / \mathrm{z}$ Calculated: 479.3744 , found: $479.3716[\mathrm{M}+\mathrm{H}]^{+}$ $=\mathrm{C}_{30} \mathrm{H}_{47} \mathrm{~N}_{4} \mathrm{O}$.

2-[2-(1-piperidyl)ethoxy]-4-[3-(1-piperidylmethyl)phenyl]- $N$-[3-(1-piperidyl)propyl]aniline (26)

Brown oil (17 mg, $0.03 \mathrm{mmol}, 5 \%) .{ }^{1} \mathrm{H}$ NMR (300 MHz, $\left.\mathrm{CDCl}_{3}\right): \delta 7.49-7.47(\mathrm{~m}, 1 \mathrm{H}), 7.45$ $-7.43(\mathrm{~m}, 1 \mathrm{H}), 7.33(\mathrm{t}, J=7.5 \mathrm{~Hz}, 1 \mathrm{H}), 7.24-7.20(\mathrm{~m}, 1 \mathrm{H}), 7.5(\mathrm{dd}, J=8.1 \mathrm{~Hz}, J=1.8 \mathrm{~Hz}$, 1H), $7.06(\mathrm{~d}, J=1.8 \mathrm{~Hz}, 1 \mathrm{H}), 6.66(\mathrm{~d}, J=8.1 \mathrm{~Hz}, 1 \mathrm{H}), 4.22$ (t, $J=6.0 \mathrm{~Hz}, 2 \mathrm{H}), 3.54(\mathrm{~s}, 2 \mathrm{H})$, $3.23(\mathrm{t}, J=6.9 \mathrm{~Hz}, 2 \mathrm{H}), 2.83(\mathrm{t}, J=6.7 \mathrm{~Hz}, 2 \mathrm{H}), 2.6-2.4(\mathrm{~m}, 14 \mathrm{H}) ; 1.89$ (quint, $J=6.7 \mathrm{~Hz}$, $2 \mathrm{H}), 1.70-1.50(\mathrm{~m}, 12 \mathrm{H}), 1.50-1.40(\mathrm{~m}, 6 \mathrm{H}) .{ }^{13} \mathrm{C} \mathrm{NMR}\left(75 \mathrm{MHz}, \mathrm{CDCl}_{3}\right): \delta 146.2,141.4$, $138.4,129.2,128.4,127.3,127.0,125.0,120.3,110.3$, 110.0, 66.6, 64.0, 58.1, 57.4, 55.1, 54.7, 
54.5, 42.5, 26.5, 26.0, 25.9, 24.4, 24.2. LCMS $m / z$ calc for $\left[\mathrm{M}+\mathrm{H}^{+}\right]$: 519.4, Found: 519.3. HRMS: m/z Calculated: 519.3985, found: $519.4060\left[\mathrm{M}+\mathrm{H}^{+}\right]=\mathrm{C}_{33} \mathrm{H}_{51} \mathrm{~N}_{4} \mathrm{O}$.

2-[2-(Piperidin-1-yl)ethoxy]- $N$-[3-(piperidin-1-yl)propyl]-4-[2-(piperidin-1ylmethyl)phenyl]aniline (27)

Colorless oil (114 mg, $0.22 \mathrm{mmol}, 66 \%)$. ${ }^{1} \mathrm{H}$ NMR (300 MHz, $\left.\mathrm{CDCl}_{3}\right): \delta 7.54-7.51(\mathrm{~m}, 1 \mathrm{H})$, $7.29-7.25(\mathrm{~m}, 3 \mathrm{H}), 6.93(\mathrm{~d}, J=1.8 \mathrm{~Hz}, 1 \mathrm{H}), 6.89$ (dd, $J=8.0 \mathrm{~Hz}, J=1.8 \mathrm{~Hz}, 1 \mathrm{H}), 6.64(\mathrm{~d}, J$ $=8.0 \mathrm{~Hz}, 1 \mathrm{H}), 4.98($ br s, $1 \mathrm{H}), 4.15(\mathrm{t}, J=6.1 \mathrm{~Hz}, 2 \mathrm{H}), 3.42(\mathrm{~s}, 2 \mathrm{H}), 3.23(\mathrm{t}, J=6.8 \mathrm{~Hz}, 2 \mathrm{H})$, $2.80(\mathrm{t}, J=6.1 \mathrm{~Hz}, 2 \mathrm{H}), 2.52-2.30(\mathrm{~m}, 14 \mathrm{H}), 1.90$ (quint, $J=6.7 \mathrm{~Hz}, 2 \mathrm{H}), 1.68-1.38(\mathrm{~m}$, 18H). $\left.{ }^{13} \mathrm{C} \mathrm{NMR} \mathrm{(75} \mathrm{MHz,} \mathrm{CDCl}_{3}\right): \delta 145.3,143.1,137.1,136.1,130.1,129.5,126.3,122.8$, 113.0, 109.3, 66.4, 60.8, 58.1, 57.4, 54.9, 54.4, 42.6, 26.6, 26.0, 24.3. LCMS $m / z$ calc for $[\mathrm{M}+\mathrm{H}]^{+}:$519.4, found: 519.2 . HR-MS: $\mathrm{m} / \mathrm{z}$ Calculated: 519.4057 , found: $519.4056[\mathrm{M}+\mathrm{H}]^{+}=$ $\mathrm{C}_{33} \mathrm{H}_{51} \mathrm{~N}_{4} \mathrm{O}$.

4-[2-(Morpholin-4-ylmethyl)phenyl]-2-[2-(piperidin-1-yl)ethoxy]- $N$-[3-(piperidin-1yl)propyl]aniline (28)

Colorless oil (126 mg, $0.24 \mathrm{mmol}, 40 \%) .{ }^{1} \mathrm{H}$ NMR (300 MHz, $\left.\mathrm{CDCl}_{3}\right): \delta 7.53-7.48(\mathrm{~m}, 1 \mathrm{H})$; $7.29-7.26(\mathrm{~m}, 3 \mathrm{H}), 6.94-6.89(\mathrm{~m}, 2 \mathrm{H}), 6.64(\mathrm{~d}, J=8.6 \mathrm{~Hz}, 1 \mathrm{H}), 4.80(\mathrm{br} \mathrm{s}, 1 \mathrm{H}), 4.14(\mathrm{t}, J=$ $6.0 \mathrm{~Hz}, 2 \mathrm{H}), 3.68(\mathrm{t}, J=4.4 \mathrm{~Hz}, 4 \mathrm{H}) ; 3.45(\mathrm{~s}, 2 \mathrm{H}) ; 3.23(\mathrm{t}, J=6.8 \mathrm{~Hz}, 2 \mathrm{H}) ; 2.79$ (t, $J=6.0 \mathrm{~Hz}$, $2 \mathrm{H}) ; 2.52-2.38(\mathrm{~m}, 14 \mathrm{H}), 1.90$ (quint, $J=6.8 \mathrm{~Hz}, 2 \mathrm{H}), 1.66-1.56(\mathrm{~m}, 8 \mathrm{H}), 1.50-1.42(\mathrm{~m}$, $4 \mathrm{H}) .{ }^{13} \mathrm{C} \mathrm{NMR}\left(75 \mathrm{MHz}, \mathrm{CDCl}_{3}\right): \delta 145.4,143.3,137.8,135.1,130.3,129.2,126.5,122.8$, $112.9,109.3,67.2,66.3,60.5,58.1,57.5,54.9,53.4,42.6,26.6,26.0,24.3$. LCMS $m / z$ calc for $[\mathrm{M}+\mathrm{H}]^{+}:$521.4, Found: 521.4. HR-MS: m/z Calculated: 521.3850 , found: $521.3852[\mathrm{M}+\mathrm{H}]^{+}=$ $\mathrm{C}_{32} \mathrm{H}_{49} \mathrm{~N}_{4} \mathrm{O}_{2}$.

4-(2-[(4-Methylpiperazin-1-yl)methyl]phenyl)-2-[2-(piperidin-1-yl)ethoxy]- $N$-[3-(piperidin-1yl) propyl]aniline (29)

Colorless oil (213 mg, $0.40 \mathrm{mmol}, 54 \%)$. ${ }^{1} \mathrm{H}$ NMR (300 MHz, $\left.\mathrm{CDCl}_{3}\right): \delta 7.48-7.45(\mathrm{~m}, 1 \mathrm{H})$, $7.27-7.24(\mathrm{~m}, 3 \mathrm{H}), 6.94-6.90(\mathrm{~m}, 2 \mathrm{H}), 6.63(\mathrm{~d}, J=8.0 \mathrm{~Hz}, 1 \mathrm{H}), 4.13(\mathrm{t}, J=6.1 \mathrm{~Hz}, 2 \mathrm{H}), 3.44$ (s, 2H), $3.22(\mathrm{t}, J=6.8 \mathrm{~Hz}, 2 \mathrm{H}), 2.79(\mathrm{t}, J=6.1 \mathrm{~Hz}, 2 \mathrm{H}), 2.50-2.27(\mathrm{~m}, 21 \mathrm{H}), 1.88$ (quint, $J=$ $7.5 \mathrm{~Hz}, 2 \mathrm{H}), 1.66-1.56(\mathrm{~m}, 8 \mathrm{H}), 1.48-1.42(\mathrm{~m}, 4 \mathrm{H}) .{ }^{13} \mathrm{C} \mathrm{NMR}\left(75 \mathrm{MHz}, \mathrm{CDCl}_{3}\right): \delta 145.3$, 143.3, 137.8, 135.5, 130.3, 129.3, 126.4, 122.8, 113.0, 109.2, 66.5, 60.1, 58.1, 57.5, 55.0, 46.1, 42.6, 26.7, 26.0, 24.3). LCMS $\mathrm{m} / z$ calc for $\left[\mathrm{M}+\mathrm{H}^{+}\right]$: 534.2, found: 534.4 . HR-MS: $\mathrm{m} / \mathrm{z}$ Calculated: 534.4166, found: $534.4170\left[\mathrm{M}+\mathrm{H}^{+}\right]=\mathrm{C}_{33} \mathrm{H}_{52} \mathrm{~N}_{5} \mathrm{O}$. 
4-(2-[(Dimethylamino)methyl]phenyl)-2-[2-(piperidin-1-yl)ethoxy]- $N$-[3-(piperidin-1yl)propyl] aniline (30)

In the present case 13 equiv. of dimethylamine $2 \mathrm{M}$ in THF was used. Compound was obtained as a colorless oil (162 mg, $0.34 \mathrm{mmol}, 51 \%) .{ }^{1} \mathrm{H}$ NMR (300 MHz, $\left.\mathrm{CDCl}_{3}\right): \delta 7.51-7.49(\mathrm{~m}$, 1H), $7.30-7.25(\mathrm{~m}, 3 \mathrm{H}), 6.91(\mathrm{~d}, J=1.8 \mathrm{~Hz}, 1 \mathrm{H}), 6.85(\mathrm{dd}, J=8.0 \mathrm{~Hz}, J=1.8 \mathrm{~Hz}, 1 \mathrm{H}), 6.65$ (d, $J=8.0 \mathrm{~Hz}, 1 \mathrm{H}), 4.74$ (br s, 1H), 4.14 (t, $J=6.2 \mathrm{~Hz}, 2 \mathrm{H}), 3.39$ (s, 2H), 3.23 (t, $J=6.7 \mathrm{~Hz}$, 2H), $2.80(\mathrm{t}, J=6.2 \mathrm{~Hz}, 2 \mathrm{H}), 2.54-2.40(\mathrm{~m}, 10 \mathrm{H}), 2.18(\mathrm{~s}, 6 \mathrm{H}), 1.93-1.84(\mathrm{~m}, 2 \mathrm{H}), 1.67-$ $1.57(\mathrm{~m}, 8 \mathrm{H}), 1.50-1.42(\mathrm{~m}, 4 \mathrm{H}) .{ }^{13} \mathrm{C} \mathrm{NMR}\left(75 \mathrm{MHz}, \mathrm{CDCl}_{3}\right): \delta 145.4,142.9,137.7,136.3$, 130.0, 129.4, 126.5, 122.7, 112.9, 109.3, 66.3, 61.1, 58.1, 57.5, 54.9, 45.4, 42.6, 26.6, 26.0, 24.3. LCMS $m / z$ calc for $\left[\mathrm{M}+\mathrm{H}^{+}\right]$: 479.3, Found: 479.3. HR-MS: $\mathrm{m} / \mathrm{z}$ Calculated: 479.3744, found: $479.3741[\mathrm{M}+\mathrm{H}]^{+}=\mathrm{C}_{30} \mathrm{H}_{47} \mathrm{~N}_{4} \mathrm{O}$.

\section{General procedure for the synthesis of compounds 31-36 is exemplified by the protocol} used for the synthesis of 31. To a solution of 3'-(2-cyclohexylethoxy)-4'-((3-(piperidin-1yl)propyl)amino)-[1,1'-biphenyl]-3-carbaldehyde $23(300 \mathrm{mg}, 0.67 \mathrm{mmol})$ and dimethylamine hydrochloride (110 mg, $1.34 \mathrm{mmol})$ in EtOH $(2 \mathrm{~mL})$ was added triethylamine (186 $\mu \mathrm{L}, 1.34$ mmol) and titanium isopropoxide ( $400 \mu \mathrm{L}, 1.34 \mathrm{mmol}$ ). The mixture was stirred for $12 \mathrm{~h}$ at $\mathrm{rt}$. $\mathrm{NaBH}_{4}(51 \mathrm{mg}, 1.34 \mathrm{mmol})$ was then added and the mixture was further stirred for 2 hours. The reaction was quenched by pouring the mixture into aqueous ammonia $(2.5 \mathrm{~mL})$ and extracted with DCM ( 3 x $10 \mathrm{~mL})$. The combined organic layers were dried over $\mathrm{MgSO}_{4}$ and evaporated. The residue was purified by flash chromatography $\left(\mathrm{DCM} / \mathrm{MeOH}\left(\mathrm{NH}_{3}\right), 10: 0\right.$ to $\left.9: 1(\mathrm{v} / \mathrm{v})\right)$ to afford 3-(2-cyclohexylethoxy)-2'-((dimethylamino)methyl)- $N$-(3-(piperidin-1-yl)propyl)-[1,1'biphenyl]-4-amine as a colorless oil (157 mg, $0.33 \mathrm{mmol}, 49 \%) .{ }^{1} \mathrm{H} \mathrm{NMR}\left(300 \mathrm{MHz}, \mathrm{CDCl}_{3}\right)$ : $\delta 7.53-7.49(\mathrm{~m}, 1 \mathrm{H}), 7.33-7.28(\mathrm{~m}, 3 \mathrm{H}), 6.91(\mathrm{~d}, J=1.8 \mathrm{~Hz}, 1 \mathrm{H}), 6.85(\mathrm{dd}, J=8.0 \mathrm{~Hz}, J=$ $1.8 \mathrm{~Hz}, 1 \mathrm{H}), 6.65$ (d, $J=8.0 \mathrm{~Hz}, 1 \mathrm{H}), 4.64(\mathrm{br} \mathrm{s}, 1 \mathrm{H}), 4.05$ (t, $J=6.8 \mathrm{~Hz}, 2 \mathrm{H}), 3.40$ (s, 2H), $3.24(\mathrm{t}, J=6.4 \mathrm{~Hz}, 2 \mathrm{H}), 2.49-2.40(\mathrm{~m}, 6 \mathrm{H}), 2.18(\mathrm{~s}, 6 \mathrm{H}), 1.94-1.85(\mathrm{~m}, 2 \mathrm{H}), 1.80-1.60(\mathrm{~m}$, $11 \mathrm{H}), 1.54-1.42(\mathrm{~m}, 3 \mathrm{H}), 1.33-1.10(\mathrm{~m}, 3 \mathrm{H}), 1.06-0.92(\mathrm{~m}, 2 \mathrm{H}) .{ }^{13} \mathrm{C} \mathrm{NMR}(75 \mathrm{MHz}$, $\left.\mathrm{CDCl}_{3}\right): \delta 145.6,143.0,137.4,136.3,130.2,129.9,129.5,126.6,126.4,122.2,112.2,109.1$, $66.3,61.1,57.6,54.8,45.4,42.7,36.8,34.8,33.4,26.6,26.5,26.2,25.9,24.4$. LCMS $m / z$ calc for $[\mathrm{M}+\mathrm{H}]^{+}:$478.4, Found: 478.3. HR-MS: m/z Calculated: 478.3719, found: 478.3799, $[\mathrm{M}+\mathrm{H}]^{+}=\mathrm{C}_{30} \mathrm{H}_{48} \mathrm{~N}_{3} \mathrm{O}$. 
2'-((Dimethylamino)methyl)-3-(3-(piperidin-1-yl)propoxy)- $N$-(3-(piperidin-1-yl)propyl)-[1,1'biphenyl]-4-amine (32)

Brown oil (75 mg, $0.15 \mathrm{mmol}, 47 \%) .{ }^{1} \mathrm{H}$ NMR (300 MHz, $\left.\mathrm{CDCl}_{3}\right): \delta 7.54-7.47(\mathrm{~m}, 1 \mathrm{H}), 7.35$ $-7.24(\mathrm{~m}, 3 \mathrm{H}), 6.91(\mathrm{~d}, J=1.8 \mathrm{~Hz}, 1 \mathrm{H}), 6.85(\mathrm{dd}, J=8.1,1.8 \mathrm{~Hz}, 1 \mathrm{H}), 6.64(\mathrm{~d}, J=8.1 \mathrm{~Hz}$, $1 \mathrm{H}), 4.58(\mathrm{~s}, 1 \mathrm{H}), 4.05(\mathrm{t}, J=6.5 \mathrm{~Hz}, 2 \mathrm{H}), 3.39(\mathrm{~s}, 2 \mathrm{H}), 3.23(\mathrm{t}, J=6.7 \mathrm{~Hz}, 2 \mathrm{H}), 2.59-2.34$ $(\mathrm{m}, 12 \mathrm{H}), 2.19(\mathrm{~s}, 6 \mathrm{H}), 2.09-1.97(\mathrm{~m}, 2 \mathrm{H}), 1.95-1.82(\mathrm{~m}, 2 \mathrm{H}), 1.69-1.53(\mathrm{~m}, 8 \mathrm{H}), 1.51$ 1.39 (m, 4H). ${ }^{13} \mathrm{C}$ NMR (75 MHz, $\left.\mathrm{CDCl}_{3}\right): \delta 145.5,143.0,137.4,136.4,130.2,129.9,129.6$, 126.6, 126.4, 122.4, 112.4, 109.2, 66.9, 61.1, 57.6, 56.2, 54.8, 54.7, 45.4, 42.6, 27.0, 26.7, 26.0, 24.5. LCMS $m / z$ calc for $[\mathrm{M}+\mathrm{H}]^{+}:$493.4, found: 493.4. HR-MS: $\mathrm{m} / \mathrm{z}$ Calculated: 493.3901, found: $493.3906[\mathrm{M}+\mathrm{H}]^{+}=\mathrm{C}_{31} \mathrm{H}_{49} \mathrm{~N}_{4} \mathrm{O}$.

2'-((Dimethylamino)methyl)-3-(2-(piperidin-1-yl)ethoxy)- $N$-(2-(piperidin-1-yl)ethyl)-[1,1'biphenyl]-4-amine (33)

Brown oil (25 mg, $0.05 \mathrm{mmol}, 30 \%) .{ }^{1} \mathrm{H} \mathrm{NMR}\left(300 \mathrm{MHz}, \mathrm{CDCl}_{3}\right): \delta 7.51$ (dd, $J=4.7,2.3 \mathrm{~Hz}$, $1 \mathrm{H}), 7.33-7.24(\mathrm{~m}, 3 \mathrm{H}), 6.91(\mathrm{~d}, J=1.8 \mathrm{~Hz}, 1 \mathrm{H}), 6.87(\mathrm{dd}, J=8.0,1.8 \mathrm{~Hz}, 1 \mathrm{H}), 6.63(\mathrm{~d}, J=$ $8.0 \mathrm{~Hz}, 1 \mathrm{H}), 4.96(\mathrm{~s}, 1 \mathrm{H}), 4.15(\mathrm{t}, J=5.8 \mathrm{~Hz}, 2 \mathrm{H}), 3.40(\mathrm{~s}, 2 \mathrm{H}), 3.25(\mathrm{t}, J=6.1 \mathrm{~Hz}, 2 \mathrm{H}), 2.84$ (t, $J=5.8 \mathrm{~Hz}, 2 \mathrm{H}), 2.73-2.39(\mathrm{~m}, 10 \mathrm{H}), 2.19(\mathrm{~s}, 6 \mathrm{H}), 1.66-1.56(\mathrm{~m}, 8 \mathrm{H}), 1.46(\mathrm{~d}, J=5.1 \mathrm{~Hz}$, $4 \mathrm{H}) .{ }^{13} \mathrm{C} \mathrm{NMR}\left(75 \mathrm{MHz}, \mathrm{CDCl}_{3}\right): \delta 145.59,142.95,137.63,136.40,130.17,129.91,129.49$, $126.59,126.47,122.65,112.71,109.33,77.45,77.03,76.60,66.41,61.11,58.21,57.65,54.93$, $54.46,45.39,40.37,26.14,26.03,24.50,24.21$. LCMS $\mathrm{m} / \mathrm{z}$ calc for $[\mathrm{M}+\mathrm{H}]^{+}:$: 465.3, found 465.4. HR-MS: m/z Calculated: 493.39010, found: $493.3906[\mathrm{M}+\mathrm{H}]^{+}=\mathrm{C}_{31} \mathrm{H}_{49} \mathrm{~N}_{4} \mathrm{O}$.

2'-((Dimethylamino)methyl)- $N$-(2-(piperidin-1-yl)ethyl)-3-(3-(piperidin-1-yl)propoxy)-[1,1'biphenyl] -4-amine (34)

Brown oil (36 mg, $0.07 \mathrm{mmol}, 30 \%) .{ }^{1} \mathrm{H}$ NMR (300 MHz, $\left.\mathrm{CDCl}_{3}\right): \delta 7.58-7.43(\mathrm{~m}, 1 \mathrm{H}), 7.37$ $-7.24(\mathrm{~m}, 3 \mathrm{H}), 6.92(\mathrm{~d}, J=1.8 \mathrm{~Hz}, 1 \mathrm{H}), 6.86(\mathrm{dd}, J=8.0,1.8 \mathrm{~Hz}, 1 \mathrm{H}), 6.63(\mathrm{~d}, J=8.0 \mathrm{~Hz}$, $1 \mathrm{H}), 4.86(\mathrm{~s}, 1 \mathrm{H}), 4.05(\mathrm{t}, J=6.2 \mathrm{~Hz}, 2 \mathrm{H}), 3.40(\mathrm{~s}, 2 \mathrm{H}), 3.33-3.16(\mathrm{~m}, 2 \mathrm{H}), 2.66(\mathrm{t}, J=6.3$ $\mathrm{Hz}, 2 \mathrm{H}), 2.59-2.32(\mathrm{~m}, 10 \mathrm{H}), 2.19(\mathrm{~s}, 6 \mathrm{H}), 2.10-1.97(\mathrm{~m}, 2 \mathrm{H}), 1.70-1.53(\mathrm{~m}, 8 \mathrm{H}), 1.53-$ $1.40(\mathrm{~m}, 4 \mathrm{H}) .{ }^{13} \mathrm{C}$ NMR (75 MHz, $\left.\mathrm{CDCl}_{3}\right): \delta 145.7,143.0,137.5,136.4,130.2,129.9,129.6$, 126.6, 126.5, 122.4, 112.3, 109.3, 66.8, 61.2, 57.6, 56.3, 54.7, 54.5, 45.4, 40.4, 27.1, 26.2, 26.0, 24.5. LCMS $m / z$ calc for $[\mathrm{M}+\mathrm{H}]^{+}: 479.4$, found: 479.4. HR-MS: $\mathrm{m} / \mathrm{z}$ Calculated: 479.3744 , found: $479.3742[\mathrm{M}+\mathrm{H}]^{+}=\mathrm{C}_{30} \mathrm{H}_{47} \mathrm{~N}_{4} \mathrm{O}$. 
2'-((Dimethylamino)methyl)-3-(4-(piperidin-1-yl)butoxy)- $N$-(2-(piperidin-1-yl)ethyl)-[1,1'biphenyl]-4-amine (35)

Brown oil (35 mg, $0.07 \mathrm{mmol}, 28 \%) .{ }^{1} \mathrm{H}$ NMR (300 MHz, $\left.\mathrm{CDCl}_{3}\right): \delta 7.61-7.41(\mathrm{~m}, 1 \mathrm{H}), 7.40$ $-7.19(\mathrm{~m}, 3 \mathrm{H}), 6.90(\mathrm{~d}, J=1.6 \mathrm{~Hz}, 1 \mathrm{H}), 6.86(\mathrm{dd}, J=8.0,1.6 \mathrm{~Hz}, 1 \mathrm{H}), 6.63(\mathrm{~d}, J=8.0 \mathrm{~Hz}$, $1 \mathrm{H}), 4.86(\mathrm{~s}, 1 \mathrm{H}), 4.16-3.91(\mathrm{~m}, 2 \mathrm{H}), 3.36(\mathrm{~s}, 2 \mathrm{H}), 3.32-3.16(\mathrm{~m}, 2 \mathrm{H}), 2.66(\mathrm{t}, J=6.3 \mathrm{~Hz}$, 2H), 2.39 (dd, $J=19.5,12.2 \mathrm{~Hz}, 10 \mathrm{H}), 2.19$ (s, 6H), $1.96-1.33(\mathrm{~m}, 16 \mathrm{H}) .{ }^{13} \mathrm{C} \mathrm{NMR}(75 \mathrm{MHz}$, $\left.\mathrm{CDCl}_{3}\right): \delta 145.7,143.0,137.5,136.4,130.2,129.9,129.5,126.6,126.4,122.3,112.3,109.3$, 68.0, 61.2, 59.2, 57.6, 54.6, 54.5, 45.4, 40.5, 27.7, 26.2, 26.0, 24.5, 24.5, 23.6. LCMS $m / z$ calc for $[\mathrm{M}+\mathrm{H}]^{+}:$: 493.4, found 493.5. HR-MS: m/z Calculated: 493.3901, found: $493.3906[\mathrm{M}+\mathrm{H}]^{+}$ $=\mathrm{C}_{31} \mathrm{H}_{49} \mathrm{~N}_{4} \mathrm{O}$.

2'-((Dimethylamino)methyl)- $N$-(4-(piperidin-1-yl)butyl)-3-(2-(piperidin-1-yl)ethoxy)-[1,1'biphenyl]-4-amine (36)

Brown oil (75 mg, $0.15 \mathrm{mmol}, 47 \%) .{ }^{1} \mathrm{H}$ NMR (300 MHz, $\left.\mathrm{CDCl}_{3}\right): \delta 7.54-7.47(\mathrm{~m}, 1 \mathrm{H}), 7.35$ $-7.24(\mathrm{~m}, 3 \mathrm{H}), 6.91(\mathrm{~d}, J=1.8 \mathrm{~Hz}, 1 \mathrm{H}), 6.85(\mathrm{dd}, J=8.0,1.8 \mathrm{~Hz}, 1 \mathrm{H}), 6.64(\mathrm{~d}, J=8.0 \mathrm{~Hz}$, $1 \mathrm{H}), 4.58(\mathrm{~s}, 1 \mathrm{H}), 4.05(\mathrm{t}, J=6.5 \mathrm{~Hz}, 2 \mathrm{H}), 3.39(\mathrm{~s}, 2 \mathrm{H}), 3.23(\mathrm{t}, J=6.7 \mathrm{~Hz}, 2 \mathrm{H}), 2.59-2.34$ (m, 12H), 2.19 (s, 6H), $2.09-1.97(\mathrm{~m}, 2 \mathrm{H}), 1.95-1.82(\mathrm{~m}, 2 \mathrm{H}), 1.69-1.53(\mathrm{~m}, 8 \mathrm{H}), 1.51-$ 1.39 (m, 4H). ${ }^{13} \mathrm{C}$ NMR (75 MHz, $\left.\mathrm{CDCl}_{3}\right): \delta 145.5,143.0,137.4,136.4,130.2,129.9,129.6$, 126.6, 126.4, 122.4, 112.4, 109.2, 66.9, 61.1, 57.6, 56.2, 54.8, 54.7, 45.4, 42.6, 27.0, 26.7, 26.0, 24.5. LCMS $m / z$ calc for $[\mathrm{M}+\mathrm{H}]^{+}:$493.4, found: 493.4. HR-MS: $\mathrm{m} / \mathrm{z}$ Calculated: 493.3901, found: $493.3906[\mathrm{M}+\mathrm{H}]^{+}=\mathrm{C}_{31} \mathrm{H}_{49} \mathrm{~N}_{4} \mathrm{O}$.

3-(2-(Piperidin-1-yl)ethoxy)- $N$-(3-(piperidin-1-yl)propyl)-[1,1'-biphenyl]-4-amine (37)

To a solution of benzeneboronic acid $(108 \mathrm{mg}, 0.88 \mathrm{mmol})$ in a mixture of toluene $(8 \mathrm{~mL})$ and EtOH (3 mL), $\mathrm{K}_{2} \mathrm{CO}_{3}(132 \mathrm{mg}, 0.96 \mathrm{mmol})$ and 11 (156 mg, $\left.0.37 \mathrm{mmol}\right)$ were added. The reaction was stirred for $30 \mathrm{~min}$ and deoxygenated by passing a stream of $\mathrm{N}_{2}$ through it. $\mathrm{Pd}_{2} \mathrm{dba}_{3}$ $(6.73 \mathrm{mg}, 0.007 \mathrm{mmol})$ and $\mathrm{P}(\mathrm{o}-\mathrm{tol})_{3}(22 \mathrm{mg}, 0.073 \mathrm{mmol})$ were added and the mixture was refluxed overnight. After cooling, the mixture was poured into $1 \mathrm{~N} \mathrm{NaOH}$ and extracted three times with dichloromethane. The combined organic layers were dried over $\mathrm{MgSO}_{4}$ and evaporated. The residue was purified by flash chromatography (DCM/MeOH$\left(\mathrm{NH}_{3}\right), 10: 0$ to 95:5 (v/v)) to afford a brown oil (110 mg, $0.26 \mathrm{mmol}, 71 \%) .{ }^{1} \mathrm{H}$ NMR (300 $\left.\mathrm{MHz}, \mathrm{CD}_{2} \mathrm{Cl}_{2}\right): \delta$ $7.61-7.53(\mathrm{~m}, 2 \mathrm{H}), 7.44-7.36(\mathrm{~m}, 2 \mathrm{H}), 7.30-7.22(\mathrm{~m}, 1 \mathrm{H}), 7.15(\mathrm{dd}, J=8.2,2.0 \mathrm{~Hz}, 1 \mathrm{H})$, $7.09(\mathrm{~d}, J=2.0 \mathrm{~Hz}, 1 \mathrm{H}), 6.68(\mathrm{~d}, J=8.2 \mathrm{~Hz}, 1 \mathrm{H}), 4.94(\mathrm{~s}, 1 \mathrm{H}), 4.18(\mathrm{t}, J=6.0 \mathrm{~Hz}, 2 \mathrm{H}), 3.24$ (t, $J=6.7 \mathrm{~Hz}, 2 \mathrm{H}), 2.78(\mathrm{t}, J=6.0 \mathrm{~Hz}, 2 \mathrm{H}), 2.60-2.31(\mathrm{~m}, 10 \mathrm{H}), 1.91-1.75(\mathrm{~m}, 2 \mathrm{H}), 1.70-1.55$ 
(m, 8H), $1.55-1.38(\mathrm{~m}, 4 \mathrm{H}) .{ }^{13} \mathrm{C} \mathrm{NMR}\left(75 \mathrm{MHz}, \mathrm{CD}_{2} \mathrm{Cl}_{2}\right): \delta 148.3,143.4,140.7,130.5,128.0$, $127.8,122.0,112.2$, 111.6, 68.6, 60.0, 59.1, 56.9, 56.6, 44.2, 28.2, 28, 27.8, 26.3, 26.2. LCMS $\mathrm{m} / \mathrm{z}$ calc 422.3 for $[\mathrm{M}+\mathrm{H}]^{+}: 422.3$, found:. HR-MS: $\mathrm{m} / \mathrm{z}$ Calculated: 422.3093 , found: 422.3156 $[\mathrm{M}+\mathrm{H}]^{+}=\mathrm{C}_{27} \mathrm{H}_{40} \mathrm{~N}_{3} \mathrm{O}$.

\section{1-(2-(3-Bromophenoxy)ethyl)piperidine (38)}

3-Bromophenol (1.63 g, $9.42 \mathrm{mmol}$ ) was suspended in $\mathrm{ACN}(50 \mathrm{~mL})$ and $\mathrm{K}_{2} \mathrm{CO}_{3}(3.91 \mathrm{~g}, 28.3$ mmol) was added. The reaction mixture was stirred at $80{ }^{\circ} \mathrm{C}$ for $30 \mathrm{~min}$. Then 1-(2Chloroethyl)piperidine hydrochloride ( $2.43 \mathrm{~g}, 13.2 \mathrm{mmol})$ was added. The reaction mixture was stirred at $80{ }^{\circ} \mathrm{C}$ for $12 \mathrm{~h}$. The inorganics were removed by filtration and the solvent was evaporated. The residue was dissolved in DCM $(50 \mathrm{~mL})$ and washed twice with a $1 \mathrm{~N} \mathrm{NaOH}$ solution. The organic layers were combined and dried over $\mathrm{MgSO}_{4}$, filtrated and concentrated in vacuo to afford $38(2.45 \mathrm{~g}, 8.57 \mathrm{mmol}, 91 \%)$. The product was used without further purification in the next step. ${ }^{1} \mathrm{H}$ NMR $\left(300 \mathrm{MHz}, \mathrm{CDCl}_{3}\right): \delta 7.14(\mathrm{~d}, J=8.1 \mathrm{~Hz}, 1 \mathrm{H}), 7.08-$ 7.04 (m, 2H), $6.83(\mathrm{ddd}, J=8.1,2.5,1.4 \mathrm{~Hz}, 1 \mathrm{H}), 4.08(\mathrm{t}, J=6.1 \mathrm{~Hz}, 2 \mathrm{H}), 2.75$ (t, $J=6.1,2 \mathrm{H})$, $1.65-1.53(\mathrm{~m}, 6 \mathrm{H}), 1.49-1.39(\mathrm{~m}, 2 \mathrm{H})$. LCMS $\mathrm{m} / z$ calc for $[\mathrm{M}+\mathrm{H}]^{+}: 286.1,288.1$ found: $286.0,288.0$

$N$-(2-(piperidin-1-yl)ethyl)-[1,1'-biphenyl]-4-amine (39)

3-Phenylphenol (1.02 g, $6.02 \mathrm{mmol}$ ) was suspended in ACN (50 mL) and $\mathrm{K}_{2} \mathrm{CO}_{3}(2.49 \mathrm{~g}, 18.0$ mmol) was added. The reaction mixture was stirred at $80{ }^{\circ} \mathrm{C}$ for $30 \mathrm{~min}$. Then 1-(2Chloroethyl)piperidine hydrochloride $(1.55 \mathrm{~g}, 8.42 \mathrm{mmol})$ was added. The reaction mixture was stirred at $80{ }^{\circ} \mathrm{C}$ for $12 \mathrm{~h}$. The inorganics were removed by filtration and the solvent was evaporated. The residue was dissolved in DCM $(50 \mathrm{~mL})$ and washed twice with a $1 \mathrm{~N} \mathrm{NaOH}$ solution. The organic layers were combined and dried over $\mathrm{MgSO}_{4}$, filtrated and concentrated. The residue was purified by flash chromatography (Cyclohexane/AcOEt), 10:0 to 5:5 (v/v)) to afford a yellow oil (690 mg, $2.45 \mathrm{mmol}, 41 \%)$. ${ }^{1} \mathrm{H} \mathrm{NMR}\left(300 \mathrm{MHz}, \mathrm{CDCl}_{3}\right): \delta 7.64-7.56$ (m, 2H), $7.44(\mathrm{t}, J=7.6 \mathrm{~Hz}, 2 \mathrm{H}), 7.35(\mathrm{t}, J=7.6 \mathrm{~Hz}, 2 \mathrm{H}), 7.22-7.14(\mathrm{~m}, 2 \mathrm{H}), 6.91$ (ddd, $J=8.2$, $2.5,0.8 \mathrm{~Hz}, 1 \mathrm{H}), 4.18(\mathrm{t}, J=6.1 \mathrm{~Hz}, 2 \mathrm{H}), 2.82(\mathrm{t}, J=6.1 \mathrm{~Hz}, 2 \mathrm{H}), 2.61-2.46(\mathrm{~m}, 4 \mathrm{H}), 1.72-$ $1.57(\mathrm{~m}, 4 \mathrm{H}), 1.53-1.41(\mathrm{~m}, 2 \mathrm{H}) .{ }^{13} \mathrm{C} \mathrm{NMR}\left(75 \mathrm{MHz}, \mathrm{CD}_{2} \mathrm{Cl}_{2}\right): \delta 159.2,142.7,141.1,129.7$, $128.7,127.4,127.2,119.7,113.7,113.3,66.0,58.0,55.1,26,24.2$. LCMS $m / z$ calc for $[\mathrm{M}+\mathrm{H}]^{+}$: 282.2 found: 282.1. HR-MS: m/z Calculated: 282.1939, found: $282.1846[\mathrm{M}+\mathrm{H}]^{+}=\mathrm{C}_{19} \mathrm{H}_{24} \mathrm{NO}$. 
3'-(2-(Piperidin-1-yl)ethoxy)-[1,1'-biphenyl]-2-carbaldehyde (40)

To a solution of 2-formylbenzeneboronic acid ( $893 \mathrm{mg}, 5.95 \mathrm{mmol})$ in a mixture of toluene $(113 \mathrm{~mL})$ and $\mathrm{EtOH}(45 \mathrm{~mL}), \mathrm{K}_{2} \mathrm{CO}_{3}(891 \mathrm{mg}, 6.45 \mathrm{mmol})$ and 38 (1.4 g, $\left.4.96 \mathrm{mmol}\right)$ were added. The reaction was stirred for $30 \mathrm{~min}$ and deoxygenated by passing a stream of $\mathrm{N}_{2}$ through it. $\mathrm{Pd}_{2} \mathrm{dba}_{3}(91 \mathrm{mg}, 0.02 \mathrm{mmol})$ and $\mathrm{P}(o \text {-tol })_{3}(302 \mathrm{mg}, 0.99 \mathrm{mmol})$ were added and the mixture was refluxed for $2 \mathrm{~h}$. After cooling, the mixture was poured into $1 \mathrm{~N} \mathrm{NaOH}$ and extracted three times with dichloromethane. The combined organic layers were dried over $\mathrm{MgSO}_{4}$ and evaporated to afford an orange oil which was used without further purification $(1.27 \mathrm{~g}, 4.11$ mmol, $83 \%$ ). ${ }^{1} \mathrm{H}$ NMR (300 MHz, $\left.\mathrm{CDCl}_{3}\right): \delta 10.00$ (d, $\left.J=0.8 \mathrm{~Hz}, 1 \mathrm{H}\right), 8.04$ (d, $J=7.5 \mathrm{~Hz}$, 1H), $7.63(\mathrm{~d}, J=7.5 \mathrm{~Hz}, 1 \mathrm{H}), 7.50-7.34(\mathrm{~m}, 3 \mathrm{H}), 6.99-6.93(\mathrm{~m}, 3 \mathrm{H}), 4.17$ (t, $J=5.9 \mathrm{~Hz}$, $2 \mathrm{H}), 2.83(\mathrm{t}, J=5.9 \mathrm{~Hz}, 2 \mathrm{H}), 2.56(\mathrm{~m}, 4 \mathrm{H}), 1.65-1.60(\mathrm{~m}, 4 \mathrm{H}), 1.50-1.44(\mathrm{~m}, 2 \mathrm{H})$. LCMS $\mathrm{m} / \mathrm{z}$ calc for $[\mathrm{M}+\mathrm{H}]^{+}: 310.1$, found: 310.12 .

$N, N$-Dimethyl-1-(3'-(2-(piperidin-1-yl)ethoxy)-[1,1'-biphenyl]-2-yl)methanamine (41) To a solution of $40(925 \mathrm{mg}, 2.99 \mathrm{mmol})$ in DCE $(37 \mathrm{~mL})$, dimethylamine $2.0 \mathrm{M}$ in THF (15 $\mathrm{mL}, 29.9 \mathrm{mmol}), \mathrm{NaBH}(\mathrm{OAc})_{3}(950 \mathrm{mg}, 4.48 \mathrm{mmol})$ and acetic acid $(0.26 \mathrm{~mL}, 4.48 \mathrm{mmol})$ were added and the mixture was stirred at $\mathrm{rt}$ for $12 \mathrm{~h}$. The reaction was quenched by pouring the mixture into saturated $\mathrm{NaHCO}_{3}$ solution $(25 \mathrm{~mL})$ and extracted with $\mathrm{DCM}(3 \times 50 \mathrm{~mL})$. The combined organic layers were dried over $\mathrm{MgSO}_{4}$ and evaporated. The residue was purified by flash chromatography (DCM/MeOH$\left(\mathrm{NH}_{3}\right), 10: 0$ to 97:3 (v/v)) to afford a brown oil (266 mg, $0.79 \mathrm{mmol}, 26 \%) .{ }^{1} \mathrm{H}$ NMR (300 MHz, MeOD): $\delta 7.51(\mathrm{dd}, J=7.4,1.6 \mathrm{~Hz}, 1 \mathrm{H}), 7.39-7.27$ $(\mathrm{m}, 3 \mathrm{H}), 7.25-7.19(\mathrm{~m}, 1 \mathrm{H}), 6.95(\mathrm{~m}, 1 \mathrm{H}), 6.92-6.84(\mathrm{~m}, 2 \mathrm{H}), 4.17(\mathrm{t}, J=5.7 \mathrm{~Hz}, 2 \mathrm{H}), 3.45$ (s, 2H), $2.80(\mathrm{t}, J=5.7 \mathrm{~Hz}, 2 \mathrm{H}), 2.57(\mathrm{~d}, J=5.2 \mathrm{~Hz}, 4 \mathrm{H}), 2.10(\mathrm{~s}, 6 \mathrm{H}), 1.64(\mathrm{~m}, 4 \mathrm{H}), 1.50$ (m, 2H). ${ }^{13} \mathrm{C} \mathrm{NMR}\left(75 \mathrm{MHz}, \mathrm{CDCl}_{3}\right): \delta 158.4,142.9,142.2,136.3,129.8,128.8,127.3,126.6$, $122.1,122.1,115.9,113.1,66,30.9,58,55.1,45.4,26,24.2$. LCMS $m / z$ calc for $[\mathrm{M}+\mathrm{H}]^{+}: 339.2$, found: 339.2. HR-MS: m/z Calculated: 339.2358, found: $339.2422[\mathrm{M}+\mathrm{H}]^{+}=\mathrm{C}_{22} \mathrm{H}_{31} \mathrm{~N}_{2} \mathrm{O}$.

\section{4-Bromo- $N$-(2-(piperidin-1-yl)ethyl)aniline (42)}

To solution of 4-bromoaniline (1.34 mL, $12 \mathrm{mmol})$ in DMF (50 mL), $\mathrm{K}_{2} \mathrm{CO}_{3}(3.2 \mathrm{~g}, 23 \mathrm{mmol})$, $\mathrm{NaI}(8.7 \mathrm{~g}, 58 \mathrm{mmol})$ and 3-chloropropylpiperidine hydrochloride (3.4 g, $18 \mathrm{mmol}$ ) were added. The reaction mixture was stirred at $100{ }^{\circ} \mathrm{C}$ for $24 \mathrm{~h}$. DMF was removed under reduced pressure and the residue was taken up in $20 \mathrm{~mL}$ of water. The aqueous layer was extracted with DCM (3 x $60 \mathrm{~mL}$ ). The combined organic layers were dried over $\mathrm{MgSO}_{4}$ and evaporated. The residue was purified by column chromatography (EtOAc/MeOH, 8.5:1.5 (v:v)) to afford a brown oil 
(779 mg, $2.76 \mathrm{mmol}, 23 \%) .{ }^{1} \mathrm{H}$ NMR (300 MHz, $\left.\mathrm{CDCl}_{3}\right): \delta 7.23$ (d, $\left.J=8.8 \mathrm{~Hz}, 2 \mathrm{H}\right), 6.47$ (d, $J=8.8 \mathrm{~Hz}, 1 \mathrm{H}), 3.15(\mathrm{t}, J=6.2 \mathrm{~Hz}, 2 \mathrm{H}), 2.67-2.41(\mathrm{~m}, 6 \mathrm{H}), 1.97-1.76(\mathrm{~m}, 2 \mathrm{H}), 1.77-1.44$ (m, 6H). ${ }^{13} \mathrm{C} \mathrm{NMR}\left(75 \mathrm{MHz}, \mathrm{CDCl}_{3}\right): \delta 147.7,131.9,114.1,108.4,57.7,54.5,43.4,29.7,25.5$, 24. LCMS $m / z$ calc for $[\mathrm{M}+\mathrm{H}]^{+}: 283.1,285.1$ found: $283.1,285.1$

4'-((3-(piperidin-1-yl)propyl)amino)-[1,1'-biphenyl]-2-carbaldehyde (43)

To a solution of 2-formylbenzeneboronic acid (791 $\mathrm{mg}, 5.27 \mathrm{mmol}$ ) in a mixture of toluene (35 $\mathrm{mL})$ and $\mathrm{EtOH}(17 \mathrm{~mL}), \mathrm{K}_{2} \mathrm{CO}_{3}(724 \mathrm{mg}, 5.24 \mathrm{mmol})$ and $42(779 \mathrm{mg}, 2.62 \mathrm{mmol}$ ) were added. The reaction was stirred for $30 \mathrm{~min}$ and deoxygenated by passing a stream of $\mathrm{N}_{2}$ through it. $\mathrm{Pd}_{2} \mathrm{dba}_{3}(133 \mathrm{mg}, 0.055 \mathrm{mmol})$ and $\mathrm{P}(o \text {-tol })_{3}(395 \mathrm{mg}, 0.48 \mathrm{mmol})$ were added and the mixture was refluxed for $96 \mathrm{~h}$. After cooling, the mixture was poured into water and extracted with dichloromethane. The combined organic layers were dried over $\mathrm{MgSO}_{4}$ and evaporated. The residue was purified by semi-preparative chromatography (eluent $\mathrm{H}_{2} \mathrm{O}$ formic, $\mathrm{ACN}$ formic, $100: 0$ to $70: 30(\mathrm{v} / \mathrm{v}))$ to afford orange oil (341 mg, $1.05 \mathrm{mmol}, 40 \%) .{ }^{1} \mathrm{H}$ NMR (300 MHz, $\left.\mathrm{CDCl}_{3}\right): \delta 10.02(\mathrm{~d}, J=0.7 \mathrm{~Hz}, 1 \mathrm{H}), 8.57(\mathrm{~s}, 1 \mathrm{H}), 7.98(\mathrm{dd}, J=7.7,1.0 \mathrm{~Hz}, 1 \mathrm{H}), 7.64-7.55$ $(\mathrm{m}, 1 \mathrm{H}), 7.47-7.35(\mathrm{~m}, 2 \mathrm{H}), 7.22-7.14(\mathrm{~m}, 2 \mathrm{H}), 6.71(\mathrm{~d}, J=8.6 \mathrm{~Hz}, 2 \mathrm{H}), 3.34-3.23(\mathrm{~m}$, 2H), $3.11-2.99(\mathrm{~m}, 6 \mathrm{H}), 2.13(\mathrm{dd}, J=13.9,6.5 \mathrm{~Hz}, 2 \mathrm{H}), 1.97-1.84(\mathrm{~m}, 4 \mathrm{H}), 1.72-1.53(\mathrm{~m}$, 2H). ${ }^{13} \mathrm{C} \mathrm{NMR}\left(75 \mathrm{MHz}, \mathrm{CDCl}_{3}\right): \delta 193.2,168.3,148.2,146.4,133.6,133.4,131.3,130.6$, $127.5,126.7,126,112.3,55.1,53.1,40.9,23.8,23.1,22.6$. LCMS $m / z$ calc for $[\mathrm{M}+\mathrm{H}]^{+}: 323.2$, found 323.2 .

2'-((Dimethylamino)methyl)- $N$-(3-(piperidin-1-yl)propyl)-[1,1'-biphenyl]-4-amine (44)

To a solution of 43 (156 mg, $0.42 \mathrm{mmol}$ ) and dimethylamine hydrochloride (69 mg, $0.85 \mathrm{mmol}$ ) in EtOH $(1 \mathrm{~mL})$ was added triethylamine $(0.12 \mathrm{~mL}, 0.85 \mathrm{mmol})$ and titanium isopropoxide $(0.25 \mathrm{~mL}, 0.85 \mathrm{mmol})$. The mixture was stirred at $\mathrm{rt}$ for $12 \mathrm{~h} . \mathrm{NaBH}_{4}(32 \mathrm{mg}, 0.85 \mathrm{mmol})$ was added and the resulting mixture was further stirred for $2 \mathrm{~h}$. The reaction was quenched by pouring the mixture into aqueous ammonia $(2.5 \mathrm{~mL})$ and extracted with DCM $(3 \times 10 \mathrm{~mL})$. The combined organic layers were dried over $\mathrm{MgSO}_{4}$ and evaporated. The residue was purified by flash chromatography (DCM/MeOH$\left(\mathrm{NH}_{3}\right), 10: 0$ to 98:2 (v/v)) to afford brown oil (119 mg, $0.34 \mathrm{mmol}, 40 \%) .{ }^{1} \mathrm{H}$ NMR (300 MHz, $\left.\mathrm{CDCl}_{3}\right): \delta 7.60-7.45(\mathrm{~m}, 1 \mathrm{H}), 7.37-7.23(\mathrm{~m}, 3 \mathrm{H})$, $7.20(\mathrm{~d}, J=8.6 \mathrm{~Hz}, 2 \mathrm{H}), 6.65(\mathrm{~d}, J=8.6 \mathrm{~Hz}, 2 \mathrm{H}), 5.08(\mathrm{~s}, 1 \mathrm{H}), 3.41(\mathrm{~s}, 2 \mathrm{H}), 3.24(\mathrm{t}, J=6.3 \mathrm{~Hz}$, 2H), $2.47(\mathrm{dd}, J=14.0,7.5 \mathrm{~Hz}, 6 \mathrm{H}), 2.18(\mathrm{~s}, 6 \mathrm{H}), 1.96-1.74(\mathrm{~m}, 2 \mathrm{H}), 1.74-1.57(\mathrm{~m}, 4 \mathrm{H})$, $1.49(\mathrm{~d}, J=5.1 \mathrm{~Hz}, 2 \mathrm{H}) .{ }^{13} \mathrm{C} \mathrm{NMR}\left(75 \mathrm{MHz}, \mathrm{CDCl}_{3}\right): \delta 147.8,142.7,136.5,130.5,130.1,130$, 129.7, 126.6, 126.5, 112.0, 61.0, 58.3, 54.7, 45.4, 43.9, 26.2, 25.8, 24.5. LCMS $\mathrm{m} / \mathrm{z}$ calc for 
$[\mathrm{M}+\mathrm{H}]^{+}:$352.3, found 352.3. HR-MS: m/z Calculated: 352.2747, found: $352.2743[\mathrm{M}+\mathrm{H}]^{+}=$ $\mathrm{C}_{23} \mathrm{H}_{34} \mathrm{~N}_{3}$.

6-Nitro-3H-1,3-benzoxazol-2-one (45)

$70 \%$ Nitric acid $(50 \mathrm{~mL}, 0.80 \mathrm{~mol})$ was cooled to $0{ }^{\circ} \mathrm{C}$ and $3 H$-1,3-benzoxazol-2-one $(5.00 \mathrm{~g}$, $37 \mathrm{mmol}$ ) was added. The reaction mixture was stirred at $\mathrm{rt}$ for $4 \mathrm{~h}$ and then poured in ice. The resulting precipitate was collected by filtration, washed with water and dried to give a pink solid (5.80 g, $32.5 \mathrm{mmol}, 87 \%) . \mathrm{Mp}>250{ }^{\circ} \mathrm{C} .{ }^{1} \mathrm{H}$ NMR (300 MHz, DMSO- $\left.d_{6}\right): \delta 12.41(\mathrm{~s}, 1 \mathrm{H}), 8.20$ $(\mathrm{d}, J=2.2 \mathrm{~Hz}, 1 \mathrm{H}), 8.13(\mathrm{dd}, J=8.6 \mathrm{~Hz}, J=2.2 \mathrm{~Hz}, 1 \mathrm{H}), 7.28(\mathrm{~d}, J=8.6 \mathrm{~Hz}, 1 \mathrm{H}) .{ }^{13} \mathrm{C} \mathrm{NMR}$ (300 MHz, DMSO- $\left.d_{6}\right): \delta 154.7,143.2,142.5,137.2,121.2,109.8,105.8$. LCMS m/z calc for $[\mathrm{M}-\mathrm{H}]^{+}:$179.0, found: 179.0 .

6-Nitro-3-[3-(piperidin-1-yl)propyl]-1,3-benzoxazol-2-one (46)

6-Nitro-3H-1,3-benzoxazol-2-one (45) (6.30 g, $35 \mathrm{mmol})$ was suspended in ACN (150 mL) and $\mathrm{K}_{2} \mathrm{CO}_{3}(6.91 \mathrm{~g}, 50 \mathrm{mmol})$ was added. The reaction mixture was stirred at $80{ }^{\circ} \mathrm{C}$ for $30 \mathrm{~min}$. 3Chloropropylpiperidine hydrochloride (3.96 g, $20 \mathrm{mmol}$ ) was added and the reaction mixture was stirred at $80^{\circ} \mathrm{C}$ for another $5 \mathrm{~h}$. The inorganics were removed by filtration and the solvent was evaporated. The residue was purified by flash chromatography (DCM/MeOH$\left(\mathrm{NH}_{3}\right)$, 9.8:0.2 $(v / v)$ ) to give compound 46 as a beige solid (5.98 g, $19.6 \mathrm{mmol}, 98 \%)$. Mp $81.1-81.7$ ${ }^{\circ} \mathrm{C} .{ }^{1} \mathrm{H}$ NMR $\left(300 \mathrm{MHz}, \mathrm{CDCl}_{3}\right): \delta 8.21(\mathrm{dd}, J=8.7 \mathrm{~Hz}, J=2.1 \mathrm{~Hz}, 1 \mathrm{H}), 8.10(\mathrm{~d}, J=2.1 \mathrm{~Hz}$, $1 \mathrm{H}), 7.25(\mathrm{~d}, J=8.7 \mathrm{~Hz}, 1 \mathrm{H}), 4.00(\mathrm{t}, J=6.5 \mathrm{~Hz}, 2 \mathrm{H}), 2.38-2.28(\mathrm{~m}, 6 \mathrm{H}), 2.02-1.98(\mathrm{~m}, 2 \mathrm{H})$, $1.56-1.53(\mathrm{~m}, 4 \mathrm{H}), 1.45-1.41(\mathrm{~m}, 2 \mathrm{H}) .{ }^{13} \mathrm{C} \mathrm{NMR}\left(75 \mathrm{MHz}, \mathrm{CDCl}_{3}\right): \delta 154.1,143.0,141.9$, $137.3,120.7,108.0,106.1,55.4,54.4,41.1,25.9,24.4,24.3$. LCMS $m / z$ calc for $[\mathrm{M}+\mathrm{H}]^{+}: 306.2$, found: 306.2 .

5-Nitro-2-([3-(piperidin-1-yl)propyl]amino)phenol (47)

To a solution of 6-nitro-3-[3-(piperidin-1-yl)propyl]-1,3-benzoxazol-2-one (46) (1.0 g, $3.28 \mathrm{mmol})$ in dioxane $(5 \mathrm{~mL})$, aqueous $2.5 \mathrm{~N} \mathrm{NaOH}(26 \mathrm{~mL}, 65.5 \mathrm{mmol})$ was added. The mixture was stirred at $20{ }^{\circ} \mathrm{C}$ for $48 \mathrm{~h}$. After cooling to $0{ }^{\circ} \mathrm{C}$, a $1 \mathrm{~N} \mathrm{HCl}$ solution was added to reach $\mathrm{pH}$ 8. After $30 \mathrm{~min}$ of stirring, the mixture was extracted with EtOAc (3 x $100 \mathrm{~mL})$. The combined organic layers were dried over $\mathrm{MgSO}_{4}$ and evaporated. The residue was purified by flash chromatography (DCM/MeOH$\left(\mathrm{NH}_{3}\right)$, 9.5:0.5 $\left.(v / v)\right)$ to give compound 47 as an orange solid (715 mg, $2.56 \mathrm{mmol}, 78 \%$ ). $\mathrm{Mp}: 152.3-153.0^{\circ} \mathrm{C} .{ }^{1} \mathrm{H} \mathrm{NMR}\left(300 \mathrm{MHz}, \mathrm{CDCl}_{3}\right): \delta 7.69$ $(\mathrm{dd}, J=8.7 \mathrm{~Hz}, J=2.4 \mathrm{~Hz}, 1 \mathrm{H}), 7.49(\mathrm{~d}, J=2.4 \mathrm{~Hz}, 1 \mathrm{H}), 6.32(\mathrm{~d}, J=8.8 \mathrm{~Hz}, 1 \mathrm{H}), 3.23(\mathrm{t}, J=$ 
$6.5 \mathrm{~Hz}, 2 \mathrm{H}) ; 2.67-2.57(\mathrm{~m}, 6 \mathrm{H}), 1.95-1.91(\mathrm{~m}, 2 \mathrm{H}), 1.71-1.67(\mathrm{~m}, 4 \mathrm{H}), 1.53-1.48(\mathrm{~m}$, 2H). ${ }^{13} \mathrm{C} \mathrm{NMR}\left(75 \mathrm{MHz}, \mathrm{CDCl}_{3}\right): \delta 145.4,144.3,136.7,118.5,108.8,106.4,56.3,54.1,41.2$, 25.1, 24.5, 23.5. LCMS $m / z$ calc for $[\mathrm{M}+\mathrm{H}]^{+}:$:280.2, found: 280.1 .

4-Nitro-2-[2-(piperidin-1-yl)ethoxy]- $N$-[3-(piperidin-1-yl)propyl]aniline (48)

5-Nitro-2-([3-(piperidin-1-yl)propyl]amino)phenol (47) (200 mg, $0.72 \mathrm{mmol})$ was suspended in $\mathrm{ACN}(6 \mathrm{~mL})$ and $\mathrm{K}_{2} \mathrm{CO}_{3}(300 \mathrm{mg}, 2.15 \mathrm{mmol})$ was added. The reaction mixture was stirred at $\mathrm{rt}$ for $10 \mathrm{~min}$. 1-(2-Chloroethyl)piperidine hydrochloride $(160 \mathrm{mg}, 0.86 \mathrm{mmol})$ was then added and the reaction mixture was stirred at $60{ }^{\circ} \mathrm{C}$ for another $5 \mathrm{~h}$. The inorganics were removed by filtration and the solvent was evaporated. The residue was purified by flash chromatography $\left(\mathrm{DCM} / \mathrm{MeOH}\left(\mathrm{NH}_{3}\right), 9.8: 0.2(v / v)\right)$ to give a brown oil $(200 \mathrm{mg}, 0.52 \mathrm{mmol}$, 72\%). ${ }^{1} \mathrm{H}$ NMR $\left(300 \mathrm{MHz}, \mathrm{CDCl}_{3}\right): \delta 7.86(\mathrm{dd}, J=8.9 \mathrm{~Hz}, J=2.4 \mathrm{~Hz}, 1 \mathrm{H}), 7.62(\mathrm{~d}, J=2.4$ $\mathrm{Hz}, 1 \mathrm{H}), 6.46$ (d, $J=8.9 \mathrm{~Hz}, 1 \mathrm{H}), 6.19$ (br t, $J=4.9 \mathrm{~Hz}, 1 \mathrm{H}), 4.17$ (t, $J=6.1 \mathrm{~Hz}, 2 \mathrm{H}), 3.28$ (m, 2H), $2.77(\mathrm{t}, J=5.8 \mathrm{~Hz}, 2 \mathrm{H}), 2.48(\mathrm{~m}, 4 \mathrm{H}), 2.45-2.33(\mathrm{~m}, 6 \mathrm{H}), 1.85-1.82(\mathrm{~m}, 2 \mathrm{H}), 1.65-$ $1.54(\mathrm{~m}, 8 \mathrm{H}), 1.49-1.39(\mathrm{~m}, 4 \mathrm{H}) .{ }^{13} \mathrm{C}$ NMR (75 MHz, $\left.\mathrm{CDCl}_{3}\right): \delta 145.1,144.3,136.3,120.3$, $106.48,106.3,66.4,57.6,57.2,54.8,54.5,42.0,25.8,25.7,24.2$. LCMS $m / z$ calc for $[\mathrm{M}+\mathrm{H}]^{+}$: 391.3, found: 391.1 .

2-[2-(Piperidin-1-yl)ethoxy]- $N$-[3-(piperidin-1-yl)propyl]benzene-1,4-diamine (49) 4-Nitro-2-[2-(piperidin-1-yl)ethoxy]- $N$-[3-(piperidin-1-yl)propyl]aniline (48) (100 mg, 0.255 mmol) was dissolved in $\mathrm{MeOH}(5 \mathrm{~mL}) . \mathrm{Pd} / \mathrm{C} 10 \%(20 \mathrm{mg}, 7 \mathrm{~mol} \%)$ was added and the reaction mixture was stirred at $40{ }^{\circ} \mathrm{C}$ for $30 \mathrm{~min}$. The catalyst was filtered through a celite pad and the filtrate was evaporated to give $\mathbf{4 9}$ as a purple oil which was used in the next step without further purification. ${ }^{1} \mathrm{H}$ NMR $\left(300 \mathrm{MHz}, \mathrm{CDCl}_{3}\right): \delta 6.43(\mathrm{~d}, J=8.2 \mathrm{~Hz}, 1 \mathrm{H}), 6.30-6.20(\mathrm{~m}, 2 \mathrm{H}), 4.03$ (t, $J=6.3 \mathrm{~Hz}, 2 \mathrm{H}), 3.63(\mathrm{br} \mathrm{s}, 3 \mathrm{H}), 3.06$ (t, $J=7.1 \mathrm{~Hz}), 2.74(\mathrm{t}, J=6.3 \mathrm{~Hz}, 2 \mathrm{H}), 2.47-2.44$ (m, $4 \mathrm{H}), 2.42-2.31(\mathrm{~m}, 6 \mathrm{H}), 1.78-1.73(\mathrm{~m}, 2 \mathrm{H}), 1.62-1.52(\mathrm{~m}, 8 \mathrm{H}), 1.47-1.35(\mathrm{~m}, 4 \mathrm{H}) .{ }^{13} \mathrm{C}$ NMR (75 MHz, $\left.\mathrm{CDCl}_{3}\right): \delta 147.2,137.3,131.8,111.8,108.0,111.4,66.3,58.0,57.5,55.0,54.7$, 43.5, 26.7, 26.0, 24.3. LCMS $m / z$ calc for $[\mathrm{M}+\mathrm{H}]^{+}: 361.3$, found: 361.1 .

1-(3-[2-(Piperidin-1-yl)ethoxy]-4-([3-(piperidin-1-yl)propyl]amino)phenyl)-1H-pyrrole-3carbaldehyde (50)

2-[2-(Piperidin-1-yl)ethoxy]- $N$-[3-(piperidin-1-yl)propyl]benzene-1,4-diamine

(49) was dissolved in acetic acid (5 mL). 2,5-Dimethoxy-3-formyl-2,3,4,5-tetrahydrofuran (380 $\mu \mathrm{L}, 2.71$ mmol) was added and the reaction mixture was heated at $90{ }^{\circ} \mathrm{C}$ for $2 \mathrm{~h}$. The solvent was then 
evaporated and the residue taken up in saturated $\mathrm{NaHCO}_{3}$ solution $(50 \mathrm{~mL})$. The aqueous layer was extracted with EtOAc ( 3 x $50 \mathrm{~mL}$ ). The combined organic layers were dried over $\mathrm{MgSO}_{4}$ and evaporated. The residue was purified by flash chromatography (DCM/MeOH(NH$)$, 9.8:0.2 $(v / v))$ to afford 50 as a brown oil (410 mg, $0.93 \mathrm{mmol}, 43 \%) .{ }^{1} \mathrm{H}$ NMR $\left(300 \mathrm{MHz}, \mathrm{CDCl}_{3}\right): \delta$ $9.81(\mathrm{~s}, 1 \mathrm{H}), 7.54(\mathrm{dd}, J=2.1 \mathrm{~Hz}, J=1.7 \mathrm{~Hz}, 1 \mathrm{H}), 6.95(\mathrm{dd}, J=2.9 \mathrm{~Hz}, J=2.2 \mathrm{~Hz}, 1 \mathrm{H}), 6.89$ $(\mathrm{dd}, J=8.2 \mathrm{~Hz}, J=2.3 \mathrm{~Hz}, 1 \mathrm{H}), 6.81(\mathrm{~d}, J=2.3 \mathrm{~Hz}, 1 \mathrm{H}), 6.74(\mathrm{dd}, J=2.8 \mathrm{~Hz}, J=1.8 \mathrm{~Hz}, 1 \mathrm{H})$, $6.59(\mathrm{~d}, J=8.4 \mathrm{~Hz}, 1 \mathrm{H}), 4.91(\mathrm{br} \mathrm{s}, 1 \mathrm{H}), 4.15(\mathrm{t}, J=6.1 \mathrm{~Hz}, 2 \mathrm{H}), 3.21(\mathrm{t}, J=6.6 \mathrm{~Hz}, 2 \mathrm{H}), 2.80$ (t, $J=6.2 \mathrm{~Hz}, 2 \mathrm{H}), 2.59-2.35(\mathrm{~m}, 10 \mathrm{H}), 1.84-1.89(\mathrm{~m}, 2 \mathrm{H}), 1.69-1.53(\mathrm{~m}, 8 \mathrm{H}), 1.53-1.38$ (m, 4H). ${ }^{13} \mathrm{C}$ NMR (75 MHz, $\left.\mathrm{CDCl}_{3}\right): \delta 185.5,146.3,138.5,129.0,127.7,127.3,123.0,114.8$, 109.3, 108.9, 105.8, 66.8, 57.9, 57.4, 55.0, 54.7, 42.5, 26.2, 25.9, 24.2. LCMS $\mathrm{m} / \mathrm{z}$ calc for $[\mathrm{M}+\mathrm{H}]^{+}:$439.3, found: 439.2 .

4-(3-[(Dimethylamino)methyl]-1H-pyrrol-1-yl)-2-[2-(piperidin-1-yl)ethoxy]- $N$-[3-(piperidin1-yl) propyl]aniline (51)

To a solution of 1-(3-[2-(piperidin-1-yl)ethoxy]-4-([3-(piperidin-1-yl)propyl]amino)phenyl)$1 H$-pyrrole-3-carbaldehyde (50) $(85 \mathrm{mg}, 0.19 \mathrm{mmol})$ in DCE $(2 \mathrm{~mL})$, dimethylamine in THF (2M, $144 \mu \mathrm{L}, 0.29 \mathrm{mmol})$ was added. After $1 \mathrm{~h} 30$ of stirring at rt, $\mathrm{NaBH}(\mathrm{OAc})_{3}(61 \mathrm{mg}, 0.29$ mmol) and acetic acid $(17 \mu \mathrm{L}, 0.29 \mathrm{mmol})$ were added. After $5 \mathrm{~h}$ at $\mathrm{rt}$, saturated $\mathrm{NaHCO}_{3}$ solution was added. The reaction mixture was stirred for another $1 \mathrm{~h}$. DCM was added and the layers were separated. The organic layer was washed twice with saturated $\mathrm{NaHCO}_{3}$ solution. The organic layer was dried over $\mathrm{MgSO}_{4}$ and evaporated. The residue was purified by semipreparative chromatography (eluent $\mathrm{H}_{2} \mathrm{O}$ formic, $\mathrm{ACN}$ formic, 9:1 to 1:9 (v/v)). to afford compound 51 as a yellow oil (28 mg, $0.06 \mathrm{mmol}, 31 \%)$. ${ }^{1} \mathrm{H}$ NMR (300 MHz, $\left.\mathrm{CDCl}_{3}\right): \delta 6.91-$ $6.85(\mathrm{~m}, 3 \mathrm{H}), 6.82(\mathrm{~d}, J=2.3 \mathrm{~Hz}, 1 \mathrm{H}), 6.58(\mathrm{~d}, J=8.4 \mathrm{~Hz}, 1 \mathrm{H}), 6.23(\mathrm{dd}, J=2.0 \mathrm{~Hz}, J=2.1$ Hz, 1H), 4.68 (br s, 1H), 4.15 (t, $J=6.2 \mathrm{~Hz}, 2 \mathrm{H}), 3.40$ (s, 2H), 3.19 (t, $J=6.7 \mathrm{~Hz}, 2 \mathrm{H}), 2.80$ (t, $J=6.2 \mathrm{~Hz}, 2 \mathrm{H}), 2.53-2.41(\mathrm{~m}, 10 \mathrm{H}), 2.29(\mathrm{~s}, 6 \mathrm{H}), 1.87-1.84(\mathrm{~m}, 2 \mathrm{H}), 1.65-1.58(\mathrm{~m}, 8 \mathrm{H})$, $1.49-1.42(\mathrm{~m}, 4 \mathrm{H}) .{ }^{13} \mathrm{C} \mathrm{NMR}\left(75 \mathrm{MHz}, \mathrm{CDCl}_{3}\right): \delta 146.3,137.1,130.9,121.4,119.5,113.9$, $110.5,109.7,105.5,66.7,57.9,57.5,56.5,54.9 ; 45.0,42.7,26.5,26.0,24.4$. LCMS $m / z$ calc for $[\mathrm{M}+\mathrm{H}]^{+}:$468.4, found: 468.3. HR-MS: m/z Calculated: 468.3697 , found: $468.3696[\mathrm{M}+\mathrm{H}]^{+}$ $=\mathrm{C}_{28} \mathrm{H}_{46} \mathrm{ON}_{5} \mathrm{O}$.

\subsection{Computational methods}

Training chemical dataset. An in-house dataset including 51 compounds from series A and 35 from series $B$ was used for the computation of pharmacophore models for inhibition of $A \beta_{1-}$ 
42 secretion (Table S1, Figure S1). Sketching, 3D conversion and conformer generation of the 86 molecules was performed with ChemAxon (Marvin 14.8.11, 2014, http://www.chemaxon.com).

Pharmacophore detection. Common pharmacophore features were generated from training set using Align-It program [36] onto a linux workstation for pharmacophore perception of anti$\mathrm{A} \beta_{1-42}$ compounds. This program takes advantage of detection of positively charged atoms and allows to customize the nature of pharmacophore features by specifying the argument funcGroup CHARGE. In this, hydrogen bond donor features were not taken into account in order to avoid the redundant and non-informative features because of overlapping with positive charge features. We chose a 3-features (Positive/Positive/Aromatic) or a more restrictive 4features (Positive/Positive/Positive/ Aromatic) layout for generation of pharmacophores models. $B \_1$ and $B \_10$ were chosen as templates for 3D flexible superimposition of other molecules. Among the 86 molecules of the entire dataset, pharmacophore detection was computed from a reduced set of molecules including only highly active (HA) compounds or from a larger set including also moderately active (HMA) compounds for anti-A $\beta_{1-42}$ activities.

Pharmacophore evaluation. Learned only from active molecules, 3D pharmacophore models were evaluated by their efficiency to discriminate active and inactive compounds. Briefly, the robustness of pharmacophore models was evaluated by screening all the conformers of 86 reference molecules against 3D pharmacophore models with Align-it program. The matching molecules were ranked according to a Tanimoto fitting value between pharmacophore features and concerned atoms of fitted molecules whereas for each non-matched molecule was conferred an arbitrary high RMSD value. ROC scores depict the area under the curve of the plot true positive $=\mathrm{f}($ false positives $)$ according to ranking (Table S4).

\subsection{Biological evaluations}

Antibodies. Primary antibodies used in this study for western-blot analysis included a wellcharacterized homemade rabbit antiserum against the last 17 amino acids of APP, named APPCter-C17 (1/5000) [14,19,37]. Anti- $\beta$-actin (1/10 000) was obtained from Sigma. Anti-LC3B (1/2000) and anti-p62/SQSTM1 (1/2000) antibodies were purchased from Cell Signaling Technology. Secondary antibodies (peroxidase-labelled goat anti-rabbit IgG, 1/5000 or peroxidase-labelled horse anti-mouse $\operatorname{IgG}, 1 / 50000)$ were obtained from Vector Laboratories. 
Cell culture and treatment. The human neuroblastoma cell line SY5Y-APP ${ }^{695 W T}$ was maintained in Dulbecco's modified Eagle medium (DMEM, high glucose, pyruvate - GIBCO, Life Technologies) supplemented with $10 \%$ foetal bovine serum, $2 \mathrm{mM}$ L-glutamine, $1 \mathrm{mM}$ non-essential amino acids and penicillin/streptomycin (GIBCO, Life Technologies) at $37{ }^{\circ} \mathrm{C}$ in a $5 \% \mathrm{CO}_{2}$ humidified incubator [14]. For compounds treatment, a $10 \mathrm{mM}$ stock solution was diluted in freshly supplemented DMEM medium to obtain the precise final concentration of drug. Bafilomycin A1 ( $\left.\mathrm{Baf}_{\mathrm{A} 1}\right)$, the vacuolar 362 type $\mathrm{H}+\mathrm{ATPase}$ inhibitor, was purchased from Merck Millipore and was used at a final dilution of $100 \mathrm{nM}$. Cells were plated at a density of $5.10^{5}$ cells per well into 12-well plates and cultured with $1 \mathrm{~mL}$ supplemented DMEM cell medium for $24 \mathrm{~h}$ before drug exposure. The following day, cell medium was replaced with fresh medium containing drugs diluted at the indicated concentrations. Cells were treated for $24 \mathrm{~h}$. At the end of treatments, the cell medium was collected and kept at $-80^{\circ} \mathrm{C}$ until use, cells were rinsed once with PBS and extracted in $100 \mu \mathrm{L}$ of Laemmli buffer (10 mM Tris, $20 \%$ glycerol and $2 \%$ Sodium dodecyl sulfate) using a cell-scraper. The cell lysate was further sonicated (30 pulses of $0.5 \mathrm{~s}, 60 \mathrm{~Hz}$ ) for $5 \mathrm{~min}$. Total protein concentration was determined using the Pierce BCA Protein Assay Kit (Thermo scientific) according to the manufacturer's instructions. Samples were stored at $-80^{\circ} \mathrm{C}$ until analysis.

Primary neuronal cultures and drug treatment. Primary neuron cultures were obtained from C57BL6 wild-type mice as described previously [38]. Briefly, females were sacrificed at 18.5 days of gestation to collect forebrains of foetuses. Dissection was performed under a microscope in ice-cold Hank's balanced salt solution containing $0.5 \%$ w/v D-glucose and $25 \mathrm{mM}$ Hepes buffer. Cells were dissociated mechanically in dissection medium containing $0.01 \% \mathrm{w} / \mathrm{v}$ papain, $0.1 \% \mathrm{w} / \mathrm{v}$ dispase II, and $0.01 \% \mathrm{w} / \mathrm{v}$ DNase and incubated at $37{ }^{\circ} \mathrm{C}$ twice for $10 \mathrm{~min}$. Cells were then centrifuged at $220 \mathrm{~g}$ for $5 \mathrm{~min}$ at $4{ }^{\circ} \mathrm{C}$, resuspended in Neurobasal medium supplemented with $2 \%$ B27, $1 \mathrm{mM}$ sodium pyruvate, 100 units/ml penicillin, $100 \mu \mathrm{g} / \mathrm{ml}$ streptomycin, $2 \mathrm{mM}$ Glutamax (Invitrogen), filtered through a $40 \mu \mathrm{m}$ cell strainer, counted, and plated on poly-L-ornithine- and laminin-coated 12 -well plates at a density of $5 * 10^{5}$ cells per well. New medium was added at a ratio of 1:3 of starting volume every 3 days until the end of experiments. Drug treatments with $\mathbf{3 0}$ and $\mathbf{3 1}$ at 1, 3 or $5 \mu \mathrm{M}$ were performed directly in the conditioned cell media for $24 \mathrm{~h}$ at 16 days in vitro (DIV).

Cytotoxycity assays. Determination of cell toxicity was assessed by measurement of lactate dehydrogenase (LDH) release (CytoTox 96® Non-Radioactive Cytotoxicity Assay - Promega) 
according to the manufacturer's instructions. SY5Y-APP ${ }^{695 W T}$ cells were plated into a 96-well plate at $2 * 10^{4}$ cells per well with $100 \mu \mathrm{L}$ of DMEM supplemented medium. Cells were treated as described above and LDH measurement was performed at the end of treatment. Primary neuronal cultures were plated into a 48 -well plate at a density of about $1.5 \times 10^{5}$ cells per well with Neurobasal supplemented medium. Cells were cultured and treated as described above. LDH measurement was performed at the end of treatment.

Western Blot Analysis. Cell protein lysates were prepared for western-blot analysis by diluting the sample with 1 volume of NuPAGE® lithium dodecyl sulfate (LDS) $2 \mathrm{X}$ sample buffer supplemented with $20 \%$ NuPAGE® sample reducing agents (Invitrogen). Samples were heated $10 \mathrm{~min}$ at $100{ }^{\circ} \mathrm{C} .10 \mu \mathrm{g}$ of total proteins per well were loaded onto precast $4-12 \%$ Criterion XT Bis-Tris polyacrylamide gels (Bio-Rad) and electrophoresis was achieved after applying a tension of $150 \mathrm{~V}$ during 90 min using a Criterion electrophoresis Cell with the NuPAGE® MOPS SDS running buffer (1X). Proteins were transferred to a nitrocellulose membrane of 0.4 $\mu \mathrm{M}$ pore size (G\&E Healthcare) using the Criterion blotting system and applying a tension of $100 \mathrm{~V}$ for $45 \mathrm{~min}$. To resolve proteins of low molecular weights such as carboxy-terminal fragments of APP, $12 \%$ Criterion XT Bis-Tris polyacrylamide gels (Bio-Rad) were used and electrophoresis was performed during $70 \mathrm{~min}$ at $150 \mathrm{~V}$ in a NuPAGE® MES SDS running buffer (1X). Proteins were transferred to a nitrocellulose membrane of $0.2 \mu \mathrm{m}$ pore size (G\&E Healthcare) at $100 \mathrm{~V}$ for $40 \mathrm{~min}$. Molecular weights calibration was achieved using molecular weight markers (Novex and Magic Marks, Life Technologies). Protein transfer and quality were determined by a reversible Ponceau Red coloration $(0.2 \%$ Xylidine Ponceau Red and 3\% Trichloroacetic acid). Membranes were then blocked in $25 \mathrm{mM}$ Tris- $\mathrm{HCl} \mathrm{pH} 8.0,150 \mathrm{mM}$ $\mathrm{NaCl}, 0.1 \%$ Tween-20 (v/v) (TBS-T) and 5\% (w/v) of skimmed milk or 5\% (w/v) of bovine serum albumin depending on the antibody during $1 \mathrm{~h}$. Membrane was rinsed three-times $10 \mathrm{~min}$ in TBS-T before incubation with the primary antibody overnight at $4{ }^{\circ} \mathrm{C}$. Membrane was rinsed 3 times $10 \mathrm{~min}$ with TBS-T and then incubated with the secondary antibody for $45 \mathrm{~min}$ at room temperature (RT). The immunoreactive complexes were revealed using the ECL ${ }^{\mathrm{TM}}$ Western Blotting Detection Reagents (G\&E Healthcare) and image acquisitions were performed with the Amersham Imager 600 (G\&E Healthcare). Quantifications of protein expression levels were performed with ImageJ Software (NIH).

Quantification of secreted A $\mathbf{A} 1-40 / 1-42$ and sAPP $\alpha / \mathbf{s A P P \beta}$. Conditioned media of SY5YAPP ${ }^{695 \mathrm{WT}}$ collected at the end of treatments were centrifuged at $1000 \mathrm{~g}$ for 5 min to eliminate 
cells debris. $A \beta_{1-40}$ and $A \beta_{1-42}$ peptide concentrations in $\mathrm{pg} / \mathrm{mL}$ were determined using amyloidbeta 40 and 42 Human ELISA kits (Invitrogen) according to the manufacturer's instructions after 1:10 and 1:2 dilution of supernatants in ELISA buffer, respectively. SAPP $\alpha$ and sAPP $\beta$ concentrations in $\mathrm{ng} / \mathrm{mL}$ were determined using the sAPP $\alpha / \mathrm{sAPP} \beta$ kit (Meso Scale Diagnostics, $\mathrm{MSD}^{\circledR}$ ) according to the manufacturer's instructions.

Immunofluorescence. SY5Y-APP ${ }^{655 T}$ cells were plated at $3 \times 10^{5}$ cells per well on poly-Dlysine coated glass coverslip with $1 \mathrm{~mL}$ of DMEM supplemented medium. Primary neurons were plated at $2.5 \times 10^{5}$ cells par well with $1 \mathrm{~mL}$ of Neurobasal supplemented medium. Treatment with compound $\mathbf{3 0}$ at $5 \mu \mathrm{M}$ was performed following the same protocols described above. At the end of treatments, cells were fixed with 4\% paraformaldehyde in PBS during 15 min at $\mathrm{rt}$ and rinsed 3 times 5 min with PBS. Cells were then permeabilized using $0.25 \%$ Triton X-100 during $15 \mathrm{~min}$ at $\mathrm{rt}$ and rinsed with PBS 3 times for 5 min before blocking in 1\% BSA in PBS for $1 \mathrm{~h}$ at $\mathrm{rt}$. After 3 washes with PBS, cells were incubated with primary antibodies directed against LC3-B (1/200) and p62 (1/200) at $4{ }^{\circ} \mathrm{C}$ overnight in a PBS solution containing $1 \%$ BSA and $0.02 \%$ Triton X-100. The following day, coveslips were rinsed with PBS and incubated with anti-IgG secondary antibodies coupled to Alexa Fluor 568 (1/500) (Invitrogen). Nuclei were visualized using DAPI (Thermo Scientific). Images were acquired on a Zeiss Axio Imager Z2 microscope (Carl Zeiss, Germany) equipped with a Hamamatsu ORCA-Flash4.0 digital camera (Hamamatsu Photonics, Japan) and ApoTome.2 system (Carl Zeiss, Germany). For Apotome image acquisition, the Axio Imager was used with optical plan-apochromat 63x/1.4 oil M27.

$\boldsymbol{\beta}$-secretase in vitro activity assay. These experiments were performed on human recombinant BACE-1 protein at Eurofins Cerep (Celle-Lévescault, France), with minor variations to the experimental protocol described by Ermolieff, J. et al. [34]. The cleavage of fluorescent McaS-E-V-N-L-D-AE-F-R-K(Dnp)-R-R-NH ${ }_{2}$ substrate to Mca-S-E-V-N-L-NH $\mathrm{NH}_{2}$ was monitored after 60 min incubation at $\mathrm{rt}$ in the presence or absence of test molecules. Compounds $\mathbf{3 0}$ and 31 were evaluated at concentrations of 1 and $10 \mu \mathrm{M}$. Both compounds were found totally inactive $(\%$ inhibition < 10\%). Under the assay conditions, reference OM 99-2 displayed an $\mathrm{IC}_{50}$ value of $59 \mathrm{nM}$. 
Statistical Analysis. For statistical analysis, the non-parametric Mann-Whitney test was selected using GraphPad Prism 6 (GraphPad Software) and statistical significance was set at $* \mathrm{p}<0.05, * * \mathrm{p}<0.001, * * * \mathrm{p}<0.001$ and $* * * * \mathrm{p}<0,0001$. All data are reported as mean \pm SEM.

\section{ASSOCIATED CONTENT}

Supporting Information. Supplementary tables S1-S3, figures S1 \& S2, ${ }^{1} \mathrm{H}$ and ${ }^{13} \mathrm{C}$ NMR spectroscopic data and HRMS spectra for all final compounds

\section{Corresponding authors:}

\section{Dr. Jamal EI Bakali}

Inserm UMR-S1172 - Onco and Neurochemistry team, School of Pharmacy, 3 rue du Pr. Laguesse - BP 83 - 59006 Lille cedex - France - Tel +33 (0)3 20964966.

e-mail : jamal.el-bakali@univ-lille.fr

\section{Dr. Valerie Vingtdeux}

Inserm UMR-S1172 - Alzheimer \& Tauopathies team - Jean-Pierre Aubert Research Centre rue M. Polonowski - 59045 Lille cedex - France - Tel + 33(0)3 20298891

e-mail : valerie.vingtdeux@inserm.fr

\section{Funding Sources}

This work was supported by Inserm and the University of Lille. Grants were obtained from ANR (VIDALZ), Laboratory of Excellence Labex DISTALZ and France Alzheimer. Marion Gay, Caroline Evrard and Florian Descamps are the recipient of fellowships from the University of Lille 2. The $300 \mathrm{MHz}$ NMR facilities were funded by the Région Nord Pas-de-Calais (France), the Ministère de la Jeunesse, de l'Education Nationale et de la Recherche (MJENR) and the Fonds Européens de Développement Régional (FEDER).

\section{Notes}

The authors declare no competing financial interest. 
We expressed our thanks to C. Mésangeau, N. Deguine, F. Copper and L. Barber for their contribution in organic synthesis, F. Sauvé, A. Trichies and R. Dufossez for their help with the in vitro experiments. We thank the animal core facility (animal facilities of Université de LilleInserm) of "Plateformes en Biologie Santé de Lille" as well as C. Degraeve, M. BesegherDumoulin, J. Devassine, R. Dehaynin and D. Taillieu for animal care.

\section{ABBREVIATIONS}

AD, Alzheimer's disease; AICD, APP intracellular domain; APP, amyloid precursor protein; $\mathrm{CTF}$, carboxy-terminal fragment; $\mathrm{CQ}$, chloroquine.

\section{References}

[1] A. Serrano-Pozo, M.P. Frosch, E. Masliah, B.T. Hyman, Neuropathological alterations in Alzheimer disease., Cold Spring Harb. Perspect. Med. 1 (2011) 1-23. doi:10.1101/cshperspect.a006189.

[2] B. De Strooper, Proteases and Proteolysis in Alzheimer Disease: A Multifactorial View on the Disease Process, Physiol. Rev. 90 (2010) 465-494. doi:10.1152/physrev.00023.2009.

[3] J. Cummings, G. Lee, T. Mortsdorf, A. Ritter, K. Zhong, Alzheimer's disease drug development pipeline: 2017, Alzheimer's Dement. Transl. Res. Clin. Interv. 3 (2017) 367-384. doi:10.1016/j.trci.2017.05.002.

[4] R.J. Andrew, K.A.B. Kellett, G. Thinakaran, N.M. Hooper, A Greek tragedy: The growing complexity of Alzheimer amyloid precursor protein proteolysis, J. Biol. Chem. 291 (2016) 19235-19244. doi:10.1074/jbc.R116.746032.

[5] H.S. Nhan, K. Chiang, E.H. Koo, The multifaceted nature of amyloid precursor protein and its proteolytic fragments: friends and foes, Acta Neuropathol. 129 (2015) 1-19. doi:10.1007/s00401-014-1347-2.

[6] R. Vassar, D.M. Kovacs, R. Yan, P.C. Wong, The -Secretase Enzyme BACE in Health and Alzheimer's Disease: Regulation, Cell Biology, Function, and Therapeutic Potential, J. Neurosci. 29 (2009) 12787-12794. doi:10.1523/JNEUROSCI.365709.2009.

[7] R. Yan, R. Vassar, Targeting the $\beta$ secretase BACE1 for Alzheimer's disease therapy, Lancet Neurol. 13 (2014) 319-329. doi:10.1016/S1474-4422(13)70276-X.

[8] T. Jonsson, J.K. Atwal, S. Steinberg, J. Snaedal, P. V. Jonsson, S. Bjornsson, H. Stefansson, P. Sulem, D. Gudbjartsson, J. Maloney, K. Hoyte, A. Gustafson, Y. Liu, Y. 
Lu, T. Bhangale, R.R. Graham, J. Huttenlocher, G. Bjornsdottir, O.A. Andreassen, E.G. Jonsson, A. Palotie, T.W. Behrens, O.T. Magnusson, A. Kong, U.

Thorsteinsdottir, R.J. Watts, K. Stefansson, A mutation in APP protects against Alzheimer's disease and age-related cognitive decline, Nature. 488 (2012) 96-99. doi:10.1038/nature11283.

[9] J.A. Maloney, T. Bainbridge, A. Gustafson, S. Zhang, R. Kyauk, P. Steiner, M. Van Der Brug, Y. Liu, J.A. Ernst, R.J. Watts, J.K. Atwal, Molecular mechanisms of Alzheimer disease protection by the A673T allele of amyloid precursor protein, J. Biol. Chem. 289 (2014) 30990-31000. doi:10.1074/jbc.M114.589069.

[10] A.K. Ghosh, H.L. Osswald, BACE1 ( $\beta$-secretase) inhibitors for the treatment of Alzheimer's disease, Chem. Soc. Rev. 43 (2014) 6765-6813. doi:10.1039/C3CS60460H.

[11] R. Vassar, BACE1 inhibitor drugs in clinical trials for Alzheimer's disease, Alzheimer's Res. Ther. 6 (2014) 1-14. doi:10.1186/s13195-014-0089-7.

[12] W.J. Netzer, K. Bettayeb, S.C. Sinha, M. Flajolet, P. Greengard, V. Bustos, Gleevec shifts APP processing from a $\beta$-cleavage to a nonamyloidogenic cleavage, Proc. Natl. Acad. Sci. 114 (2017) 1389-1394. doi:10.1073/pnas.1620963114.

[13] S. Ben Halima, S. Mishra, K.M.P. Raja, M. Willem, A. Baici, K. Simons, O. Brüstle, P. Koch, C. Haass, A. Caflisch, L. Rajendran, Specific Inhibition of $\beta$-Secretase Processing of the Alzheimer Disease Amyloid Precursor Protein, Cell Rep. 14 (2016) 2127-2141. doi:10.1016/j.celrep.2016.01.076.

[14] V. Vingtdeux, M. Hamdane, A. Loyens, P. Gelé, H. Drobeck, S. Bégard, M.C. Galas, A. Delacourte, J.C. Beauvillain, L. Buée, N. Sergeant, Alkalizing drugs induce accumulation of amyloid precursor protein by-products in luminal vesicles of multivesicular bodies, J. Biol. Chem. 282 (2007) 18197-18205. doi:10.1074/jbc.M609475200.

[15] T. Hamano, T.F. Gendron, E. Causevic, S.H. Yen, W.L. Lin, C. Isidoro, M. Deture, L.W. Ko, Autophagic-lysosomal perturbation enhances tau aggregation in transfectants with induced wild-type tau expression, Eur. J. Neurosci. 27 (2008) 1119-1130. doi:10.1111/j.1460-9568.2008.06084.x.

[16] J.H.K. Tam, R.M. Cobb, C. Seah, S.H. Pasternak, Tyrosine binding protein sites regulate the intracellular trafficking and processing of amyloid precursor protein through a novel lysosome-directed pathway, PLoS One. 11 (2016) 1-24. doi:10.1371/journal.pone.0161445. 
[17] P. Melnyk, V. Vingtdeux, S. Burlet, S. Eddarkaoui, M.E. Grosjean, P.E. Larchanché, G. Hochart, C. Sergheraert, C. Estrella, M. Barrier, V. Poix, P. Plancq, C. Lannoo, M. Hamdane, A. Delacourte, P. Verwaerde, L. Buée, N. Sergeant, Chloroquine and Chloroquinoline Derivatives as Models for the Design of Modulators of Amyloid Peptide Precursor Metabolism, ACS Chem. Neurosci. 6 (2015) 559-569. doi:10.1021/cn5003013.

[18] C. Evrard, P. Kienlen-Campard, R. Opsomer, B. Tasiaux, J.-N. Octave, L. Buée, N. Sergeant, V. Vingtdeux, Contribution of the endosomal-lysosomal and proteasomal systems in Amyloid- $\beta$ Precursor Protein derived fragments processing, (2018). doi:https://doi.org/10.1101/300921.

[19] V. Vingtdeux, M. Hamdane, S. Bégard, A. Loyens, A. Delacourte, J.C. Beauvillain, L. Buée, P. Marambaud, N. Sergeant, Intracellular pH regulates amyloid precursor protein intracellular domain accumulation, Neurobiol. Dis. 25 (2007) 686-696. doi:10.1016/j.nbd.2006.09.019.

[20] A.E. González, V.C. Muñoz, V.A. Cavieres, H.A. Bustamante, V.H. Cornejo, Y.C. Januário, I. González, C. Hetz, L.L. Dasilva, A. Rojas-Fernández, R.T. Hay, G.A. Mardones, P. V. Burgos, Autophagosomes cooperate in the degradation of intracellular C-terminal fragments of the amyloid precursor protein via the MVB/lysosomal pathway, FASEB J. 31 (2017) 2446-2459. doi:10.1096/fj.201600713R.

[21] D.J. Klionsky, D.J. Klionsky, K. Abdelmohsen, A. Abe, M.J. Abedin, H. Abeliovich, A.A. Arozena, H. Adachi, C.M. Adams, P.D. Adams, K. Adeli, P.J. Adhihetty, S.G. Adler, G. Agam, R. Agarwal, M.K. Aghi, M. Agnello, P. Agostinis, P. V. Aguilar, J. Aguirre-Ghiso, J. Aguirre-Ghiso, E.M. Airoldi, E.M. Airoldi, S. Ait-Si-Ali, T. Akematsu, E.T. Akporiaye, M. Al-Rubeai, G.M. Albaiceta, C. Albanese, D. Albani, M.L. Albert, J. Aldudo, H. Algül, M. Alirezaei, I. Alloza, I. Alloza, A. Almasan, M. Almonte-Beceril, E.S. Alnemri, C. Alonso, N. Altan-Bonnet, D.C. Altieri, S. Alvarez, L. Alvarez-Erviti, S. Alves, G. Amadoro, A. Amano, C. Amantini, S. Ambrosio, I. Amelio, A.O. Amer, M. Amessou, A. Amon, Z. An, F.A. Anania, S.U. Andersen, U.P. Andley, C.K. Andreadi, N. Andrieu-Abadie, A. Anel, D.K. Ann, S. AnoopkumarDukie, M. Antonioli, M. Antonioli, H. Aoki, N. Apostolova, S. Aquila, K. Aquilano, K. Araki, E. Arama, A. Aranda, J. Araya, A. Arcaro, E. Arias, H. Arimoto, A.R. Ariosa, J.L. Armstrong, T. Arnould, I. Arsov, K. Asanuma, V. Askanas, E. Asselin, R. Atarashi, S.S. Atherton, J.D. Atkin, L.D. Attardi, P. Auberger, G. Auburger, L. Aurelian, R. Autelli, L. Avagliano, L. Avagliano, M.L. Avantaggiati, L. Avrahami, S. 
Awale, N. Azad, T. Bachetti, J.M. Backer, D.H. Bae, J.S. Bae, O.N. Bae, S.H. Bae, E.H. Baehrecke, S.H. Baek, S. Baghdiguian, A. Bagniewska-Zadworna, H. Bai, J. Bai, X.Y. Bai, Y. Bailly, K.N. Balaji, W. Balduini, A. Ballabio, R. Balzan, R. Banerjee, G. Bánhegyi, H. Bao, B. Barbeau, M.D. Barrachina, E. Barreiro, B. Bartel, A. Bartolomé, D.C. Bassham, M.T. Bassi, R.C. Bast, A. Basu, M.T. Batista, H. Batoko, M. Battino, K. Bauckman, B.L. Baumgarner, K.U. Bayer, R. Beale, J.F. Beaulieu, G.R. Beck, G.R. Beck, C. Becker, J.D. Beckham, P.A. Bédard, P.J. Bednarski, T.J. Begley, C. Behl, C. Behrends, G.M.N. Behrens, K.E. Behrns, E. Bejarano, A. Belaid, F. Belleudi, G. Bénard, G. Berchem, D. Bergamaschi, M. Bergami, B. Berkhout, L. Berliocchi, A. Bernard, M. Bernard, F. Bernassola, A. Bertolotti, A.S. Bess, S. Besteiro, S. Bettuzzi, S. Bhalla, S. Bhattacharyya, S.K. Bhutia, C. Biagosch, M.W. Bianchi, M.W. Bianchi, M.W. Bianchi, M. Biard-Piechaczyk, V. Billes, C. Bincoletto, B. Bingol, S.W. Bird, M. Bitoun, I. Bjedov, C. Blackstone, L. Blanc, G.A. Blanco, H.K. Blomhoff, E. BoadaRomero, S. Böckler, M. Boes, K. Boesze-Battaglia, L.H. Boise, L.H. Boise, A. Bolino, A. Boman, P. Bonaldo, M. Bordi, M. Bordi, J. Bosch, L.M. Botana, J. Botti, G. Bou, M. Bouché, M. Bouchecareilh, M.J. Boucher, M.E. Boulton, S.G. Bouret, P. Boya, M. Boyer-Guittaut, P. V. Bozhkov, N. Brady, V.M.M. Braga, C. Brancolini, G.H. Braus, J.M. Bravo-San-Pedro, J.M. Bravosan-Pedro, J.M. Bravosan-Pedro, J.M. BravosanPedro, L.A. Brennan, E.H. Bresnick, P. Brest, D. Bridges, M.A. Bringer, M. Brini, G.C. Brito, B. Brodin, P.S. Brookes, E.J. Brown, K. Brown, H.E. Broxmeyer, A. Bruhat, A. Bruhat, P.C. Brum, J.H. Brumell, N. Brunetti-Pierri, N. Brunetti-Pierri, R.J. Bryson-Richardson, S. Buch, A.M. Buchan, H. Budak, D. V. Bulavin, D. V. Bulavin, D. V. Bulavin, S.J. Bultman, G. Bultynck, V. Bumbasirevic, Y. Burelle, R.E. Burke, R.E. Burke, M. Burmeister, P. Bütikofer, L. Caberlotto, K. Cadwell, M. Cahova, D. Cai, J. Cai, Q. Cai, S. Calatayud, N. Camougrand, M. Campanella, G.R. Campbell, M. Campbell, S. Campello, S. Campello, R. Candau, I. Caniggia, L. Cantoni, L. Cao, A.B. Caplan, M. Caraglia, C. Cardinali, S.M. Cardoso, J.S. Carew, L.A. Carleton, C.R. Carlin, S. Carloni, S.R. Carlsson, D. Carmona-Gutierrez, L.A.M. Carneiro, O. Carnevali, S. Carra, A. Carrier, B. Carroll, C. Casas, J. Casas, G. Cassinelli, P. Castets, S. Castro-Obregon, G. Cavallini, I. Ceccherini, F. Cecconi, F. Cecconi, F. Cecconi, A.I. Cederbaum, V. Ceña, V. Ceña, S. Cenci, S. Cenci, C. Cerella, D. Cervia, S. Cetrullo, H. Chaachouay, H.J. Chae, A.S. Chagin, C.Y. Chai, C.Y. Chai, G. Chakrabarti, G. Chamilos, E.Y.W. Chan, M.T.V. Chan, D. Chandra, P. Chandra, C.P. Chang, R.C.C. Chang, T.Y. Chang, J.C. Chatham, S. Chatterjee, S. Chauhan, Y. Che, M.E. Cheetham, 
R. Cheluvappa, C.J. Chen, G. Chen, G. Chen, G.C. Chen, G. Chen, H. Chen, J.W. Chen, J.K. Chen, J.K. Chen, M. Chen, M. Chen, P. Chen, Q. Chen, Q. Chen, S. Der Chen, S. Chen, S.S.L. Chen, W. Chen, W.J. Chen, W.Q. Chen, W. Chen, X. Chen, Y.H. Chen, Y.G. Chen, Y. Chen, Y. Chen, Y. Chen, Y. Chen, Y.J. Chen, Y.Q. Chen, Y. Chen, Z. Chen, Z. Chen, A. Cheng, C.H.K. Cheng, H. Cheng, H. Cheong, S. Cherry, J. Chesney, C.H.A. Cheung, E. Chevet, H.C. Chi, S.G. Chi, F. Chiacchiera, H.L. Chiang, R. Chiarelli, M. Chiariello, M. Chiariello, M. Chiariello, M. Chieppa, L.S. Chin, M. Chiong, G.N.C. Chiu, D.H. Cho, S.G. Cho, W.C. Cho, Y.Y. Cho, Y.S. Cho, A.M.K. Choi, E.J. Choi, E.K. Choi, E.K. Choi, E.K. Choi, E.K. Choi, J. Choi, M.E. Choi, S. Il Choi, S. Il Choi, T.F. Chou, S. Chouaib, D. Choubey, V. Choubey, K.C. Chow, K. Chowdhury, C.T. Chu, T.H. Chuang, T. Chun, H. Chung, T. Chung, Y.L. Chung, Y.J. Chwae, V. Cianfanelli, R. Ciarcia, I.A. Ciechomska, M.R. Ciriolo, M. Cirone, S. Claerhout, S. Claerhout, M.J. Clague, J. Clària, P.G.H. Clarke, R. Clarke, E. Clementi, E. Clementi, C. Cleyrat, M. Cnop, E.M. Coccia, T. Cocco, P. Codogno, J. Coers, E.E.W. Cohen, D. Colecchia, D. Colecchia, D. Colecchia, L. Coletto, N.S. Coll, E. Colucci-Guyon, S. Comincini, M. Condello, K.L. Cook, G.H. Coombs, C.D. Cooper, J.M. Cooper, I. Coppens, M.T. Corasaniti, M. Corazzari, M. Corazzari, R. Corbalan, E. Corcelle-Termeau, M.D. Cordero, C. Corral-Ramos, O. Corti, O. Corti, A. Cossarizza, P. Costelli, S. Costes, S.L. Cotman, A. Coto-Montes, S. Cottet, S. Cottet, E. Couve, L.R. Covey, L.A. Cowart, J.S. Cox, F.P. Coxon, C.B. Coyne, M.S. Cragg, R.J. Craven, T. Crepaldi, J.L. Crespo, A. Criollo, V. Crippa, M.T. Cruz, A.M. Cuervo, J.M. Cuezva, T. Cui, P.R. Cutillas, M.J. Czaja, M.F. Czyzyk-Krzeska, R.K. Dagda, U. Dahmen, C. Dai, W. Dai, Y. Dai, K.N. Dalby, L.D. Valle, G. Dalmasso, M. D’amelio, M. Damme, A. Darfeuille-Michaud, C. Dargemont, V.M. Darley-Usmar, S. Dasarathy, B. Dasgupta, S. Dash, C.R. Dass, H.M. Davey, L.M. Davids, D. Dávila, R.J. Davis, T.M. Dawson, T.M. Dawson, V.L. Dawson, P. Daza, J. de Belleroche, P. de Figueiredo, P. de Figueiredo, R.C.B.Q. de Figueiredo, J. de la Fuente, L. De Martino, A. De Matteis, G.R.Y. De Meyer, A. De Milito, M. De Santi, W. de Souza, V. De Tata, D. De Zio, J. Debnath, R. Dechant, J.P. Decuypere, J.P. Decuypere, S. Deegan, B. Dehay, B. Del Bello, D.P. Del Re, R. Delage-Mourroux, L.M.D. Delbridge, L. Deldicque, E. Delorme-Axford, Y. Deng, J. Dengjel, M. Denizot, P. Dent, C.J. Der, V. Deretic, B. Derrien, E. Deutsch, T.P. Devarenne, R.J. Devenish, S. Di Bartolomeo, N. Di Daniele, F. Di Domenico, A. Di Nardo, S. Di Paola, A. Di Pietro, L. Di Renzo, A. Di Antonio, G. Díaz-Araya, I. Díaz-Laviada, M.T. Diaz-Meco, J. Diaz-Nido, C.A. 
Dickey, R.C. Dickson, M. Diederich, P. Digard, I. Dikic, S.P. Dinesh-Kumar, C. Ding, W.X. Ding, Z. Ding, L. Dini, J.H.W. Distler, A. Diwan, M. Djavaheri-Mergny, K. Dmytruk, R.C.J. Dobson, V. Doetsch, K. Dokladny, S. Dokudovskaya, M. Donadelli, X.C. Dong, X. Dong, Z. Dong, T.M. Donohue, T.M. Donohue-Jr, K.S. Doran, G. D’orazi, G.W. Dorn, V. Dosenko, S. Dridi, L. Drucker, J. Du, L.L. Du, L. Du, A. du Toit, P. Dua, L. Duan, P. Duann, V.K. Dubey, M.R. Duchen, M.A. Duchosal, H. Duez, I. Dugail, V.I. Dumit, M.C. Duncan, E.A. Dunlop, W.A. Dunn, N. Dupont, L. Dupuis, L. Dupuis, R. V. Durán, T.M. Durcan, S. Duvezin-Caubet, U. Duvvuri, V. Eapen, D. Ebrahimi-Fakhari, A. Echard, L. Eckhart, C.L. Edelstein, A.L. Edinger, L. Eichinger, T. Eisenberg, A. Eisenberg-Lerner, N.T. Eissa, W.S. El-Deiry, V. El-Khoury, Z. Elazar, H. Eldar-Finkelman, C.J.H. Elliott, E. Emanuele, U. Emmenegger, N. Engedal, A.M. Engelbrecht, S. Engelender, J.M. Enserink, R. Erdmann, J. Erenpreisa, R. Eri, J.L. Eriksen, A. Erman, R. Escalante, E.L. Eskelinen, L. Espert, L. Esteban-Martínez, T.J. Evans, M. Fabri, G. Fabrias, C. Fabrizi, A. Facchiano, N.J. Færgeman, A. Faggioni, W.D. Fairlie, W.D. Fairlie, W.D. Fairlie, C. Fan, D. Fan, J. Fan, S. Fang, M. Fanto, A. Fanzani, T. Farkas, M. Faure, F.B. Favier, F.B. Favier, H. Fearnhead, M. Federici, E. Fei, T.C. Felizardo, H. Feng, Y. Feng, Y. Feng, Y. Feng, T.A. Ferguson, Á.F. Fernández, M.G. Fernandez-Barrena, J.C. Fernandez-Checa, J.C. FernandezCheca, A. Fernández-López, M.E. Fernandez-Zapico, O. Feron, E. Ferraro, C.V. Ferreira-Halder, L. Fesus, R. Feuer, F.C. Fiesel, E.C. Filippi-Chiela, G. Filomeni, G. Filomeni, G.M. Fimia, G.M. Fimia, J.H. Fingert, J.H. Fingert, S. Finkbeiner, S. Finkbeiner, T. Finkel, F. Fiorito, F. Fiorito, P.B. Fisher, M. Flajolet, F. Flamigni, O. Florey, S. Florio, R.A. Floto, M. Folini, C. Follo, E.A. Fon, F. Fornai, F. Fornai, F. Fortunato, A. Fraldi, R. Franco, A. Francois, A. Francois, A. François, L.B. Frankel, I.D.C. Fraser, N. Frey, D.G. Freyssenet, C. Frezza, S.L. Friedman, D.E. Frigo, D.E. Frigo, D. Fu, J.M. Fuentes, J. Fueyo, Y. Fujitani, Y. Fujiwara, M. Fujiya, M. Fukuda, S. Fulda, C. Fusco, B. Gabryel, M. Gaestel, P. Gailly, M. Gajewska, S. Galadari, S. Galadari, G. Galili, I. Galindo, M.F. Galindo, G. Galliciotti, L. Galluzzi, L. Galluzzi, L. Galluzzi, L. Galluzzi, L. Galluzzi, V. Galy, N. Gammoh, S. Gandy, S. Gandy, A.K. Ganesan, S. Ganesan, I.G. Ganley, M. Gannagé, F.B. Gao, F. Gao, J.X. Gao, L.G. Nannig, E.G. Véscovi, M. Garcia-Macía, C. Garcia-Ruiz, A.D. Garg, P.K. Garg, R. Gargini, N.C. Gassen, D. Gatica, D. Gatica, E. Gatti, E. Gatti, E. Gatti, J. Gavard, E. Gavathiotis, L. Ge, P. Ge, S. Ge, P.W. Gean, V. Gelmetti, A.A. Genazzani, J. Geng, P. Genschik, L. Gerner, J.E. Gestwicki, D.A. Gewirtz, S. Ghavami, E. Ghigo, D. Ghosh, 
A.M. Giammarioli, A.M. Giammarioli, F. Giampieri, C. Giampietri, A.

Giatromanolaki, D.J. Gibbings, L. Gibellini, S.B. Gibson, V. Ginet, A. Giordano, A. Giordano, F. Giorgini, E. Giovannetti, E. Giovannetti, S.E. Girardin, S. Gispert, S.

Giuliano, S. Giuliano, C.L. Gladson, A. Glavic, M. Gleave, N. Godefroy, R.M. Gogal, K. Gokulan, G.H. Goldman, D. Goletti, M.S. Goligorsky, A. V. Gomes, L.C. Gomes, H. Gomez, C. Gomez-Manzano, R. Gómez-Sánchez, D.A.P. Gonçalves, E. Goncu, Q. Gong, C. Gongora, C.B. Gonzalez, P. Gonzalez-Alegre, P. Gonzalez-Cabo, P. Gonzalez-Cabo, R.A. González-Polo, I.S. Goping, C. Gorbea, N. V. Gorbunov, D.R. Goring, A.M. Gorman, S.M. Gorski, S.M. Gorski, S. Goruppi, S. Goto-Yamada, C. Gotor, R.A. Gottlieb, I. Gozes, D. Gozuacik, Y. Graba, M. Graef, G.E. Granato, G.D. Grant, S. Grant, G.L. Gravina, D.R. Green, A. Greenhough, M.T. Greenwood, B. Grimaldi, F. Gros, C. Grose, J.F. Groulx, F. Gruber, P. Grumati, P. Grumati, T. Grune, J.L. Guan, K.L. Guan, B. Guerra, C. Guillen, C. Guillen, K. Gulshan, J. Gunst, C. Guo, L. Guo, M. Guo, W. Guo, X.G. Guo, A.A. Gust, Å.B. Gustafsson, E. Gutierrez, M.G. Gutierrez, H.S. Gwak, A. Haas, J.E. Haber, S. Hadano, M. Hagedorn, D.R. Hahn, A.J. Halayko, A. Hamacher-Brady, K. Hamada, A. Hamai, A. Hamann, M. Hamasaki, I. Hamer, Q. Hamid, E.M. Hammond, F. Han, W. Han, J.T. Handa, J.A. Hanover, M. Hansen, M. Harada, L. Harhaji-Trajkovic, J.W. Harper, A.H. Harrath, A.L. Harris, J. Harris, U. Hasler, P. Hasselblatt, K. Hasui, R.G. Hawley, T.S. Hawley, C. He, C.Y. He, F. He, G. He, R.R. He, X.H. He, Y.W. He, Y.Y. He, J.K. Heath, M.J. Hébert, R.A. Heinzen, G.V. Helgason, M. Hensel, E.P. Henske, C. Her, P.K. Herman, A. Hernández, C. Hernandez, S. Hernández-Tiedra, C. Hetz, C. Hetz, P.R. Hiesinger, K. Higaki, S. Hilfiker, B.G. Hill, J.A. Hill, W.D. Hill, W.D. Hill, W.D. Hill, W.D. Hill, K. Hino, D. Hofius, P. Hofman, G.U. Höglinger, G.U. Höglinger, J. Höhfeld, M.K. Holz, M.K. Holz, Y. Hong, D.A. Hood, J.J.M. Hoozemans, T. Hoppe, C. Hsu, C.Y. Hsu, L.C. Hsu, D. Hu, G. Hu, H.M. Hu, H. Hu, M.C. Hu, Y.C. Hu, Z.W. Hu, F. Hua, Y. Hua, C. Huang, C. Huang, H.L. Huang, K.H. Huang, K.Y. Huang, S. Huang, S. Huang, W.P. Huang, Y.R. Huang, Y. Huang, Y. Huang, T.B. Huber, T.B. Huber, T.B. Huber, P. Huebbe, W.K. Huh, J.J. Hulmi, J.J. Hulmi, G.M. Hur, J.H. Hurley, Z. Husak, S.N.A. Hussain, S.N.A. Hussain, S. Hussain, J.J. Hwang, S. Hwang, T.I.S. Hwang, A. Ichihara, Y. Imai, C. Imbriano, M. Inomata, T. Into, V. Iovane, J.L. Iovanna, R. V. Iozzo, N.Y. Ip, J.E. Irazoqui, P. Iribarren, Y. Isaka, A.J. Isakovic, H. Ischiropoulos, H. Ischiropoulos, J.S. Isenberg, M. Ishaq, H. Ishida, I. Ishii, J.E. Ishmael, C. Isidoro, K.I. Isobe, E. Isono, S. Issazadeh-Navikas, K. Itahana, E. Itakura, A.I. Ivanov, A.K. V. Iyer, 
J.M. Izquierdo, Y. Izumi, V. Izzo, V. Izzo, V. Izzo, V. Izzo, M. Jäättelä, N. Jaber, D.J. Jackson, W.T. Jackson, T.G. Jacob, T.S. Jacques, C. Jagannath, A. Jain, A. Jain, N.R. Jana, B.K. Jang, A. Jani, A. Jani, B. Janji, P.R. Jannig, P.J. Jansson, S. Jean, M. Jendrach, J.H. Jeon, N. Jessen, E.B. Jeung, K. Jia, L. Jia, H. Jiang, H. Jiang, L. Jiang, T. Jiang, X. Jiang, X. Jiang, X. Jiang, Y. Jiang, Y. Jiang, Y. Jiang, Y. Jiang, A. Jiménez, C. Jin, H. Jin, L. Jin, M. Jin, M. Jin, S. Jin, U.K. Jinwal, E.K. Jo, T. Johansen, D.E. Johnson, G.V.W. Johnson, J.D. Johnson, E. Jonasch, C. Jones, L.A.B. Joosten, J. Jordan, A.M. Joseph, B. Joseph, A.M. Joubert, D. Ju, J. Ju, H.F. Juan, K. Juenemann, G. Juhász, H.S. Jung, J.U. Jung, Y.K. Jung, H. Jungbluth, H. Jungbluth, H. Jungbluth, M.J. Justice, M.J. Justice, B. Jutten, N.O. Kaakoush, K. Kaarniranta, A. Kaasik, T. Kabuta, B. Kaeffer, K. Kågedal, A. Kahana, S. Kajimura, O. Kakhlon, M. Kalia, D. V. Kalvakolanu, Y. Kamada, K. Kambas, V.O. Kaminskyy, H.H. Kampinga, M. Kandouz, C. Kang, C. Kang, R. Kang, T.C. Kang, T. Kanki, T.D. Kanneganti, H. Kanno, A.G. Kanthasamy, M. Kantorow, M. Kaparakis-Liaskos, O. Kapuy, V. Karantza, M.R. Karim, P. Karmakar, A. Kaser, S. Kaushik, T. Kawula, A.M. Kaynar, A.M. Kaynar, P.Y. Ke, Z.J. Ke, J.H. Kehrl, K.E. Keller, J.K. Kemper, A.K. Kenworthy, O. Kepp, A. Kern, S. Kesari, D. Kessel, R. Ketteler, I. do C. Kettelhut, B. Khambu, M.M. Khan, V.K.M. Khandelwal, S. Khare, J.G. Kiang, A.A. Kiger, A. Kihara, A.L. Kim, C.H. Kim, D.R. Kim, D.H. Kim, E.K. Kim, E.K. Kim, H.Y. Kim, H.R. Kim, J.S. Kim, J.H. Kim, J.H. Kim, J.C. Kim, J.H. Kim, J.H. Kim, K.W. Kim, M.D. Kim, M.M. Kim, P.K. Kim, S.W. Kim, S.Y. Kim, Y.S. Kim, Y. Kim, A. Kimchi, A.C. Kimmelman, T. Kimura, J.S. King, K. Kirkegaard, V. Kirkin, L.A. Kirshenbaum, S. Kishi, Y. Kitajima, K. Kitamoto, Y. Kitaoka, K. Kitazato, R.A. Kley, W.T. Klimecki, M. Klinkenberg, J. Klucken, H. Knævelsrud, E. Knecht, L. Knuppertz, J.L. Ko, S. Kobayashi, J.C. Koch, C. Koechlin-Ramonatxo, U. Koenig, Y.H. Koh, K. Köhler, S.D. Kohlwein, M. Koike, M. Komatsu, E. Kominami, D. Kong, H.J. Kong, E.G. Konstantakou, B.T. Kopp, T. Korcsmaros, L. Korhonen, V.I. Korolchuk, N. V. Koshkina, Y. Kou, M.I.

Koukourakis, C. Koumenis, A.L. Kovács, T. Kovács, W.J. Kovacs, D. Koya, C. Kraft, D. Krainc, H. Kramer, T. Kravic-Stevovic, W. Krek, C. Kretz-Remy, C. Kretz-Remy, C. Kretz-Remy, R. Krick, M. Krishnamurthy, J. Kriston-Vizi, G. Kroemer, G. Kroemer, G. Kroemer, G. Kroemer, M.C. Kruer, R. Kruger, N.T. Ktistakis, K. Kuchitsu, C. Kuhn, A.P. Kumar, A. Kumar, A. Kumar, D. Kumar, D. Kumar, R. Kumar, S. Kumar, M. Kundu, H.J. Kung, H.J. Kung, A. Kuno, S.H. Kuo, J. Kuret, T. Kurz, T. Kwok, T. Kwok, T.K. Kwon, Y.T. Kwon, I. Kyrmizi, A.R. La Spada, A.R. La 
Spada, F. Lafont, T. Lahm, A. Lakkaraju, T. Lam, T. Lamark, S. Lancel, T.H.

Landowski, D.J.R. Lane, J.D. Lane, C. Lanzi, P. Lapaquette, L.R. Lapierre, J. Laporte, J. Laukkarinen, G.W. Laurie, S. Lavandero, S. Lavandero, L. Lavie, M.J. Lavoie, B.Y.K. Law, H.K.W. Law, K.B. Law, R. Layfield, P.A. Lazo, P.A. Lazo, L. Le Cam, L. Le Cam, L. Le Cam, K.G. Le Roch, H. Le Stunff, H. Le Stunff, V. Leardkamolkarn, M. Lecuit, B.H. Lee, C.H. Lee, E.F. Lee, E.F. Lee, E.F. Lee, G.M. Lee, H.J. Lee, H. Lee, J.K. Lee, J. Lee, J.H. Lee, J.H. Lee, J.H. Lee, M. Lee, M.S. Lee, P.J. Lee, S.W. Lee, S.J. Lee, S.J. Lee, S.Y. Lee, S.H. Lee, S.S. Lee, S.S. Lee, S.J. Lee, S. Lee, Y.R. Lee, Y.J. Lee, Y.H. Lee, C. Leeuwenburgh, S. Lefort, R. Legouis, J. Lei, Q.Y. Lei, D.A. Leib, G. Leibowitz, I. Lekli, S.D. Lemaire, J.J. Lemasters, M.K. Lemberg, A. Lemoine, S. Leng, G. Lenz, P. Lenzi, L.O. Lerman, D.L. Barbato, J.I.J. Leu, H.Y. Leung, H.Y. Leung, B. Levine, B. Levine, P.A. Lewis, P.A. Lewis, F. Lezoualch, C. Li, F. Li, F.J. Li, J. Li, K. Li, L. Li, M. Li, M. Li, Q. Li, R. Li, S. Li, W. Li, W. Li, X. Li, Y. Li, J. Lian, C. Liang, Q. Liang, Y. Liao, J. Liberal, P.P. Liberski, P. Lie, A.P. Lieberman, H.J. Lim, K.L. Lim, K.L. Lim, K. Lim, R.T. Lima, R.T. Lima, R.T. Lima, C.S. Lin, C.S. Lin, C.F. Lin, F. Lin, F. Lin, F.C. Lin, K. Lin, K.H. Lin, P.H. Lin, T. Lin, W.W. Lin, Y.S. Lin, Y. Lin, R. Linden, D. Lindholm, L.M. Lindqvist, P. Lingor, A. Linkermann, L.A. Liotta, M.M. Lipinski, V.A. Lira, M.P. Lisanti, P.B. Liton, B. Liu, C. Liu, C.F. Liu, F. Liu, H.J. Liu, J. Liu, J.J. Liu, J.L. Liu, K. Liu, L. Liu, L. Liu, Q. Liu, R.Y. Liu, S. Liu, S. Liu, W. Liu, X. De Liu, X. Liu, X.H. Liu, X. Liu, X. Liu, X. Liu, X. Liu, X. Liu, Y. Liu, Y. Liu, Z. Liu, Z. Liu, J.P. Liuzzi, G. Lizard, M. Ljujic, I.J. Lodhi, S.E. Logue, B.L. Lokeshwar, Y.C. Long, S. Lonial, B. Loos, C. López-Otín, C. López-Vicario, M. Lorente, P.L. Lorenzi, P.L. Lorenzi, P. Lõrincz, M. Los, M.T. Lotze, P.E. Lovat, B. Lu, B. Lu, J. Lu, Q. Lu, S.M. Lu, S. Lu, Y. Lu, F. Luciano, S. Luckhart, J.M. Lucocq, P. Ludovico, P. Ludovico, A. Lugea, N.W. Lukacs, J.J. Lum, J.J. Lum, J.J. Lum, A.H. Lund, H. Luo, J. Luo, S. Luo, C. Luparello, T. Lyons, J. Ma, Y. Ma, Y. Ma, Z. Ma, J. Machado, G.M. Machado-Santelli, F. Macian, G.C. MacIntosh, J.P. MacKeigan, K.F. Macleod, J.D. MacMicking, L.A. MacMillan-Crow, F. Madeo, M. Madesh, M. Madesh, J. Madrigal-Matute, A. Maeda, T. Maeda, G. Maegawa, E. Maellaro, H. Maes, M. Magariños, K. Maiese, T.K. Maiti, L. Maiuri, M.C. Maiuri, C.G. Maki, R. Malli, W. Malorni, W. Malorni, A. Maloyan, F. MamiChouaib, N. Man, N. Man, J.D. Mancias, E.M. Mandelkow, M.A. Mandell, A.A. Manfredi, S.N. Manié, C. Manzoni, C. Manzoni, K. Mao, K. Mao, Z. Mao, Z.W. Mao, P. Marambaud, A.M. Marconi, Z. Marelja, G. Marfe, M. Margeta, E. Margittai, M. 
Mari, F. V. Mariani, C. Marin, S. Marinelli, G. Mariño, I. Markovic, R. Marquez, A.M. Martelli, S. Martens, K.R. Martin, S.J. Martin, S. Martin, M.A. Martin-Acebes, P. Martín-Sanz, C. Martinand-Mari, W. Martinet, J. Martinez, N. Martinez-Lopez, U. Martinez-Outschoorn, M. Martínez-Velázquez, M. Martinez-Vicente, W.K. Martins, W.K. Martins, H. Mashima, J.A. Mastrianni, G. Matarese, G. Matarese, P. Matarrese, R. Mateo, S. Matoba, N. Matsumoto, T. Matsushita, A. Matsuura, T. Matsuzawa, M.P. Mattson, S. Matus, S. Matus, S. Matus, N. Maugeri, C. Mauvezin, A. Mayer, D. Maysinger, G.D. Mazzolini, M.K. McBrayer, K. McCall, C. McCormick, G.M. McInerney, S.C. McIver, S. McKenna, J.J. McMahon, I.A. McNeish, F. MechtaGrigoriou, J.P. Medema, D.L. Medina, K. Megyeri, M. Mehrpour, J.L. Mehta, Y. Mei, U.C. Meier, A.J. Meijer, A. Meléndez, G. Melino, G. Melino, S. Melino, E.J.T. de Melo, M.A. Mena, M.D. Meneghini, J.A. Menendez, R. Menezes, R. Menezes, L. Meng, L.H. Meng, S. Meng, R. Menghini, A.S. Menko, R.F.S. Menna-Barreto, M.B. Menon, M.A. Meraz-Ríos, G. Merla, L. Merlini, A.M. Merlot, A. Meryk, S. Meschini, J.N. Meyer, M.T. Mi, C.Y. Miao, L. Micale, S. Michaeli, C. Michiels, A.R. Migliaccio, A.S. Mihailidou, A.S. Mihailidou, D. Mijaljica, K. Mikoshiba, E. Milan, E. Milan, L. Miller-Fleming, G.B. Mills, I.G. Mills, I.G. Mills, I.G. Mills, G. Minakaki, B.A. Minassian, X.F. Ming, F. Minibayeva, E.A. Minina, J.D. Mintern, S. Minucci, A. Miranda-Vizuete, C.H. Mitchell, S. Miyamoto, K. Miyazawa, N. Mizushima, K. Mnich, B. Mograbi, S. Mohseni, L.F. Moita, M. Molinari, M. Molinari, M. Molinari, A.B. Møller, B. Mollereau, F. Mollinedo, M. Mongillo, M.M. Monick, S. Montagnaro, C. Montell, C. Montell, D.J. Moore, M.N. Moore, R. Mora-Rodriguez, P.I. Moreira, E. Morel, M.B. Morelli, S. Moreno, M.J. Morgan, A. Moris, Y. Moriyasu, J.L. Morrison, L.A. Morrison, E. Morselli, J. Moscat, P.L. Moseley, S. Mostowy, E. Motori, D. Mottet, J.C. Mottram, C.E.H. Moussa, V.E. Mpakou, H. Mukhtar, J.M.M. Levy, S. Muller, R. Muñoz-Moreno, C. Muñoz-Pinedo, C. Münz, M.E. Murphy, J.T. Murray, A. Murthy, I.U. Mysorekar, I.R. Nabi, M. Nabissi, G.A. Nader, Y. Nagahara, Y. Nagai, K. Nagata, A. Nagelkerke, P. Nagy, S.R. Naidu, S. Nair, H. Nakano, H. Nakatogawa, M. Nanjundan, G. Napolitano, N.I. Naqvi, R. Nardacci, D.P. Narendra, M. Narita, A.C. Nascimbeni, R. Natarajan, L.C. Navegantes, S.T. Nawrocki, T.Y. Nazarko, V.Y. Nazarko, T. Neill, L.M. Neri, M.G. Netea, R.T. Netea-Maier, B.M. Neves, P.A. Ney, I.P. Nezis, H.T.T. Nguyen, H.P. Nguyen, A.S. Nicot, H. Nilsen, H. Nilsen, P. Nilsson, P. Nilsson, M. Nishimura, I. Nishino, M. Niso-Santano, H. Niu, R.A. Nixon, V.C.O. Njar, T. Noda, A.A. Noegel, E.M. Nolte, E. Norberg, K.K. Norga, S.K. Noureini, S. 
Notomi, L. Notterpek, K. Nowikovsky, N. Nukina, T. Nürnberger, V.B. O’donnell, T. O’donovan, P.J. O’dwyer, I. Oehme, C.L. Oeste, M. Ogawa, B. Ogretmen, Y. Ogura, Y.J. Oh, M. Ohmuraya, T. Ohshima, R. Ojha, K. Okamoto, T. Okazaki, F.J. Oliver, K. Ollinger, S. Olsson, D.P. Orban, D.P. Orban, P. Ordonez, I. Orhon, L. Orosz, E.J.

O'rourke, H. Orozco, H. Orozco, A.L. Ortega, E. Ortona, L.D. Osellame, J. Oshima, S. Oshima, H.D. Osiewacz, T. Otomo, K. Otsu, J.H.J. Ou, T.F. Outeiro, D.Y. Ouyang, H. Ouyang, M. Overholtzer, M.A. Ozbun, P.H. Ozdinler, B. Ozpolat, C. Pacelli, P. Paganetti, G. Page, G. Pages, U. Pagnini, B. Pajak, B. Pajak, S.C. Pak, K. PakosZebrucka, N. Pakpour, Z. Palková, F. Palladino, K. Pallauf, N. Pallet, M. Palmieri, S.R. Paludan, C. Palumbo, S. Palumbo, O. Pampliega, H. Pan, W. Pan, T. Panaretakis, A. Pandey, A. Pandey, A. Pantazopoulou, Z. Papackova, D.L. Papademetrio, I. Papassideri, A. Papini, N. Parajuli, J. Pardo, V. V. Parekh, G. Parenti, J.I. Park, J. Park, O.K. Park, R. Parker, R. Parlato, R. Parlato, J.B. Parys, K.R. Parzych, K.R. Parzych, J.M. Pasquet, B. Pasquier, K.B.S. Pasumarthi, D. Patschan, C. Patterson, S. Pattingre, S. Pattingre, S. Pattison, A. Pause, H. Pavenstädt, F. Pavone, Z. Pedrozo, F.J. Peña, M.A. Peñalva, M. Pende, J. Peng, F. Penna, J.M. Penninger, A. Pensalfini, S. Pepe, G.J.S. Pereira, P.C. Pereira, V.P. de la Cruz, M.E. Pérez-Pérez, D. Pérez-Rodríguez, D. Pérez-Sala, C. Perier, A. Perl, D.H. Perlmutter, I. Perrotta, S. Pervaiz, S. Pervaiz, S. Pervaiz, M. Pesonen, J.E. Pessin, G.J. Peters, M. Petersen, I. Petrache, B.J. Petrof, G. Petrovski, G. Petrovski, G. Petrovski, J.M. Phang, M. Piacentini, M. Pierdominici, P. Pierre, P. Pierre, P. Pierre, P. Pierre, V. Pierrefite-Carle, F. Pietrocola, F. Pietrocola, F. Pietrocola, F. Pietrocola, F.X. Pimentel-Muiños, M. Pinar, B. Pineda, R. PinkasKramarski, M. Pinti, P. Pinton, B. Piperdi, J.M. Piret, L.C. Platanias, L.C. Platanias, H.W. Platta, E.D. Plowey, S. Pöggeler, M. Poirot, P. Polčic, A. Poletti, A.H. Poon, H. Popelka, B. Popova, I. Poprawa, S.M. Poulose, J. Poulton, S.K. Powers, T. Powers, M. Pozuelo-Rubio, K. Prak, R. Prange, M. Prescott, M. Priault, S. Prince, R.L. Proia, T. Proikas-Cezanne, H. Prokisch, V.J. Promponas, K. Przyklenk, R. Puertollano, S. Pugazhenthi, L. Puglielli, A. Pujol, A. Pujol, A. Pujol, J. Puyal, J. Puyal, D. Pyeon, X. Qi, W. Bin Qian, Z.H. Qin, Y. Qiu, Z. Qu, J. Quadrilatero, F. Quinn, N. Raben, H. Rabinowich, F. Radogna, M.J. Ragusa, M. Rahmani, K. Raina, S. Ramanadham, R. Ramesh, A. Rami, S. Randall-Demllo, F. Randow, F. Randow, H. Rao, V.A. Rao, B.B. Rasmussen, T.M. Rasse, E.A. Ratovitski, P.E. Rautou, P.E. Rautou, P.E. Rautou, P.E. Rautou, S.K. Ray, B. Razani, B. Razani, B.H. Reed, F. Reggiori, M. Rehm, A.S. Reichert, T. Rein, D.J. Reiner, E. Reits, J. Ren, X. Ren, M. Renna, J.E.B. Reusch, 
J.E.B. Reusch, J.L. Revuelta, L. Reyes, A.R. Rezaie, R.I. Richards, D.R. Richardson, C. Richetta, M.A. Riehle, B.H. Rihn, Y. Rikihisa, B.E. Riley, G. Rimbach, M.R. Rippo, K. Ritis, F. Rizzi, E. Rizzo, P.J. Roach, J. Robbins, M. Roberge, G. Roca, M.C. Roccheri, S. Rocha, C.M.P. Rodrigues, C.I. Rodríguez, S.R. de Cordoba, N.

Rodriguez-Muela, J. Roelofs, V. V. Rogov, T.T. Rohn, B. Rohrer, D. Romanelli, L. Romani, P.S. Romano, M.I.G. Roncero, J.L. Rosa, A. Rosello, K. V. Rosen, K. V. Rosen, P. Rosenstiel, M. Rost-Roszkowska, K.A. Roth, G. Roué, M. Rouis, K.M. Rouschop, D.T. Ruan, D. Ruano, D.C. Rubinsztein, E.B. Rucker, A. Rudich, E. Rudolf, R. Rudolf, M.A. Ruegg, C. Ruiz-Roldan, A.A. Ruparelia, P. Rusmini, D.W. Russ, G.L. Russo, G. Russo, R. Russo, T.E. Rusten, T.E. Rusten, V. Ryabovol, K.M. Ryan, S.W. Ryter, D.M. Sabatini, M. Sacher, M. Sacher, C. Sachse, M.N. Sack, J. Sadoshima, P. Saftig, R. Sagi-Eisenberg, S. Sahni, P. Saikumar, T. Saito, T. Saitoh, K. Sakakura, M. Sakoh-Nakatogawa, Y. Sakuraba, M. Salazar-Roa, P. Salomoni, A.K. Saluja, P.M. Salvaterra, R. Salvioli, A. Samali, A.M.J. Sanchez, J.A. Sánchez-Alcázar, R. SanchezPrieto, M. Sandri, M.A. Sanjuan, S. Santaguida, L. Santambrogio, G. Santoni, C.N. Dos Santos, C.N. Dos Santos, S. Saran, M. Sardiello, G. Sargent, P. Sarkar, S. Sarkar, M.R. Sarrias, M.M. Sarwal, C. Sasakawa, M. Sasaki, M. Sass, K. Sato, M. Sato, J. Satriano, N. Savaraj, S. Saveljeva, L. Schaefer, U.E. Schaible, M. Scharl, H.M. Schatzl, R. Schekman, W. Scheper, W. Scheper, W. Scheper, A. Schiavi, A. Schiavi, H.M. Schipper, H.M. Schipper, H. Schmeisser, J. Schmidt, I. Schmitz, I. Schmitz, B.E. Schneider, E.M. Schneider, J.L. Schneider, E.A. Schon, M.J. Schönenberger, A.H. Schönthal, D.F. Schorderet, D.F. Schorderet, B. Schröder, S. Schuck, R.J. Schulze, M. Schwarten, T.L. Schwarz, S. Sciarretta, S. Sciarretta, S. Sciarretta, K. Scotto, A.I. Scovassi, R.A. Screaton, R.A. Screaton, M. Screen, H. Seca, H. Seca, H. Seca, S. Sedej, L. Segatori, L. Segatori, N. Segev, P.O. Seglen, J.M. Seguí-Simarro, J. SeguraAguilar, I. Seiliez, E. Seki, C. Sell, C.F. Semenkovich, G.L. Semenza, U. Sen, A.L. Serra, A. Serrano-Puebla, H. Sesaki, T. Setoguchi, C. Settembre, J.J. Shacka, A.N. Shajahan-Haq, I.M. Shapiro, S. Sharma, H. She, C.K.J. Shen, C.C. Shen, H.M. Shen, S. Shen, W. Shen, R. Sheng, X. Sheng, Z.H. Sheng, T.G. Shepherd, J. Shi, J. Shi, Q. Shi, Q. Shi, Y. Shi, S. Shibutani, K. Shibuya, Y. Shidoji, J.J. Shieh, C.M. Shih, Y. Shimada, S. Shimizu, D.W. Shin, M.L. Shinohara, M. Shintani, T. Shintani, T. Shioi, K. Shirabe, R. Shiri-Sverdlov, O. Shirihai, G.C. Shore, C.W. Shu, D. Shukla, A.A. Sibirny, A.A. Sibirny, V. Sica, V. Sica, V. Sica, V. Sica, C.J. Sigurdson, E.M. Sigurdsson, P.S. Sijwali, B. Sikorska, W.A. Silveira, S. Silvente-Poirot, G.A. Silverman, J. Simak, T. 
Simmet, A.K. Simon, H.U. Simon, C. Simone, M. Simons, A. Simonsen, R. Singh, S. V. Singh, S.K. Singh, D. Sinha, S. Sinha, F.A. Sinicrope, A. Sirko, K. Sirohi, B.J.N. Sishi, A. Sittler, P.M. Siu, E. Sivridis, A. Skwarska, R. Slack, I. Slaninová, N. Slavov, S.S. Smaili, K.S.M. Smalley, D.R. Smith, S.J. Soenen, S.A. Soleimanpour, A. Solhaug, K. Somasundaram, J.H. Son, A. Sonawane, C. Song, F. Song, H.K. Song, J.X. Song, W. Song, K.Y. Soo, A.K. Sood, A.K. Sood, T.W. Soong, V. Soontornniyomkij, M. Sorice, F. Sotgia, D.R. Soto-Pantoja, A. Sotthibundhu, M.J. Sousa, H.P. Spaink, P.N. Span, A. Spang, J.D. Sparks, P.G. Speck, S.A. Spector, C.D. Spies, W. Springer, D.S. Clair, A. Stacchiotti, B. Staels, M.T. Stang, D.T. Starczynowski, P. Starokadomskyy, C. Steegborn, J.W. Steele, L. Stefanis, J. Steffan, C.M. Stellrecht, H. Stenmark, T.M. Stepkowski, S.T. Stern, C. Stevens, B.R. Stockwell, B.R. Stockwell, V. Stoka, Z.

Storchova, B. Stork, V. Stratoulias, D.J. Stravopodis, D.J. Stravopodis, P. Strnad, A.M. Strohecker, A.L. Ström, P. Stromhaug, J. Stulik, Y.X. Su, Z. Su, C.S. Subauste, S. Subramaniam, C.M. Sue, S.W. Suh, X. Sui, S. Sukseree, D. Sulzer, F.L. Sun, J. Sun, J. Sun, S.Y. Sun, Y. Sun, Y. Sun, Y. Sun, V. Sundaramoorthy, J. Sung, H. Suzuki, K. Suzuki, N. Suzuki, T. Suzuki, Y.J. Suzuki, M.S. Swanson, C. Swanton, K. Swärd, G. Swarup, S.T. Sweeney, P.W. Sylvester, Z. Szatmari, E. Szegezdi, P.W. Szlosarek, H. Taegtmeyer, M. Tafani, E. Taillebourg, S.W.G. Tait, K. Takacs-Vellai, Y. Takahashi, S. Takáts, G. Takemura, N. Takigawa, N.J. Talbot, E. Tamagno, J. Tamburini, C.P. Tan, L. Tan, M.L. Tan, M.L. Tan, M. Tan, Y.J. Tan, Y.J. Tan, K. Tanaka, M. Tanaka, D. Tang, D. Tang, G. Tang, I. Tanida, K. Tanji, B.A. Tannous, J.A. Tapia, I. TassetCuevas, M. Tatar, I. Tavassoly, N. Tavernarakis, N. Tavernarakis, N. Tavernarakis, A. Taylor, G.S. Taylor, G.A. Taylor, G.A. Taylor, G.A. Taylor, G.A. Taylor, J.P. Taylor, M.J. Taylor, E. V. Tchetina, A.R. Tee, F. Teixeira-Clerc, F. Teixeira-Clerc, S. Telang, T. Tencomnao, B.B. Teng, R.J. Teng, F. Terro, G. Tettamanti, A.L. Theiss, A.E. Theron, K.J. Thomas, M.P. Thomé, P.G. Thomes, A. Thorburn, J. Thorner, T. Thum, M. Thumm, T.L.M. Thurston, L. Tian, A. Till, A. Till, J.P.Y. Ting, J.P.Y. Ting, V.I. Titorenko, L. Toker, S. Toldo, S.A. Tooze, I. Topisirovic, I. Topisirovic, M.L. Torgersen, M.L. Torgersen, M.L. Torgersen, L. Torosantucci, A. Torriglia, M.R. Torrisi, C. Tournier, R. Towns, V. Trajkovic, L.H. Travassos, G. Triola, D.N. Tripathi, D. Trisciuoglio, R. Troncoso, R. Troncoso, I.P. Trougakos, A.C. Truttmann, K.J. Tsai, M.P. Tschan, Y.H. Tseng, T. Tsukuba, A. Tsung, A.S. Tsvetkov, S. Tu, H.Y. Tuan, M. Tucci, D.A. Tumbarello, B. Turk, V. Turk, R.F.B. Turner, A.A. Tveita, S.C. Tyagi, M. Ubukata, Y. Uchiyama, A. Udelnow, T. Ueno, M. Umekawa, R. Umemiya-Shirafuji, 
B.R. Underwood, C. Ungermann, R.P. Ureshino, R. Ushioda, V.N. Uversky, N.L. Uzcátegui, T. Vaccari, M.I. Vaccaro, L. Váchová, H. Vakifahmetoglu-Norberg, R. Valdor, E.M. Valente, F. Vallette, A.M. Valverde, G. Van den Berghe, L. Van Den Bosch, G.R. van den Brink, F.G. van der Goot, I.J. van der Klei, L.J.W. van der Laan, W.G. van Doorn, M. van Egmond, K.L. van Golen, K.L. van Golen, K.L. van Golen, L. Van Kaer, M. van L. Campagne, P. Vandenabeele, W. Vandenberghe, W. Vandenberghe, I. Vanhorebeek, I. Varela-Nieto, M.H. Vasconcelos, M.H. Vasconcelos, M.H. Vasconcelos, R. Vasko, D.G. Vavvas, I. Vega-Naredo, G. Velasco, A.D. Velentzas, P.D. Velentzas, T. Vellai, E. Vellenga, M.H. Vendelbo, K. Venkatachalam, N. Ventura, N. Ventura, S. Ventura, P.S.T. Veras, M. Verdier, B.G. Vertessy, A. Viale, M. Vidal, H.L.A. Vieira, R.D. Vierstra, N. Vigneswaran, N. Vij, M. Vila, M. Vila, M. Vila, M. Villar, V.H. Villar, J. Villarroya, C. Vindis, G. Viola, M.T. Viscomi, G. Vitale, D.T. Vogl, O. V. Voitsekhovskaja, C. von Haefen, K. von Schwarzenberg, D.E. Voth, V. Vouret-Craviari, K. Vuori, J.M. Vyas, C. Waeber, C.L. Walker, M.J. Walker, J. Walter, L. Wan, L. Wan, X. Wan, B. Wang, C. Wang, C.Y. Wang, C. Wang, C. Wang, C. Wang, D. Wang, F. Wang, F. Wang, G. Wang, H.J. Wang, H. Wang, H.G. Wang, H. Wang, H.D. Wang, J. Wang, J. Wang, M. Wang, M.Q. Wang, P.Y. Wang, P. Wang, R.C. Wang, S. Wang, T.F. Wang, X. Wang, X.J. Wang, X.W. Wang, X. Wang, X. Wang, Y. Wang, Y. Wang, Y. Wang, Y.J. Wang, Y. Wang, Y. Wang, Y.T. Wang, Y. Wang, Z.N. Wang, P. Wappner, C. Ward, D.M.V. Ward, G. Warnes, H. Watada, Y. Watanabe, K. Watase, T.E. Weaver, C.D. Weekes, J. Wei, T. Weide, C.C. Weihl, G. Weindl, S.N. Weis, L. Wen, X. Wen, X. Wen, Y. Wen, Y. Wen, B. Westermann, C.M. Weyand, A.R. White, E. White, J.L. Whitton, A.J. Whitworth, J. Wiels, F. Wild, M.E. Wildenberg, T. Wileman, D.S. Wilkinson, S. Wilkinson, D. Willbold, D. Willbold, C. Williams, C. Williams, K. Williams, P.R. Williamson, K.F. Winklhofer, S.S. Witkin, S.E. Wohlgemuth, T. Wollert, E.J. Wolvetang, E. Wong, G.W. Wong, R.W. Wong, V.K.W. Wong, E.A. Woodcock, K.L. Wright, C. Wu, D. Wu, G.S. Wu, J. Wu, J. Wu, M. Wu, M. Wu, S. Wu, W.K.K. Wu, Y. Wu, Z. Wu, C.P.R. Xavier, C.P.R. Xavier, R.J. Xavier, G.X. Xia, T. Xia, W. Xia, W. Xia, Y. Xia, H. Xiao, J. Xiao, S. Xiao, W. Xiao, C.M. Xie, Z. Xie, Z. Xie, M. Xilouri, Y. Xiong, C. Xu, C. Xu, F. Xu, H. Xu, H. Xu, J. Xu, J. Xu, J. Xu, J. Xu, L. Xu, X. Xu, Y. Xu, Y. Xu, Z.X. Xu, Z. Xu, Z. Xu, Y. Xue, T. Yamada, A. Yamamoto, K. Yamanaka, S. Yamashina, S. Yamashiro, B. Yan, B. Yan, X. Yan, Z. Yan, Y. Yanagi, D.S. Yang, J.M. Yang, L. Yang, M. Yang, P.M. Yang, P. Yang, Q. Yang, W. Yang, W.Y. Yang, X. Yang, Y. Yang, Y. Yang, Z. Yang, Z. Yang, 
M.C. Yao, P.J. Yao, X. Yao, Z. Yao, Z. Yao, Z. Yao, L.S. Yasui, M. Ye, B.

Yedvobnick, B. Yeganeh, E.S. Yeh, P.L. Yeyati, F. Yi, L. Yi, X.M. Yin, C.K. Yip, Y.M. Yoo, Y.H. Yoo, S.Y. Yoon, K.I. Yoshida, T. Yoshimori, K.H. Young, H. Yu, J.J. Yu, J.T. Yu, J. Yu, L. Yu, W.H. Yu, X.F. Yu, Z. Yu, J. Yuan, Z.M. Yuan, B.Y.J.T. Yue, J. Yue, Z. Yue, D.N. Zacks, E. Zacksenhaus, N. Zaffaroni, T. Zaglia, Z. Zakeri, V. Zecchini, J. Zeng, M. Zeng, Q. Zeng, A.S. Zervos, D.D. Zhang, F. Zhang, G. Zhang, G.C. Zhang, H. Zhang, H. Zhang, H. Zhang, H. Zhang, H. Zhang, J. Zhang, J. Zhang, J. Zhang, J. Zhang, J.P. Zhang, L. Zhang, L. Zhang, L. Zhang, L. Zhang, L. Zhang, M.Y. Zhang, X. Zhang, X.D. Zhang, Y. Zhang, Y. Zhang, Y. Zhang, Y. Zhang, Y. Zhang, Y. Zhang, M. Zhao, W.L. Zhao, W.L. Zhao, W.L. Zhao, X. Zhao, Y.G. Zhao, Y. Zhao, Y. Zhao, Y.X. Zhao, Z. Zhao, Z.J. Zhao, D. Zheng, X.L. Zheng, X. Zheng, B.

Zhivotovsky, B. Zhivotovsky, Q. Zhong, Q. Zhong, G.Z. Zhou, G. Zhou, H. Zhou, S.F. Zhou, X.J. Zhou, X.J. Zhou, X.J. Zhou, H. Zhu, H. Zhu, W.G. Zhu, W. Zhu, X.F. Zhu, Y. Zhu, S.M. Zhuang, X. Zhuang, E. Ziparo, C.E. Zois, T. Zoladek, W.X. Zong, A. Zorzano, A. Zorzano, A. Zorzano, S.M. Zughaier, Guidelines for the use and interpretation of assays for monitoring autophagy (3rd edition), Autophagy. 12 (2016) 1-222. doi:10.1080/15548627.2015.1100356.

[22] S. Ghavami, S. Shojaei, B. Yeganeh, S.R. Ande, J.R. Jangamreddy, M. Mehrpour, J. Christoffersson, W. Chaabane, A.R. Moghadam, H.H. Kashani, M. Hashemi, A.A. Owji, M.J. Łos, Autophagy and apoptosis dysfunction in neurodegenerative disorders, Prog. Neurobiol. 112 (2014) 24-49. doi:10.1016/j.pneurobio.2013.10.004.

[23] S.C. Correia, R. Resende, P.I. Moreira, C.M. Pereira, Alzheimer's Disease-Related Misfolded Proteins and Dysfunctional Organelles on Autophagy Menu, DNA Cell Biol. 34 (2015) 261-273. doi:10.1089/dna.2014.2757.

[24] A. Peric, W. Annaert, Early etiology of Alzheimer's disease: tipping the balance toward autophagy or endosomal dysfunction?, Acta Neuropathol. 129 (2015) 363-381. doi:10.1007/s00401-014-1379-7.

[25] P. Melnyk, S. Burlet, N. Le Fur, A. Delacourte, Heterocycle compounds and uses thereof for the treatment of diseases involving formation of amyloid plaques and/or where a dysfunction of the APP metabolism occurs, US 8,680,095 B2, 2014. doi:10.1126/science.Liquids.

[26] P. Melnyk, N. Sergeant, L. Buée, A. Delacourte, Use of 1,4-bis(3aminoalkylyl)piperazine derivatives in the treatment of neurodegenerative diseases., WO 2006 051489, 2006. 
[27] P. Melnyk, P. Carato, S. Burlet, T.H. Nguyen, P. Verwaerde, N. Sergeant, C. Estrella, Beta and gamma-carbolines derivatives for the treatment of neurodegenerative diseases., WO 2014 207240, 2014.

[28] M. Barrier, L. Buée, S. Burlet, A. Delacourte, C. Estrella, P. Melnyk, N. Sergeant, P. Verwaerde, Sulfate salts of N-(3-(4-(3-(diisobutylamino)propyl)piperazin-1-yl)propyl)1H-benzo[d]imidazol-2-amine, preparation thereof and use of the same., WO 2014 102339, 2014.

[29] S.Y. Yang, Pharmacophore modeling and applications in drug discovery: Challenges and recent advances, Drug Discov. Today. 15 (2010) 444-450. doi:10.1016/j.drudis.2010.03.013.

[30] M. Gay, P. Carato, M. Coevoet, N. Renault, P.E. Larchanché, A. Barczyk, S. Yous, L. Buée, N. Sergeant, P. Melnyk, New phenylaniline derivatives as modulators of amyloid protein precursor metabolism, Bioorganic Med. Chem. 26 (2018) 2151-2164. doi:10.1016/j.bmc.2018.03.016.

[31] P. Carato, P. Depreux, D. Lesieur, M. Millan, A. Newman-Tancredi, M.C. Rettori, D.H. Caignard, Synthesis and binding studies on a new series of arylpiperazino benzoxazol-2-one and benzoxazin-3-one deriv-atives as selective D4 ligands, Drug Des. Disc. 17 (2000) 173-181.

[32] S. Bhattacharyya, Reductive Alkylations of Dimethylamine Using Titanium(IV) Isopropoxide and Sodium Borohydride: An Efficient, Safe, and Convenient Method for the Synthesis of N,N-Dimethylated Tertiary Amines, J. Org. Chem. 60 (1995) 49284929. doi:10.1021/jo00120a044.

[33] G. Sbardella, A. Mai, M. Artico, R. Loddo, M.G. Setzu, P. La Colla, Synthesis and in vitro antimycobacterial activity of novel 3-(1H-pyrrol-1-yl)-2-oxazolidinone analogues of PNU-100480, Bioorganic Med. Chem. Lett. 14 (2004) 1537-1541. doi:10.1016/j.bmcl.2004.01.010.

[34] J. Ermolieff, J.A. Loy, G. Koelsch, J. Tang, Proteolytic activation of recombinant promemapsin 2 (pro- $\beta$-secretase) studied with new fluorogenic substrates, Biochemistry. 39 (2000) 12450-12456. doi:10.1021/bi001494f.

[35] A. Yamamoto, Y. Tagawa, T. Yoshimori, Y. Moriyama, R. Masaki, Y. Tashiro, Bafilomycin A1 Prevents Maturation of Autophagic Vacuoles by Inhibiting Fusion between Autophagosomes and Lysosomes in Rat Hepatoma Cell Line, H-4-II-E Cells, Cell Struct. Funct. 23 (1998) 33-42. doi:10.1247/csf.23.33.

[36] J. Taminau, G. Thijs, H. De Winter, Pharao: Pharmacophore alignment and 
optimization, J. Mol. Graph. Model. 27 (2008) 161-169.

doi:10.1016/j.jmgm.2008.04.003.

[37] N. Sergeant, J.P. David, D. Champain, A. Ghestem, A. Wattez, A. Delacourte, Progressive decrease of amyloid precursor protein carboxy terminal fragments (APPCTFs), associated with tau pathology stages, in Alzheimer's disease, J. Neurochem. 81 (2002) 663-672. doi:10.1046/j.1471-4159.2002.00901.x.

[38] M. Domise, S. Didier, C. Marinangeli, H. Zhao, P. Chandakkar, L. Buée, B. Viollet, P. Davies, P. Marambaud, V. Vingtdeux, AMP-activated protein kinase modulates tau phosphorylation and tau pathology in vivo, Sci. Rep. 6 (2016) 1-12. doi:10.1038/srep26758. 


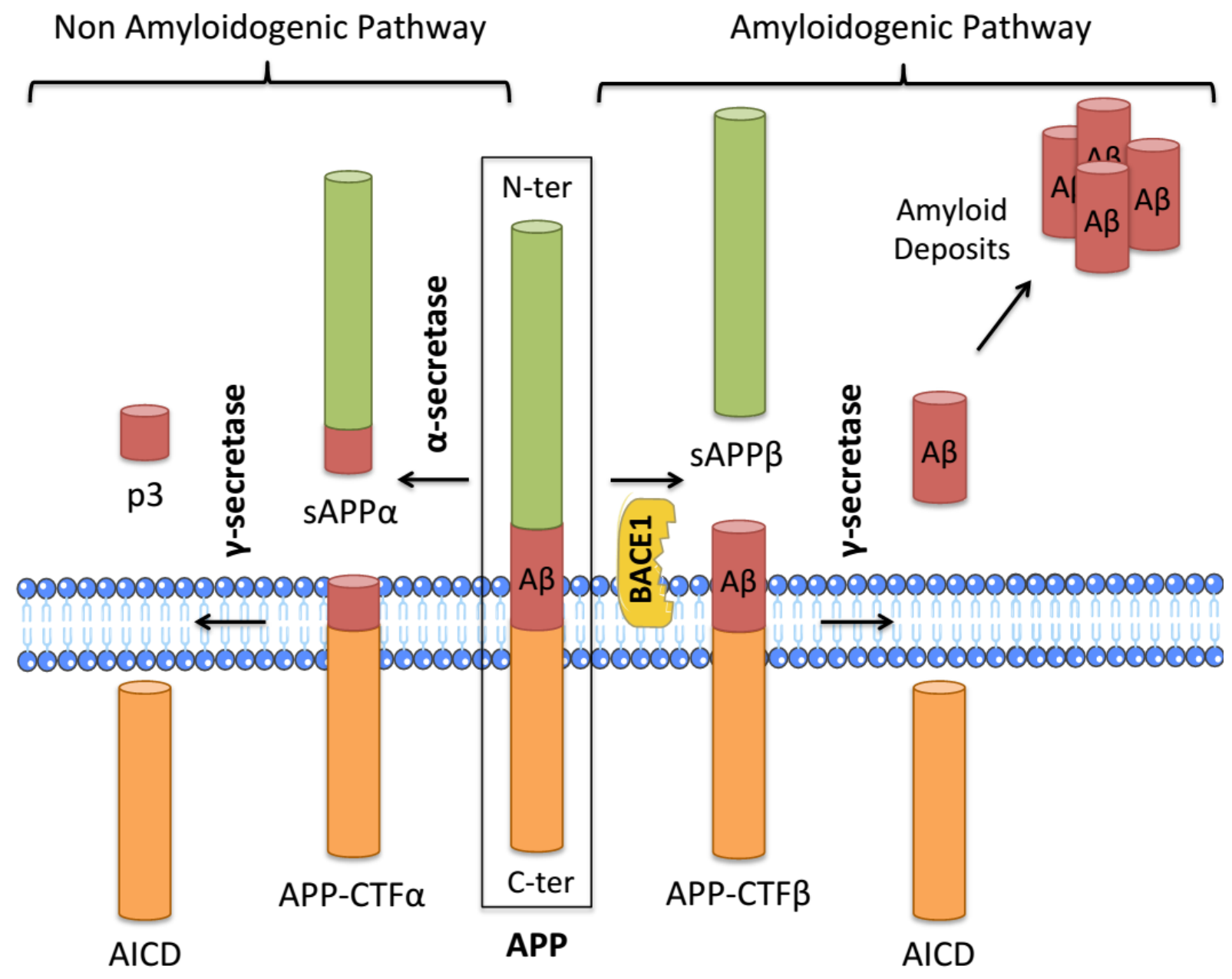

Figure 1. Amyloid protein precursor (APP) processing. 
A

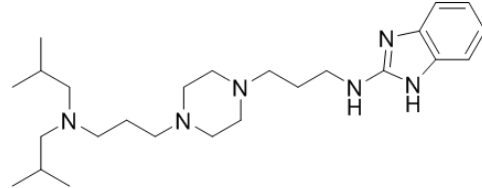

A1

B

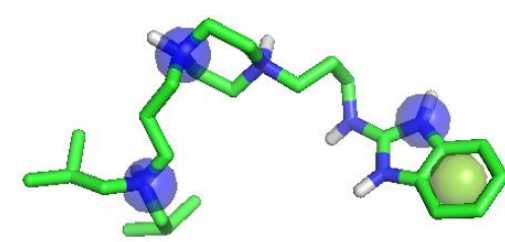

Series A (51 cpds)

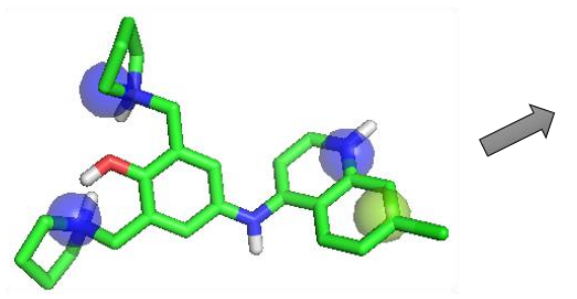

Series B (35 cpds)

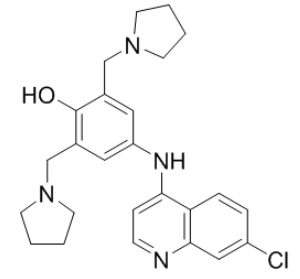

B1

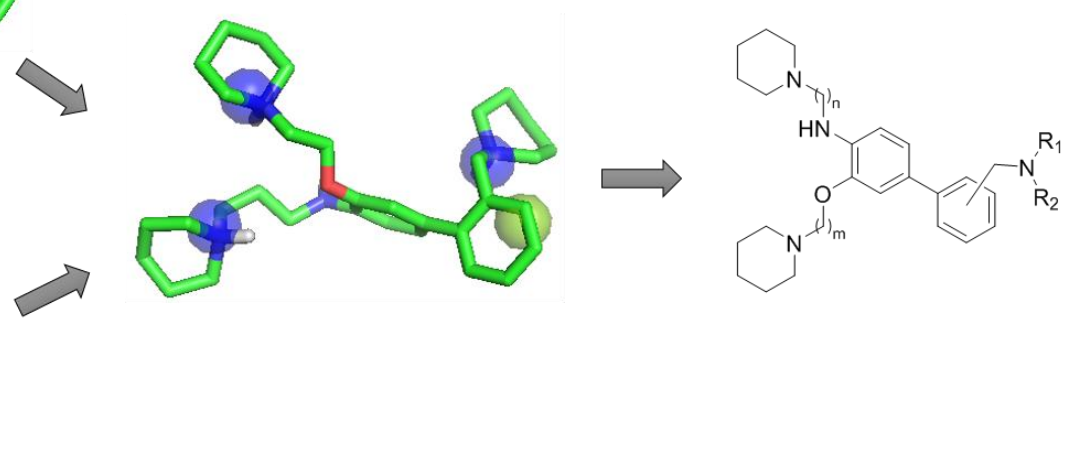

Figure 2. Design of biaryl series based on series A and B. A. Structure of compound A1 and B1, representative compounds of series A and B, respectively. B. Ligand-based approach leading to biaryl series. 
A

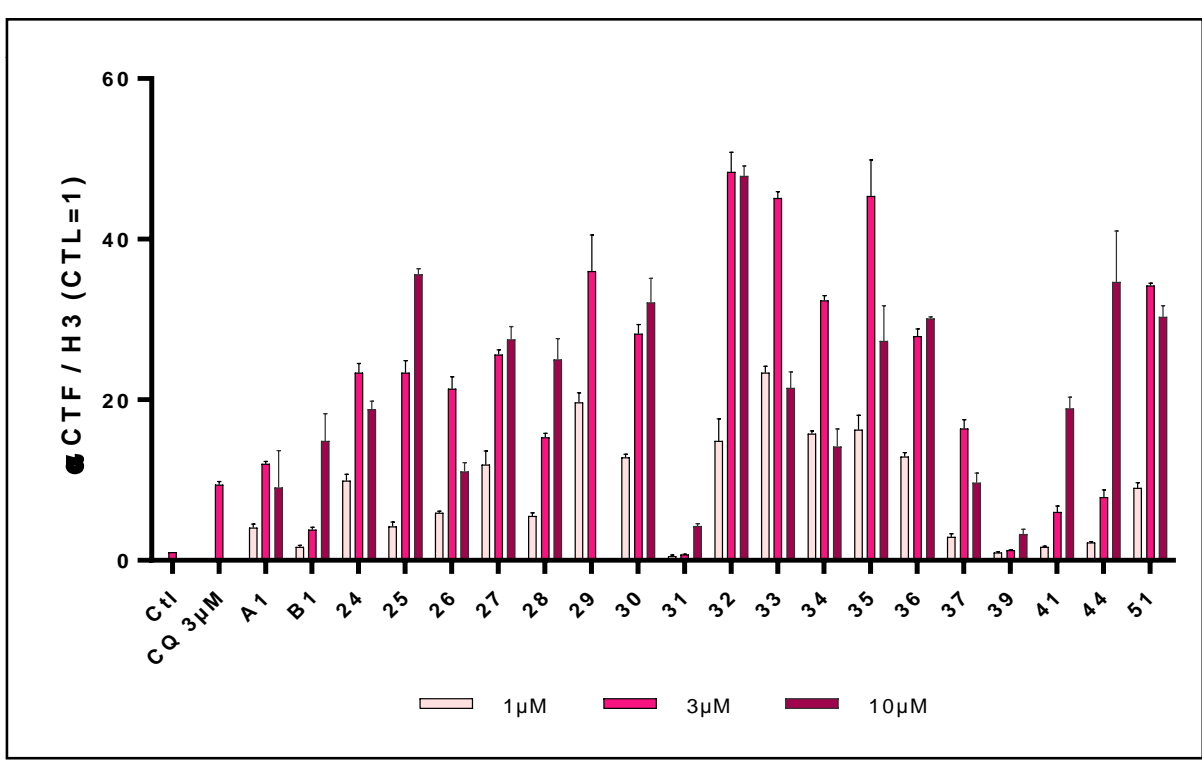

B

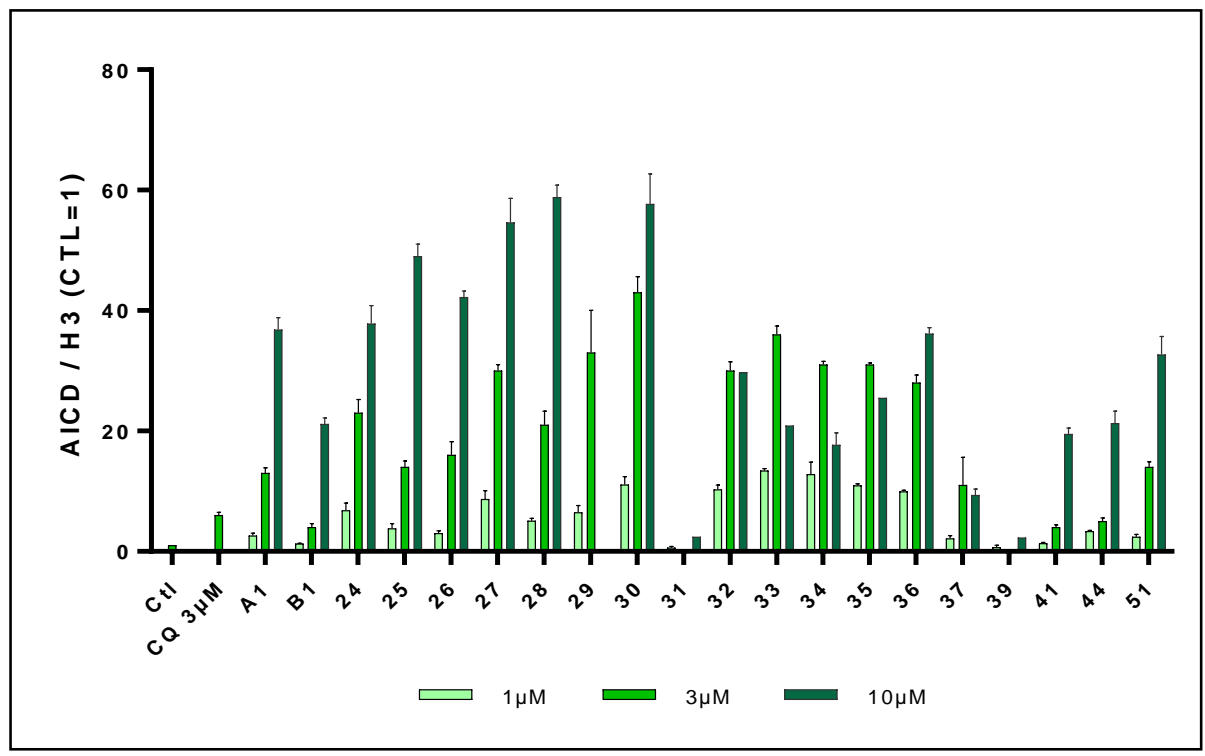

Figure 3. Effect of target compounds on $\alpha$ CTF (A) and AICD (B) stabilities. The effect of reference and tested compounds at 1,3 and $10 \mu \mathrm{M}$ are expressed as the intensity of corresponding Western Blot bands of at least three independent experiments. 
A

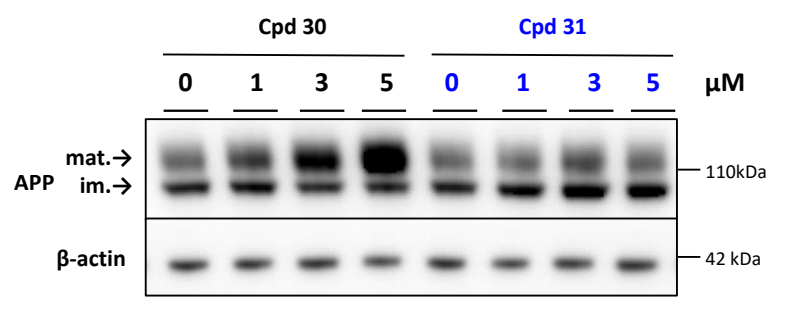

B

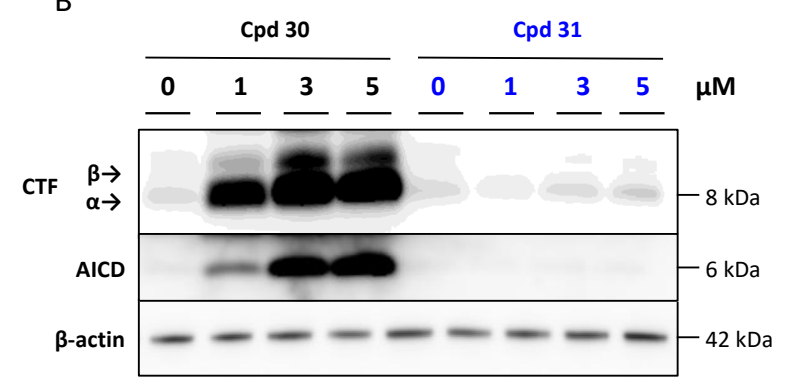

$A \beta$

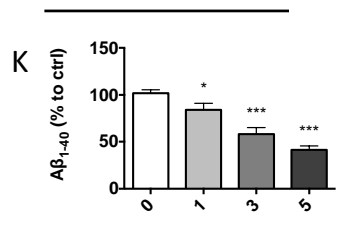

Cpd 30 ( $\mu \mathrm{M})$

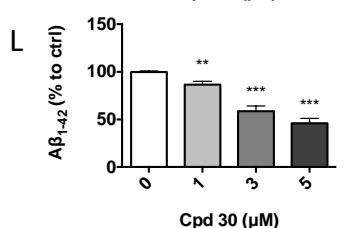

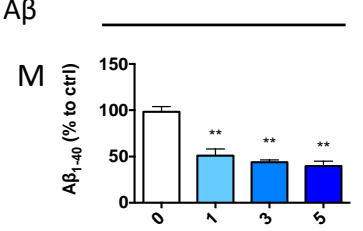

Cpd 31 ( $\mu \mathrm{M})$

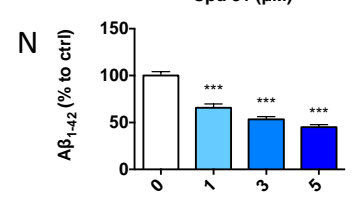

Cpd 31 ( $\mu \mathrm{M})$
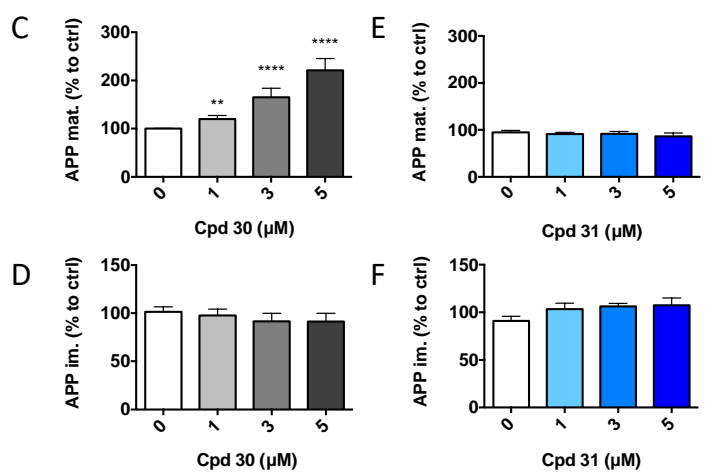

G
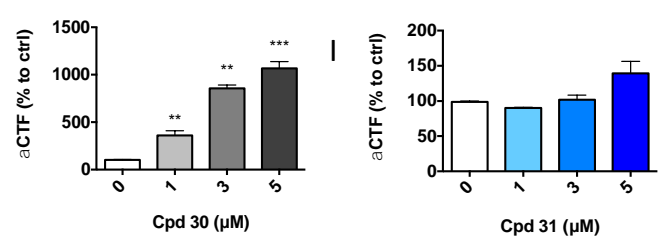

Cpd 31 ( $\mu \mathrm{M})$
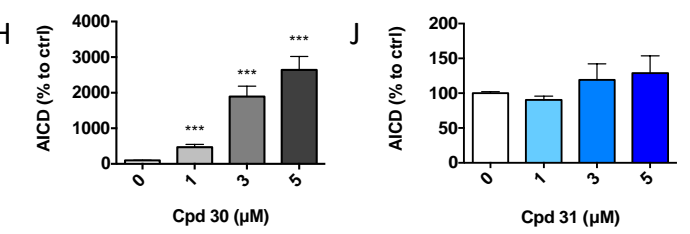

SAPP
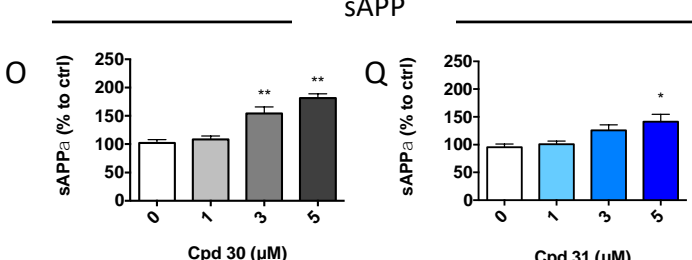

P

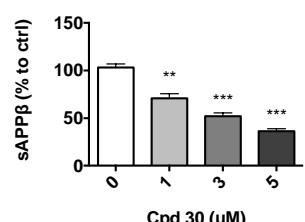

Cpd $30(\mu \mathrm{M})$

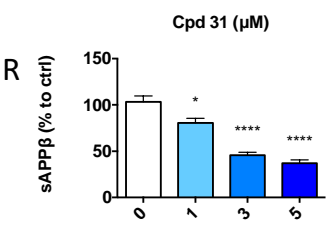

Cpd 31 ( $\mu \mathrm{M})$

Figure 4. Comparison of compounds 30 and 31 effect on APP metabolism in SY5Y-APP ${ }^{655 T}$ cells.

SY5Y-APP ${ }_{w t}$ cells were treated for $24 \mathrm{~h}$ with increasing concentrations of compound 30 (Cpd 30) or compound 31 (Cpd 31) as indicated. Cell lysates were immunolabeled with the following antibodies: APP-Cter-C17 and $\beta$-actin as loading control (panel $\mathbf{A}$ and $\mathbf{B}$ ). Densitometric analysis and quantification of immature and mature APP levels (panel $\mathbf{C}, \mathbf{D}, \mathbf{E}$ and $\mathbf{F}$ ), APP $\alpha$-carboxy-terminal fragments and AICD (panel $\mathbf{G}, \mathbf{H}, \mathbf{I}$ and $\mathbf{J}$ ). Conditioned medium was analysed by ELISA to measure secreted $A \beta_{1-40}$ and $A \beta_{1-42}$ peptides (panel $\mathbf{K}, \mathbf{L}, \mathbf{M}$ and $\mathbf{N}$ ) and by electro-chemiluminescence immunoassay to measure secreted sAPP $\alpha$ and sAPP $\beta$ (panel $\mathbf{O}, \mathbf{P}, \mathbf{Q}$ and $\mathbf{R}$ ). Histograms indicate the mean \pm SD. a. u., arbitrary units, $\mathrm{n}=6 * \mathrm{p}<0.05, * * \mathrm{p}<0.01, * * * \mathrm{p}<0.005, * * * * \mathrm{p}<0.001$ Mann-Whitney. 

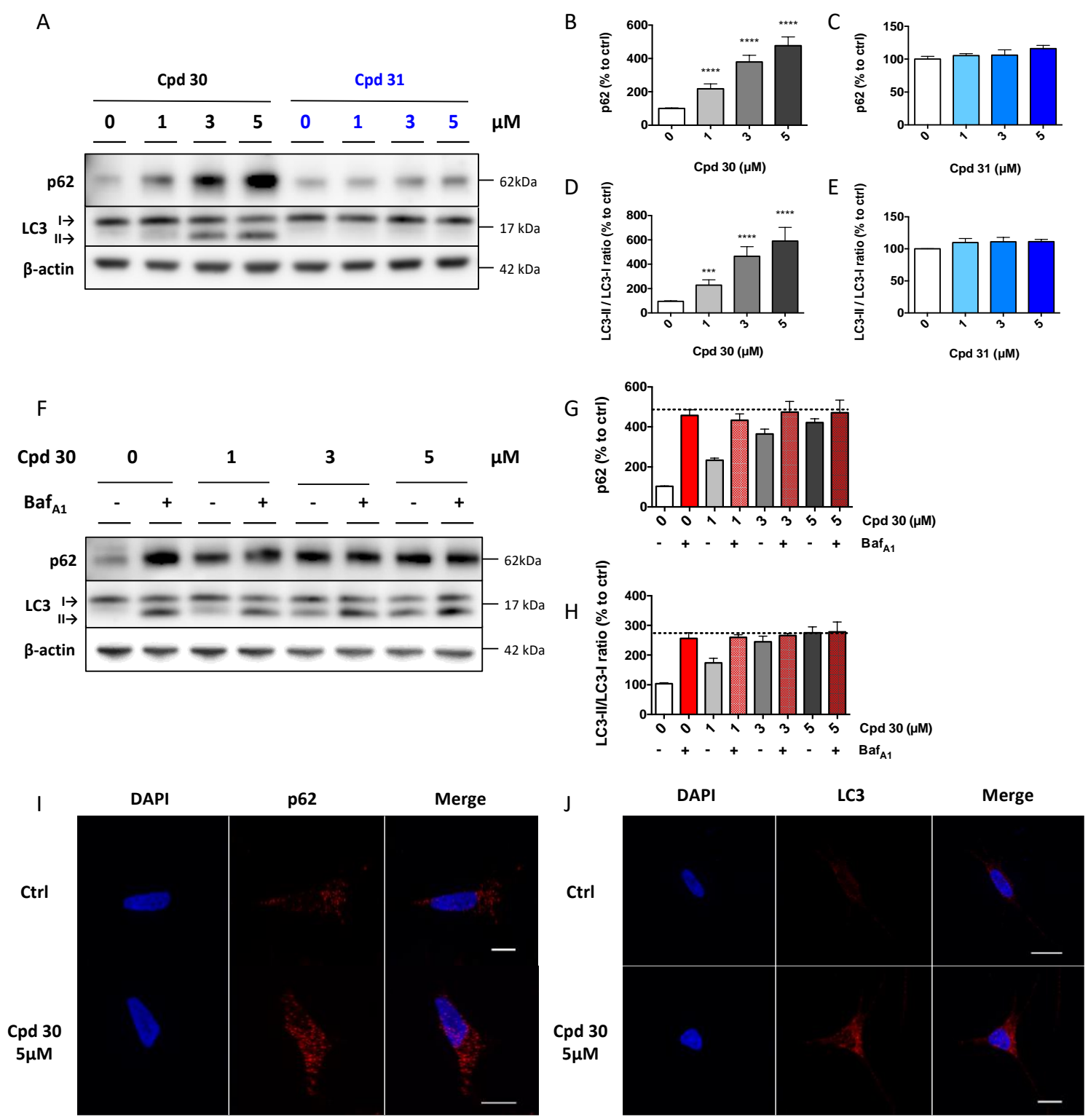

Figure 5. Effect of compound 30 on the autophagic flux in SY5Y-APP ${ }_{w t}$ cells. SY5Y-APP ${ }_{w t}$ cells were treated for $24 \mathrm{~h}$ with increasing concentrations of compound 30 (Cpd 30) or compound 31 (Cpd $31)$ as indicated and co-treated with Bafilomycine $\mathrm{A} 1\left(\mathrm{Baf}_{\mathrm{Al}}\right)$ at $100 \mathrm{nM}$ or not. Cell lysates were immunolabeled with the following antibodies: p62, LC3-B and $\beta$-actin, used as loading control (panel $\mathbf{A}$ and $\mathbf{F}$ ). Densitometric analysis and quantification of p62/ $\beta$-actin (panel $\mathbf{B}$ and $\mathbf{C}$ ) and LC3-II/LC3-I ratio (panel D, E, $\mathbf{G}$ and $\mathbf{H}$ ) expressed in $\%$ to control. Histograms indicate the mean \pm SD. a. u., arbitrary units. $\mathrm{n}=6 * \mathrm{p}<0.05, * * \mathrm{p}<0.01, * * * \mathrm{p}<0.005, * * * * \mathrm{p}<0.001$ Mann-Whitney. Immunofluorescence staining of p62 (red, panel I) and LC3-B (red, panel J) in SY5Y-APP ${ }^{695 W T}$ cells after 24h of compound 30 treatment at $5 \mu \mathrm{M}$ versus untreated cells. Scale bars $=25 \mu \mathrm{m}$. 
Scheme $\mathbf{1}^{a}$. Synthesis of compounds 24-37

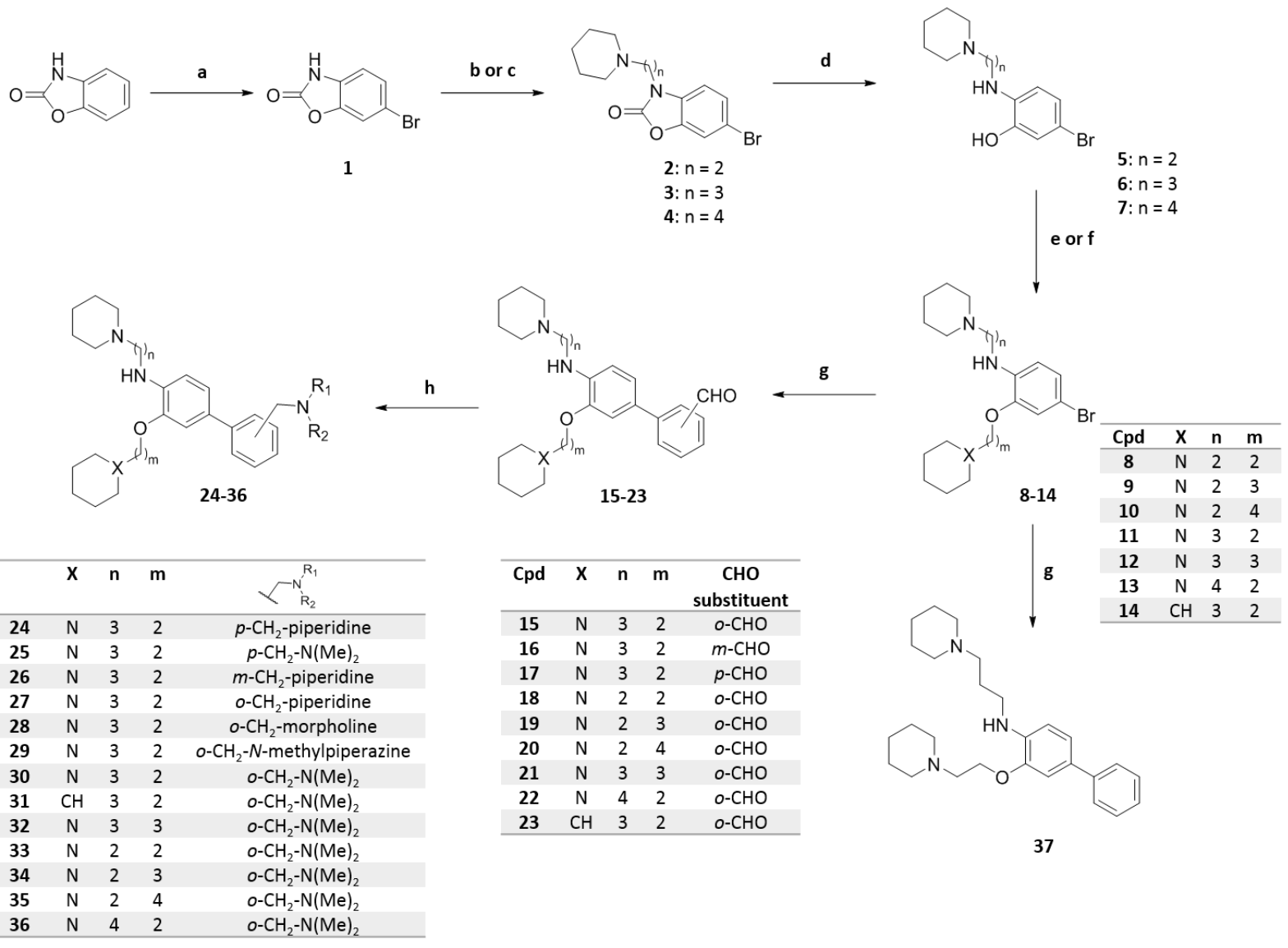

a Reagents and conditions: (a) $\mathrm{Br}_{2}, \mathrm{AcOH}, \mathrm{rt}, 4 \mathrm{~h}, 94 \%$; (b) 1-(2-Chloroethyl)piperidine hydrochloride or 3-chloropropylpiperidine hydrochloride, $\mathrm{K}_{2} \mathrm{CO}_{3}, \mathrm{ACN}, 80{ }^{\circ} \mathrm{C}, 5 \mathrm{~h}, 98-99 \%$; (c) $i$ ) 1-Bromo-4-chlorobutane, $\mathrm{K}_{2} \mathrm{CO}_{3}, \mathrm{ACN}, 80^{\circ} \mathrm{C}, 12 \mathrm{~h}$, ii) Piperidine, reflux, $12 \mathrm{~h}, 16 \%$; (d) $2.5 \mathrm{~N} \mathrm{NaOH}$, dioxane, rt, $12 \mathrm{~h}, 50-95 \%$; (e) 1-(2-Chloroethyl)piperidine hydrochloride or 3chloropropylpiperidine hydrochloride or 2-bromoethylcyclohexane, NaH, DMF, rt, 12 h, 3279\%; (f) i) 1-Bromo-4-chlorobutane, NaH, DMF, rt, 12 h, ii) Piperidine, reflux, 12 h, 18\%; (g) Corresponding boronic acid, $\mathrm{K}_{2} \mathrm{CO}_{3}, \mathrm{P}(o \text {-tol })_{3}, \mathrm{Pd}_{2} \mathrm{dba}_{3}$, toluene, EtOH, reflux, $18 \mathrm{~h}, 71-97 \%$; (h) Procedure A: corresponding secondary amine, $\mathrm{NaBH}(\mathrm{OAc})_{3}, \mathrm{AcOH}, \mathrm{DCE}, \mathrm{rt}, 18$ h, 5-77\%. Procedure B: $i$ ) Dimethylamine hydrochloride, $\mathrm{Et}_{3} \mathrm{~N}$, Titanium isopropoxide, $\mathrm{EtOH}, \mathrm{rt}, 12 \mathrm{~h}, \mathrm{ii}$ ) $\mathrm{NaBH}_{4}, \mathrm{rt}, 2$ h, $28-47 \%$. 
Scheme $2^{a}$. Synthesis of compounds 39,41 and 44.
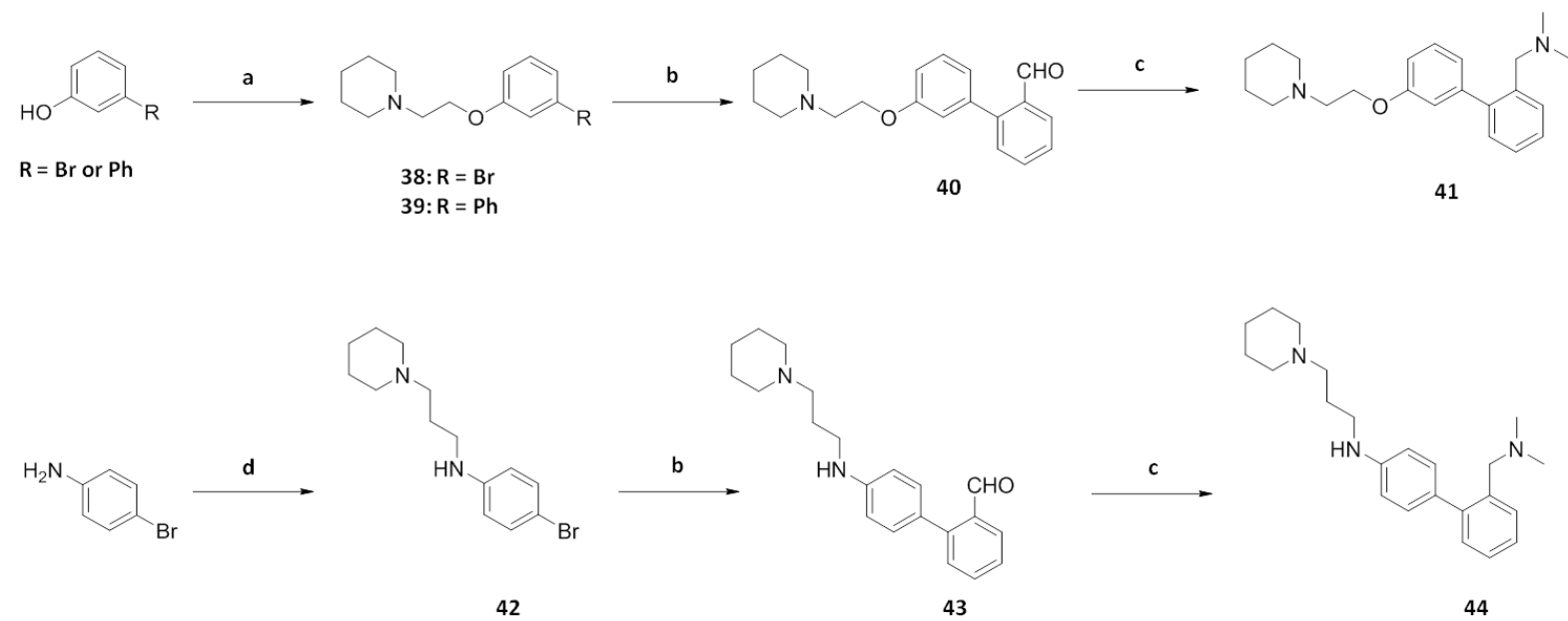

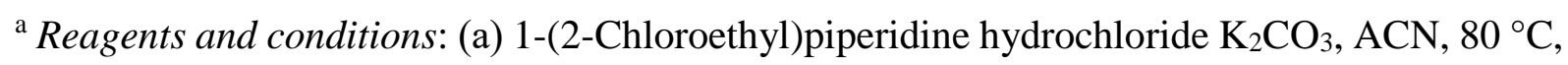
12 h, 41-91\%; (b) 38, 2-Formylphenylboronic acid, $\mathrm{K}_{2} \mathrm{CO}_{3}, \mathrm{P}(o \text {-tol })_{3}, \mathrm{Pd}_{2} \mathrm{dba}_{3}$, toluene, EtOH, reflux, 18 or 96 h, 40-68\%; (c) Procedure A: Dimethylamine 2M in THF, $\mathrm{NaBH}(\mathrm{OAc})_{3}, \mathrm{AcOH}$, DCE, rt, 18 h, 26\%. Procedure B: i) Dimethylamine hydrochloride, $\mathrm{Et}_{3} \mathrm{~N}$, Titanium isopropoxide, EtOH, rt, 12 h, ii) $\mathrm{NaBH}_{4}, \mathrm{rt}, 2 \mathrm{~h}, 40 \%$; (d) 3-Chloropropylpiperidine hydrochloride, $\mathrm{NaI}, \mathrm{K}_{2} \mathrm{CO}_{3}, \mathrm{DMF}, 100{ }^{\circ} \mathrm{C}, 24 \mathrm{~h}, 23 \%$. 
Scheme $3^{a}$. Synthesis of compound 51 .
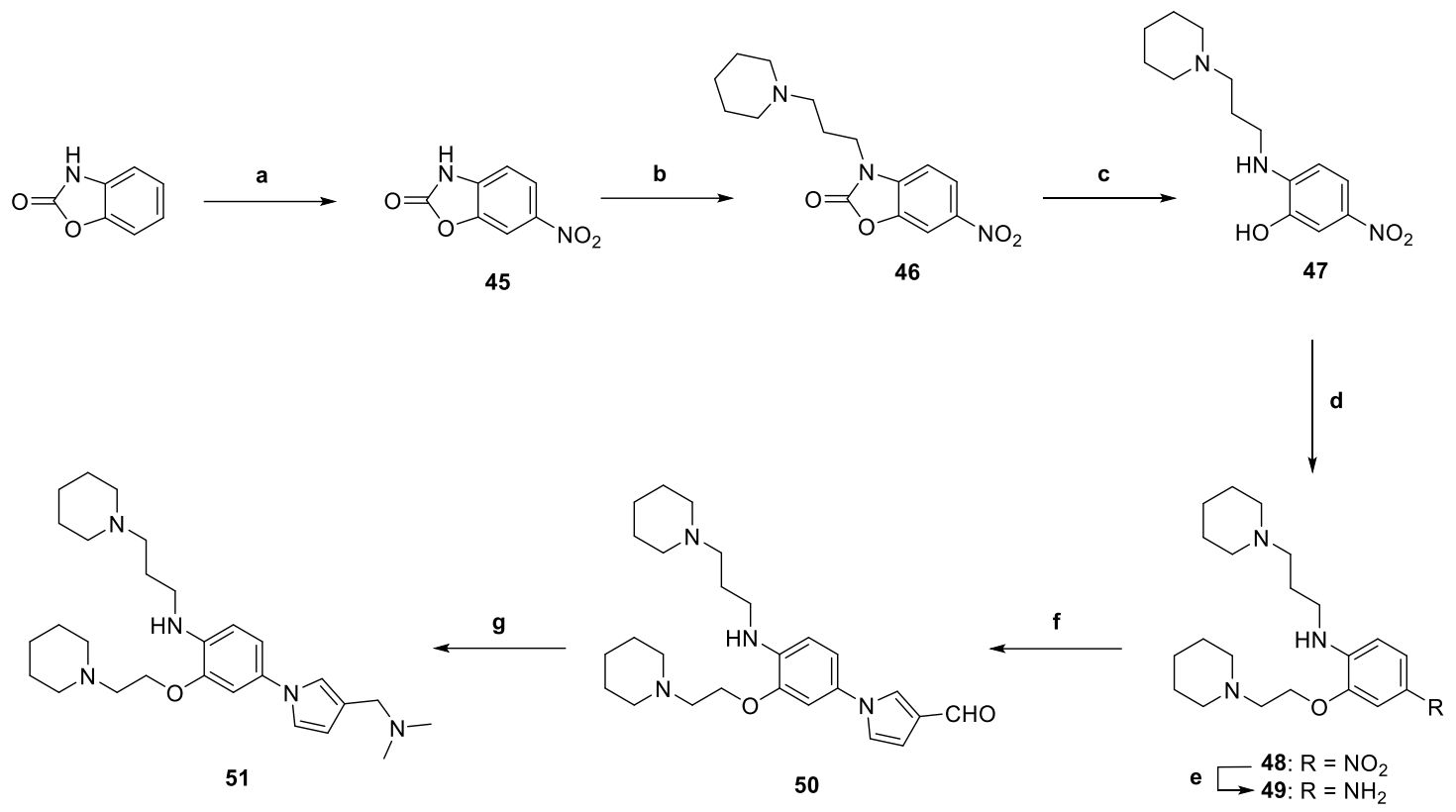

a Reagents and conditions: (a) 70\% $\mathrm{HNO}_{3}, \mathrm{rt}, 4 \mathrm{~h}, 87 \%$; (b) 3-Chloropropylpiperidine hydrochloride, $\mathrm{K}_{2} \mathrm{CO}_{3}$, ACN, reflux, 5 h, 98\%; (c) $2.5 \mathrm{~N} \mathrm{NaOH}$, dioxane, rt, 48 h, 50-95\%; (d) 1-(2-Chloroethyl)piperidine, $\mathrm{K}_{2} \mathrm{CO}_{3}, \mathrm{ACN}, 5$ h, $60{ }^{\circ} \mathrm{C}, 72 \%$; (e) $\mathrm{HCOONH}_{4}, \mathrm{EtOH}$, reflux,

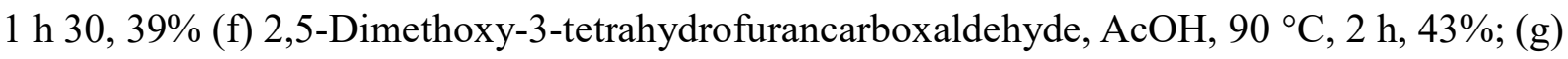
Dimethylamine $2 \mathrm{M}$ in THF, $\mathrm{NaBH}(\mathrm{OAc})_{3}, \mathrm{AcOH}, \mathrm{DCE}, \mathrm{rt}, 18 \mathrm{~h}, 31 \%$. 
Table 1. Effects of compounds 24-37, 39, 41, 44 and 51 on $A \beta_{1-40}$ and $A \beta_{1-42}$ secretion

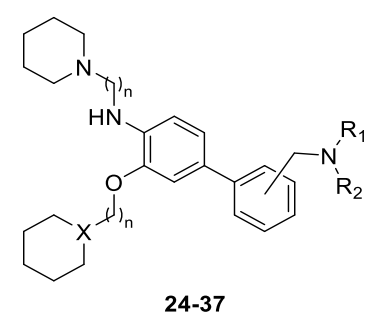

24-37

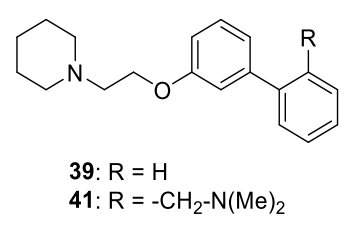

Cpd $\quad \mathrm{X} \quad \mathrm{n} \quad \mathrm{m}$

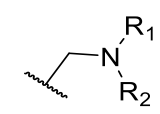

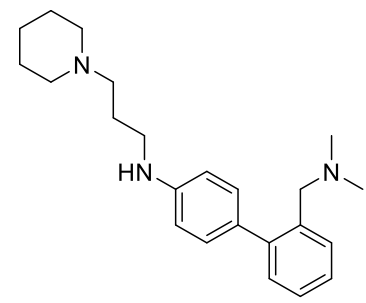

44

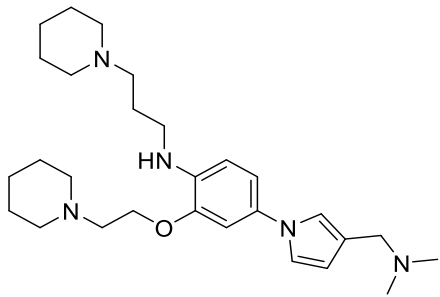

51

$\alpha \mathrm{CTF} \quad \mathrm{AICD}$

$\mathrm{A} \beta_{1-40} \quad \mathrm{~A} \beta_{1-42}$

$\mathrm{IC}_{50}(\mu \mathrm{M})^{\mathrm{a}} \mathrm{IC}_{50}(\mu \mathrm{M})^{\mathrm{a}}$ vs CQ vs CQ $(3 \mu \mathrm{M})^{\mathrm{b}, \mathrm{c}}(3 \mu \mathrm{M})^{\mathrm{b}, \mathrm{d}}$

\section{CQ}

A1

B1

$\begin{array}{llll}24 & \mathrm{~N} & 3 & 2\end{array}$

$\begin{array}{llll}25 & \mathrm{~N} & 3 & 2\end{array}$

$\begin{array}{llll}26 & \mathrm{~N} & 3 & 2\end{array}$

$\begin{array}{llll}27 & \mathrm{~N} & 3 & 2\end{array}$

$\begin{array}{llll}28 & N & 3 & 2\end{array}$

$\begin{array}{llll}29 & N & 3 & 2\end{array}$

$\begin{array}{llll}30 & \mathrm{~N} & 3 & 2\end{array}$

$\begin{array}{llll}31 & \mathrm{CH} & 3 & 2\end{array}$

$\begin{array}{llll}32 & \mathrm{~N} & 3 & 3\end{array}$

$33 \quad \mathrm{~N} 22$

$34 \quad \mathrm{~N} \quad 2 \quad 3$

$\begin{array}{llll}35 & \mathrm{~N} & 2 & 4\end{array}$

$\begin{array}{llll}36 & \mathrm{~N} & 4 & 2\end{array}$

$\begin{array}{llll}37 & \mathrm{~N} & 3 & 2\end{array}$

39

41

44

51

7.0

$1.7 \pm 0.2$

$5.1 \pm 0$.

$2.1 \pm 0.6 \quad 3.3 \pm 2.1$

$1.5 \pm 0.1 \quad 1.7 \pm 0.4$

$4.3 \pm 0.7 \quad 4.8 \pm 0.6$

$2.6 \pm 0.1 \quad 4.1 \pm 1.3$

$2.8 \pm 1.2 \quad 4.2 \pm 1.5$

$o-\mathrm{CH}_{2}$-morpholine

$o-\mathrm{CH}_{2}-\mathrm{N}$-methylpiperazine

$2.6 \pm 0$.

$2.7 \pm 0.8$

$2.8 \pm 1.2 \quad 3.4 \pm 1.9$

$2.1 \pm 0.3 \quad 2.8 \pm 0.1$

$2.1 \pm 0.3 \quad 2.0 \pm 0.1$

$1.4 \pm 0.5 \quad 1.2 \pm 0.6 \quad 5.0$

$2.0 \pm 0.2 \quad 1.8 \pm 0.7$

4.5

$1.6 \pm 0.1 \quad 1.6 \pm 0.3$

4.4

$1.7 \pm 0.3 \quad 1.6 \pm 0.8$

4.2

$5.2 \pm 0.1 \quad 4.0 \pm 0.4 \quad 2.4$

0.1

$9.1 \pm 0.6 \quad 13.7 \pm 3.3$

0.6

$1.5 \pm 0.3 \quad 1.2 \pm 0.3$

0.9

$3.9 \pm 1.0 \quad 3.6 \pm 0.1$

3.6

$5.0 \pm 0.9 \quad 6.5 \pm 2.0$ 3.6

${ }^{\mathrm{a}}$ Compound concentration inhibiting $50 \%$ of $\mathrm{A} \beta_{1-40}$ or $\mathrm{A} \beta_{1-42}$ peptide secretion in SY5Y cells. $\mathrm{IC}_{50}$ values are expressed as mean $\pm \mathrm{SD}$ of at least two experiments performed in triplicate. ${ }^{\mathrm{b}}$ Mean values calculated on the basis of at least three independent experiments with less than 
$10 \%$ deviation. ${ }^{\mathrm{c}} \mathrm{CTF} \alpha$ increase compared to chloroquine ([CTF]compound/[CTF]CQ) at $3 \mu \mathrm{M}$.

${ }^{d}$ AICD increase compared to chloroquine ([AICD]compound/[AICD]CQ) at $3 \mu \mathrm{M}$ 